\title{
Technology Diffusion of Energy-Related Products in Residential Markets
}

\author{
L. J. Davis \\ C. L. Bruneau \\ D. L. Ivey, Project Manager
}

May 1987

Prepared for the U.S. Department of Energy under Contract DE-AC06-76RLO 1830

Pacific Northwest Laboratory Operated for the U.S. Department of Energy by Battelle Memorial Institute 


\title{
DISCLAIMER
}

This report was prepared as an account of work sponsored by an agency of the United States Government. Neither the United States Government nor any agency thereof, nor Battelle Memorial Institute, nor any of their employees, makes any warranty, expressed or implied, or assumes any legal liability or responsibility for the accuracy, completeness, or usefulness of any information, apparatus, product, or process disclosed, or represents that its use would not infringe privately owned rights. Reference herein to any specific commercial product, process, or service by trade name, trademark, manufacturer, or othenwise, does not necessarily constitute or imply its endorsement, recommendation, or favoring by the United States Government of any agency thereof, or Battelle Memorial Institute. The views and opinions of authors expressed herein do not necessarly state or reflect those of the United States Government or any agency thereof, or Battelle Memorial Institute.

\author{
PACIFIC NORTHWEST LABORATORY \\ operated by \\ BATTELLE MEMORIAL INSTITUTE \\ for the \\ UNITED STATES DEPARTMENT OF ENERGY \\ under Contract DE-AC06-76RLO 1830
}

\begin{tabular}{|c|c|}
\hline \multirow{2}{*}{\multicolumn{2}{|c|}{ Printed in the United States of America }} \\
\hline & \\
\hline \multicolumn{2}{|c|}{$\begin{array}{l}\text { Available from } \\
\text { National Technical Information Service }\end{array}$} \\
\hline \multicolumn{2}{|c|}{ United States Department of Commerce } \\
\hline \multirow{2}{*}{\multicolumn{2}{|c|}{$\begin{array}{c}5285 \text { Port Royal Road } \\
\text { Springfield, Virginia } 22161\end{array}$}} \\
\hline & \\
\hline \multirow{2}{*}{\multicolumn{2}{|c|}{$\begin{array}{l}\text { NTIS Price Codes } \\
\text { Microfiche A01 }\end{array}$}} \\
\hline & \\
\hline \multicolumn{2}{|c|}{ Printed Copy } \\
\hline & Price \\
\hline Pages & Codes \\
\hline $001-025$ & A02 \\
\hline $026-050$ & $\mathrm{~A} 03$ \\
\hline $051-075$ & A04 \\
\hline $076-100$ & A05 \\
\hline $101-125$ & $A 06$ \\
\hline $126-150$ & A07 \\
\hline $151-175$ & $A 0 B$ \\
\hline $176-200$ & A09 \\
\hline $201-225$ & $\mathrm{~A} 010$ \\
\hline $226-250$ & A011 \\
\hline $251-275$ & A012 \\
\hline $276-300$ & $\mathrm{~A} 013$ \\
\hline
\end{tabular}


TECHNOLOGY DIFFUSION OF ENERGY-RELATED PRODUCTS

IN RESIDENTIAL MARKETS

L. J. Davis

C. L. Bruneau

D. L. Ivey, Project Manager

May 1987

Prepared for the U.S. Department of Energy under Contract DE-AC06-76RLO 1830

Pacific Northwest Laboratory Richland, Washington 99352 
, 


\section{SUMMARY}

Acceptance of energy-related technologies by end residential consumers, manufacturers of energy-related products, and other influential intermediate markets such as builders will influence the potential for market penetration of innovative energy-related technologies developed by the Department of Energy, Office of Building and Community Systems (OBCS). In this report, Pacific Northwest Laboratory reviewed the available information on technology adoption, diffusion, and decision-making processes to provide OBCS with a background and understanding of the type of research that has previously been conducted on this topic. Insight was gained as to the potential decision-making criteria and motivating factors that influence the decision-maker(s) selection of new technologies, and some of the barriers to technology adoption faced by potential markets for OBCS technologies. Some of the specific findings follow:

\section{RESIDENTIAL CONSUMER MARKET}

- As many of the products and ideas developed by OBCS are technological innovations, it is important to understand the process by which innovations are diffused through society. This process may vary with: 1) the characteristics of the innovation, 2) the characteristics of the consumers, and 3) the social networks in which the consumers are members.

- Consumers making an energy-related purchasing decision usually pass through the following stages: 1) problem recognition, 2) information search, 3) evaluation of alternatives, 4) purchase decision, and 5) post-purchase behavior.

- Economic factors are purchasing criteria which are especially critical to consumers of energy-efficient products. High returns and short payback periods can influence the consumer to purchase a more efficient product.

- Attitudes which are specific to the purchase of energy-related products can influence the consumer's behavior. This is an area in 
which further study is especially necessary to determine which attitudes are related to energy-related purchasing.

- Self-perception theories and decision heuristics demonstrate that the consumer is not always a rational thinker who makes optimal purchasing decisions. Often the consumer takes decision-making shortcuts to make the process less complex.

- Several barriers to energy-efficient investment exist which make it more difficult for the consumer to make the best decision. Strategies to overcome these barriers can be developed.

\section{MANUFACTURERS}

- Great potential exists for private sector involvement in government research programs. To realize this potential, the reasons for manufacturing companies becoming involved in an energy-related market must be examined. These reasons include: 1) response to market needs and demand, 2) the need to diversify into new business areas, 3) government, environment, and safety factors, 4) scarcity of resources, and 5) concern over the energy situation.

- Industries with the following characteristics have been demonstrated to be more receptive to the adoption of new technologies: 1) intermediate level of heterogeneity, 2) intermediate level of competition, 3) high level of demand uncertainty, 3) clear and frequent signaling between industry competitors, 4) professionalism, and 5) high level of external integration.

- There are two types of innovation strategy used by manufacturers. These are "demand pu11" and "technology push." Different decision criteria become important depending on which of these strategies is being used by a firm.

- The decision to adopt and invest in the development of a new technology is a risky one for an organization because of the time and monetary commitments involved. Therefore it is important to involve the firm's "decision-making elite" in this decision. Factors which 
influence the decision-making elite's choice include their attitudes toward risk, change, and traditional technologies.

- A different set of barriers exist which deter manufacturers from producing energy-efficient products. Again, strategies can be developed which minimize the effects of these barriers.

\section{RESIDENTIAL INTERMEDIATE MARKET (BUILDERS)}

- Because approximately $40 \%$ of all major appliance purchases are made by builders (Science Applications, Inc. 1982), they represent a very important target market for OBCS. Very few studies have been conducted concerning this influential market.

- Builders are initially stimulated to use an energy-efficient feature because of market and cost factors.

- Builders use a variety of information sources to obtain facts about energy-efficient products. These sources include electric utility companies, suppliers, mass media, consumers, and trade publications.

Although there have been many theoretical works involving consumers' decision-making processes for energy-related purchases, there have been relatively few empirical studies on the subject. Those studies which do exist were primarily conducted in the late 1970 s and the early 1980s when there was greater consumer concern about the energy situation due primarily to higher energy costs. It is important for OBCS to be aware of the current trends in consumer decision-making which are probably quite different than those of a decade ago. Past studies on new technology adoption patterns of manufacturers and other intermediate markets such as builders are even more scarce than those pertaining to the residential end consumer.

One important result of this study was discovering how few studies have been conducted concerning the residential intermediate market of builders, contractors, engineers, and architects. These groups of ten make purchase decisions for end residential consumers. Only in the builder market is some information available concerning the criteria used when choosing the energy related products which will be included in a new home or apartment building. 
Therefore, it is suggested that this intermediate market be one of the focal points of future research. Further study of the decision makers in the intermediate residential market (the builders, engineers, contractors, architects, etc.) would benefit OBCS by providing information that could be used to better understand one of its major target markets.

The findings of this study conclude that more research is required to determine the evaluation criteria and motivating factors that influence 1) the decision by end consumers to invest in energy-conserving products, 2$)$ the decision by manufacturers to invest in the development of energy-related technologies, and 3) the decision by the residential intermediate market to design and construct energy-efficient homes.

Although this study has helped to fill in many of the gaps about the energy consumer's decision-making processes, criteria, and motivation, there is still much to be learned. Questions that need to be answered for each of the three OBCS target market areas include:

1. Who are the key decision-maker(s) in energy-related investments?

2. What decision-making criteria are used to evaluate energy-related investments?

3. What motivating factors are most influential in energy-related decisions?

4. What are the decision-making processes that are incorporated into the decision to make an energy-related purchase?

5. Who and what influence the decision-maker(s)?

6. What information sources are considered most credible by decisionmakers?

It is recommended that surveys and focus groups involving decision participants in each of the three major target markets be conducted. The above questions suggest some of the areas in which further research would be beneficial. Topics specific to each of the three markets are discussed in the final chapter of this report. 


\section{CONTENTS}

SUMMARY

$i j i$

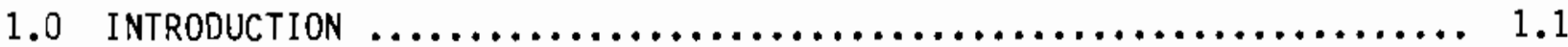

CHAPTER 2.0 - THE RESIOENTIAL CONSUMER MARKET $\ldots \ldots \ldots \ldots \ldots \ldots \ldots \ldots .2$

CHAPTER $3 . D$ - MANUFACTURERS OF ENERGY-RELATED PRODUCTS $\ldots \ldots \ldots \ldots \ldots 1.4$

CHAPTER 4.0 - RESIDENTIAL INTERMEOIATE MARKET - BUILOERS $\ldots \ldots \ldots \ldots .4$

2.0 THE RESIOENTIAL CONSUMER MARKET $\ldots \ldots \ldots \ldots \ldots \ldots \ldots \ldots \ldots \ldots \ldots \ldots \ldots \ldots$

2.1 DIFFUSION OF ENERGY-RELATED TECHNOLOGICAL INNOVATIONS....... 2.2

2.1.1 Characteristics of Consumers $\ldots \ldots \ldots \ldots \ldots \ldots \ldots \ldots \ldots .2 .2$

2.1 .2 Characteristics of Innovations $\ldots \ldots \ldots \ldots \ldots \ldots \ldots \ldots . . \ldots$

2.1.3 Symbolism and Technology Dimensions ............. 2.8

2.1.4 Effects of Social Networks on Diffusion ............ 2.10

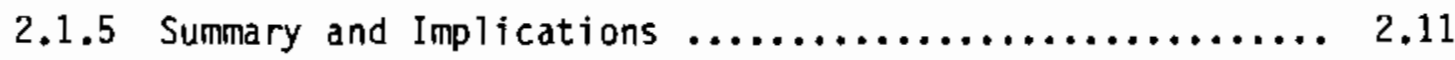

2.2 CONSUMER DECISION-MAKING FOR ENERGY-RELATED INVESTMENTS $\ldots \ldots \ldots 2.11$

2.2.1 Problem Recognition ........................ 2.12

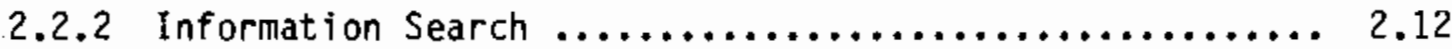

2.2.3 Evaluation of Alternatives $\ldots \ldots \ldots \ldots \ldots \ldots \ldots \ldots \ldots \ldots . \ldots \ldots$

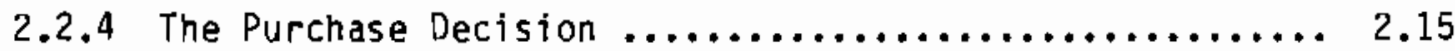

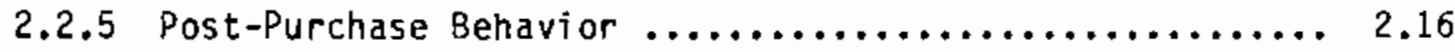

2.2 .6 Summary and Implications $\ldots \ldots \ldots \ldots \ldots \ldots \ldots \ldots \ldots \ldots \ldots .17$

2.3 ECONOMIC DISCOUNT RATES AND CONSUMER CHOICES $\ldots \ldots \ldots \ldots \ldots \ldots \ldots . . . . .17$

2.3.1 Importance of Discount Rates $\ldots \ldots \ldots \ldots \ldots \ldots \ldots \ldots \ldots . . \ldots \ldots$

2.3 .2 Estimations of Discount Rates $\ldots \ldots \ldots \ldots \ldots \ldots \ldots \ldots \ldots \ldots .18$

2.3.3 The Importance of Short Payback Periods ............ 2.21

2.3 .4 Investment Influence Factors $\ldots \ldots \ldots \ldots \ldots \ldots \ldots \ldots \ldots .2 .22$ 


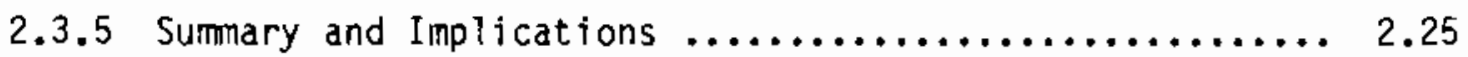

2.4 CONSUMER ATTITUDES AND ENERGY-RELATED INVESTMENTS $\ldots \ldots \ldots \ldots \ldots 2.26$

2.4.1 Fishbein's Attitudinal Moder $\ldots \ldots \ldots \ldots \ldots \ldots \ldots \ldots . . .2 .26$

2.4.2 The Role of Past Experience $\ldots \ldots \ldots \ldots \ldots \ldots \ldots \ldots \ldots, 2.27$

2.4.3 Other Attitudinal Factors ....................... 2.29

2.4.4 Summary and Implications $\ldots \ldots \ldots \ldots \ldots \ldots \ldots \ldots \ldots, 2.30$

2.5 SELF-PERCEPTION THEORIES AND HEURISTICS $\ldots \ldots \ldots \ldots \ldots \ldots \ldots \ldots .2 .30$

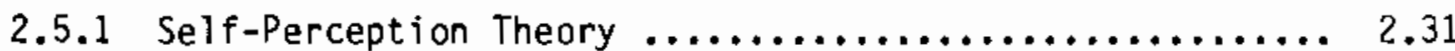

2.5 .2 Heuristics $\ldots \ldots \ldots \ldots \ldots \ldots \ldots \ldots \ldots \ldots \ldots \ldots \ldots \ldots, 2.35$

2.5.3 Summary and Implications $\ldots \ldots \ldots \ldots \ldots \ldots \ldots \ldots \ldots \ldots, 2.38$

2.6 BARRIERS TO ENERGY EFFICIENCY AND INVESTMENT $\ldots \ldots \ldots \ldots \ldots \ldots, 2.38$

2.6.1 The Role of Intermediaries $\ldots \ldots \ldots \ldots \ldots \ldots \ldots \ldots \ldots, 2.33$

2.6.2 Manufacturers of Energy Technologies $\ldots \ldots \ldots \ldots \ldots \ldots .2 .39$

2.6.3 Limited Capital of Consumers $. . \ldots \ldots \ldots \ldots \ldots \ldots \ldots \ldots . . .2 .39$

2.6.4 The Invisibility of Energy $\ldots \ldots \ldots \ldots \ldots \ldots \ldots \ldots \ldots . . . \ldots \ldots$

2.6.5 Additional Barriers to Energy Efficiency ............ 2.42

2.6.6 Strategies for Overcoming Barriers .............. 2.44

2.6 .7 Summary and Implications $\ldots \ldots \ldots \ldots \ldots \ldots \ldots \ldots \ldots \ldots, 2.45$

2.7 SUMMARY AND RECOMMENDATIONS $\ldots \ldots \ldots \ldots \ldots \ldots \ldots \ldots \ldots \ldots \ldots \ldots \ldots \ldots \ldots \ldots \ldots, 2.46$

2.7.1 A Framework of Consumer Behavior ................. 2.46

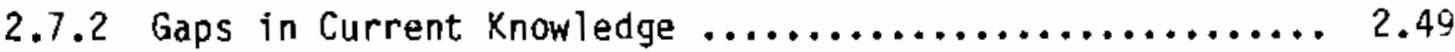

3.0 manufacturers $\ldots \ldots \ldots \ldots \ldots \ldots \ldots \ldots \ldots \ldots \ldots \ldots \ldots \ldots \ldots \ldots \ldots \ldots \ldots \ldots \ldots \ldots \ldots, 1$

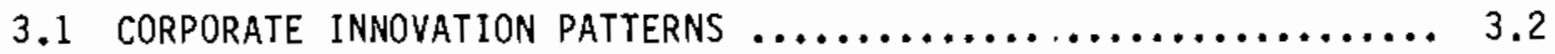

3.1 .1 Why Companies Innovate $\ldots \ldots \ldots \ldots \ldots \ldots \ldots \ldots \ldots \ldots \ldots, 3.3$

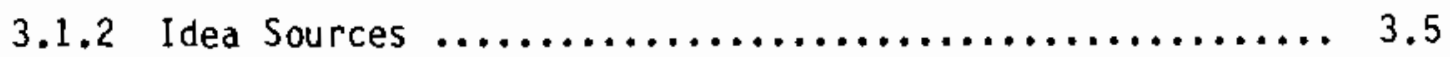

3.1 .3 Summary and Implications $\ldots \ldots \ldots \ldots \ldots \ldots \ldots \ldots \ldots, 3.5$ 
3.2 Diffusion OF OBCS TEChNOLOGIES tO MANUfaCtuRERS $\ldots \ldots \ldots \ldots \ldots \ldots, 3.6$

3.2.1 Aspects of New Technology $\ldots \ldots \ldots \ldots \ldots \ldots \ldots \ldots \ldots, 3.7$

3.2.2 Stage of Research and Development $\ldots \ldots \ldots \ldots \ldots \ldots \ldots, 3.7$

3.2.3 Industry Factors Affecting Diffusion $\ldots \ldots \ldots \ldots \ldots \ldots . .3 .8$

3.2.4 Summary and Implications $\ldots \ldots \ldots \ldots \ldots \ldots \ldots \ldots \ldots \ldots \ldots \ldots \ldots \ldots \ldots \ldots, 3.15$

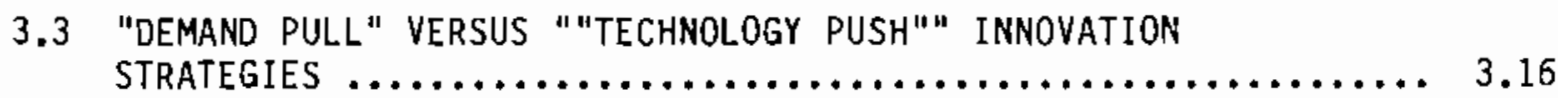

3.3.1 "Demand Pull" Strategy $\ldots \ldots \ldots \ldots \ldots \ldots \ldots \ldots \ldots \ldots \ldots, 3.16$

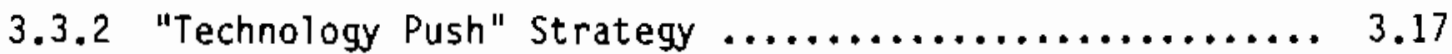

3.3.3 New Product Introduction Strategies $\ldots \ldots \ldots \ldots \ldots \ldots \ldots . . .6 .20$

3.3.4 Summary and Implications $\ldots \ldots \ldots \ldots \ldots \ldots \ldots \ldots \ldots \ldots, 3.23$

3.4 THE DECISION-MAKING PROCESS OF THE COMPANY $\ldots \ldots \ldots \ldots \ldots \ldots, 3.24$

3.4.1 The Importance of Attitudes $\ldots \ldots \ldots \ldots \ldots \ldots \ldots \ldots \ldots, 3.25$

3.4.2 Issues of Importance to Decision Makers $\ldots \ldots \ldots \ldots \ldots . . .26$

3.4.3 New Product/Innovation Screening Methods Potential ..... 3.27

3.4 .4 Summary and Implications $\ldots \ldots \ldots \ldots \ldots \ldots \ldots \ldots \ldots \ldots \ldots \ldots \ldots .29$

3.5 BARR IERS TO SUCCESSFUl MARKET PENETRATION $\ldots \ldots \ldots \ldots \ldots \ldots \ldots, 3.30$

3.5.1 Barriers in the Adoption Process ................... 3.30

3.5.2 Barriers to Innovation in Large Companies ............ 3.36

3.5.3 Barriers Encountered in the Implementation of
Industrial Process Technology $\ldots \ldots \ldots \ldots \ldots \ldots \ldots \ldots . \ldots . . .38$

3.5.4 Summary and Implications $\ldots \ldots \ldots \ldots \ldots \ldots \ldots \ldots \ldots \ldots, 3.40$

3.6 SUMMARY AND CONCLUSION $\ldots \ldots \ldots \ldots \ldots \ldots \ldots \ldots \ldots \ldots \ldots \ldots \ldots \ldots \ldots \ldots \ldots, 31$

4.0 THE RESidential intermediate Market OF BUILders $\ldots \ldots \ldots \ldots \ldots \ldots \ldots, 4.1$

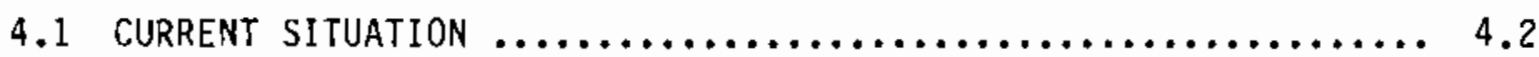

4.2 TYPICAL ENERGY-EFFICIENT FEATURES ADOPTED BY BUILDERS $\ldots \ldots \ldots 4.2$

4.3 THE ADOPTION OF ENERGY FEATURES BY BUILDERS $\ldots \ldots \ldots \ldots \ldots \ldots . .3$ 


\subsubsection{Initial Stimuli for Adding Energy-Efficient}

Features ............................... 4.4

4.4 DECISION CRITERIA FOR SPECIFIC ENERGY-EFFICIENT FEATURES $\ldots \ldots .4 .7$

4.5 INFORMATION SOURCES FOR ENERGY-EFFICIENT FEATURES $\ldots \ldots \ldots \ldots \ldots 4.9$

4.5 .1 Information 0esired by Builders $\ldots \ldots \ldots \ldots \ldots \ldots \ldots \ldots \ldots . . \ldots .11$

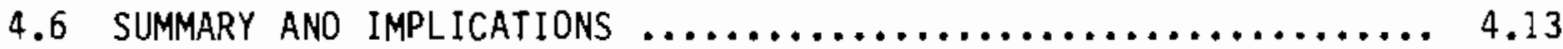

5.0 RECOMMENDATIONS FOR FURTHER STUDY $\ldots \ldots \ldots \ldots \ldots \ldots \ldots \ldots \ldots \ldots \ldots \ldots \ldots \ldots$

5.1 OETAILED INFORMATION NEEOEO IN THESE THREE OBCS MARKET

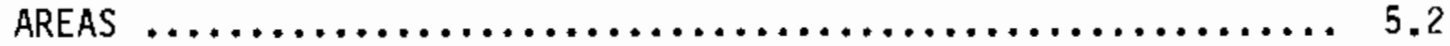

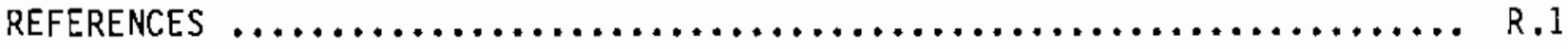




\section{FIGURES}

$1.1 \mathrm{OBCS}$ and the Interrelationships of its Markets $\ldots \ldots \ldots \ldots \ldots \ldots \ldots \ldots$

2.1 Categories of Adopters of Innovative Products $\ldots \ldots \ldots \ldots \ldots \ldots \ldots \ldots .2 .3$

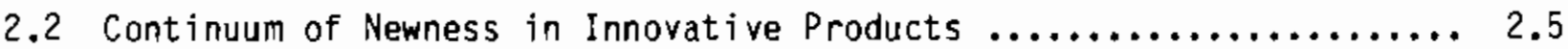

2.3 Energy Investments Categorized by Symbolism/Technology

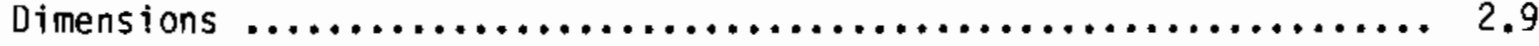

2.4 A Model of Consumer Decision-Making $\ldots \ldots \ldots \ldots \ldots \ldots \ldots \ldots \ldots \ldots, 2.12$

2.5 Steps Between Purchase Intention and Decision $\ldots \ldots \ldots \ldots \ldots \ldots \ldots . . .15$

2.6 Fishbein's Model of Attitude Development $\ldots \ldots \ldots \ldots \ldots \ldots \ldots \ldots \ldots .2 .27$

2.7 Attitude Model which Includes Past Experience $\ldots \ldots \ldots \ldots \ldots \ldots \ldots .2 .28$

2.8 A Comprehensive Framework of Consumer Behavior $\ldots \ldots \ldots \ldots \ldots \ldots . .2 .47$

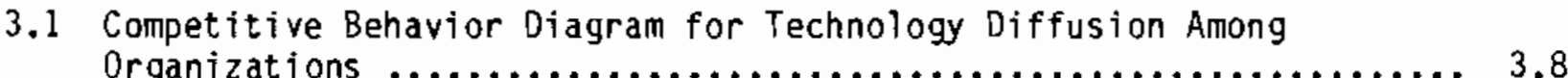

3.2 New Product Planning in a "Demand Pull" Strategy ................ 3.18

3.3 New Product Planning Process in a "Technology Push" Strategy ....... 3.19

4.1 The Adoption Process of Energy-Conservation Features by

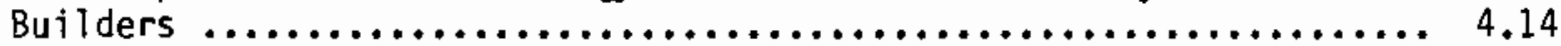




\section{TABLES}

2.1 Product Characteristics of Innovative Success $\ldots \ldots \ldots \ldots \ldots \ldots \ldots \ldots$

2.2 Consumer Information Sources $\ldots \ldots \ldots \ldots \ldots \ldots \ldots \ldots \ldots \ldots \ldots \ldots \ldots \ldots \ldots$

2.3 Successive Sets in Consumer Decision-Making ................. 2.14

2.4 Implicit Discount Rates for 1978 Purchases of Energy-Related Durables By Single-Family Homeowners ...................... 2.19

3.1 Differences in the Approach to Planning in a "Technology Push" Versus "Demand Pult" Company .............................. 3.16

3.2 Typical Functional Requirements of Alternative

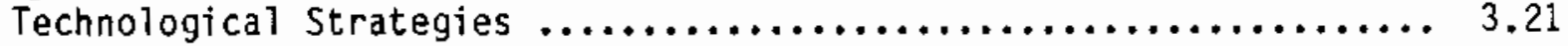

3.3 Importance Criteria in Industrial Marketing ................ 3.27

3.4 New Product Profile Chart $\ldots \ldots \ldots \ldots \ldots \ldots \ldots \ldots \ldots \ldots \ldots \ldots \ldots \ldots \ldots . \ldots \ldots$

3.5 The New Product Development Process: The "Decision-Making ETite's" Perspective ................................. 3.32

4.1 Stimuli to Consider Putting Energy Features into New Houses ....... 4.5

4.2 Decision Criteria Used in Making Final Decision About Use of an Energy Conservation Feature $\ldots \ldots \ldots \ldots \ldots \ldots \ldots \ldots \ldots \ldots \ldots \ldots \ldots . \ldots . \ldots . \ldots$

4.3 Builders' Use of Sources of Information About Energy Conservation Features and Their Influence on Adoption ........... 4.10 


\subsection{INTRODUCTION}

New energy-related technologies will result in energy-saving products for use by residential consumers (product technologies), and lower-cost manufacturing processes (process technologies). The use of these new technologies will result in lower product prices for residential consumers and will increase the competitiveness of U.S. manufacturers. The development of these new technologies is an important function of the U.S. Department of Energy (DOE), Office of Building and Community Systems (OBCS). The successful transfer of these technologies from the laboratory to industry, and later from manufacturers to residential consumers, depends on the acceptance or "adoption" of the technology by a number of distinct markets and market segments. In $19 B 6$ DBCS requested that Pacific Northwest Laboratory (PNL) (a) conduct a preliminary effort to 1) identify and assess various market factors that affect the adoption of energy-related technologies and to 2) identify areas requiring further research in order to enhance and encourage technology commercialization efforts.

The three markets that will be addressed in this study are:

- Residential Consumer Market - This market is made up of the residential consumers who will ultimately use energy-related technologies in their homes. Manufacturers and the residential intermediate market (explained below) both attempt to satisfy the needs and wants of these consumers who are the final indicator of overall market acceptance of a new technology.

- Manufacturers - Before most energy-related technologies are available in the residential consumer market, manufacturers must first adopt the technology, further develop it, and eventually market it to residential consumers.

(a) PNL is operated for the U.S. Department of Energy by Battelle Memorial Institute under contract DE-AC06-76RLO 1830. 
- Residential Intermediate Market - This market consists of builders, contractors, architectural firms, or other organizations that inf?uence and often make purchase decisions for residential consumers. The residential intermediate market often provides a link between manufacturers and residential consumers. This study focuses primarily on builders because of the lack of information on other irtermediate market participants.

The successful transfer or market penetration of OBCS technologies from laboratories to residential consumers often depends on the technology's acceptance by these three markets. Understanding the relationships between the markets and how their individual internal and external characteristics influence the willingness to adopt a new technology will better enable OBCS to develop strategies to gain support of manufacturers and the residential intermediate market. Figure 1.1 illustrates the interrelationships between these markets.

Chapters in this report will cover the following areas.

CHAPTER 2.0 - THE RESIDENTIAL CONSUMER MARKET

Several facets of consumer decision-making will be examined in Chapter 2.0. Specific components of consumer behavior will be combined to form a comprehensive framework that can be used by OBCS to develop and implement strategic marketing plans. Residential consumers are the ultimate users of many OBCS technologies. Their acceptance or purchase of an energy-related products is the final indicator of success for a new OBCS technology. OBCS should be aware of the needs and preferences of residential consumers in order to better serve this market. Understanding the needs and behaviors of the residential consumer will enable OBCS to provide helpful marketing information to other markets involved in the diffusion/adoption process such as manufacturers and builders. Manufacturers, builders, architects, and engineers can use the information to determine which OBCS technologies to develop or adopt. 


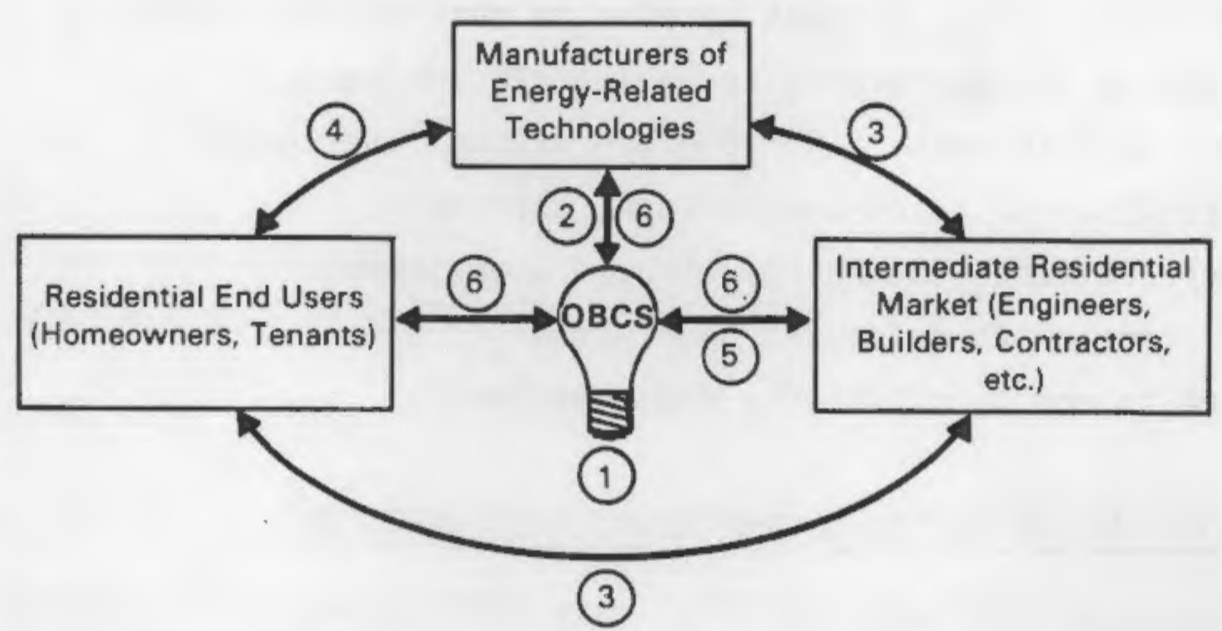

1) Energy-saving product and process ideas are generated by OBCS. These ideas may result from specific market needs or from new technological developments.

2) OBCS transfers information on new technologies to manufacturing firms that produce and market energy-related products. Participating firms manufacture and market OBCS's product ideas.

3) The finished product may take one of two routes, both of which have the residential end user of energy-related products as the ultimate destination. The first route is through an intermediate market such as builders. contractors, architects, or engineers. While this market may not actually use the energy-related technologies, it is responsible for many purchasing decisions. These decision affect the products which are then used by the resident of the dwelling.

4) The second route flows directly from the manufacturer to the end user of the technological innovations including homeowners and tenants. The end user is often the ultimate decision-maker for retrofit and replacement decisions, as well as for those decisions made while custom building a new home.

5) In the case of process innovation, the technology or idea may be directed to the manufacturer or it may bypass the manufacturer and be used directly by the intermediate residential market. An example of a process that might bypass the manufacturer is a new way to more efficiently combine existing products such as insulation and thermal windows.

6) OBCS needs to know and understand the needs and wants of each of these markets and how the demand in one market influences the demand in other markets.

NOTE: Feedback is present in all of these relationships between markets as indicated by the arrows. Information flows in two directions, both to and from the consumers. It is important for each member of the marketing channel to know the needs of the other members. This allow optimal diffusion of the innovation.

FIGURE 1.1. OBCS and the Interrelationships of its Markets 
A brief description of each section in this chapter follows:

- diffusion of energy-related technological innovations

- consumer decision-making for energy-related investments

- economic discount rates and consumer choices

- consumer attitudes and energy-related investments

- self-perception theories and heuristics

- barriers to energy-efficiency and investment.

\section{CHAPTER 3.0 - MANUFACTURERS OF ENERGY-RELATED PRODUCTS}

Successful market penetration of many OBCS technologies depends on the acceptance or adoption of energy-related product technologies/processes by manufacturers. Support from these manufacturers is often necessary to develop the technology into an end product or process that will better meet the energy requirements of residential consumers. A brief description of the major subjects covered in Chapter 3.0 follows:

corporate innovation patterns

- diffusion of innovations from OBCS to manufacturers

- "demand pull" versus "technology push" innovation strategies

- the decision-making process of the firm

- barriers to successful market penetration.

\section{CHAPTER 4.0 - RESIDENTIAL INTERMEDIATE MARKET - BUILDERS}

The residential intermediate market is made up of individuals and organizations that make purchase decision for residential end consumers. This market includes builders, contractors, architectural firms, rental property owners, and others. This chapter focuses on the decision processes, decision criteria, risks, and energy-related product information sources used by builders and contractors. The information regarding builders was obtained from a 1978 survey of North Carolina home builders. Focus is not provided on other intermediate residential markets because of lack of information. A brief description of the major subjects covered in Chapter 4.0 follows: 
- initial stimuli for adding energy-conservation features

- decision criteria for specific energy-conservation features

- information sources referred to by builders. 


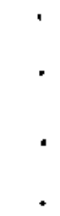




\subsection{THE RESIDENTIAL CONSUMER MARKET}

One of the three major markets which OBCS serves consists of residentia] end users of energy and energy-related products. Included in this market are the homeowners and tenants who actually use the energy and energy-related products in a residence. Although this consumer market ultimately uses products and ideas developed by OBCS, it does not necessarily choose or pay for the products. Often intermediaries provide these functions for the homeowner or tenant.

However, there are situations in which the residential consumer is the decision maker in an energy-related investment. Two such situations are those of custom-built homes and replacements or retrofits to existing homes. Also, as the ultimate users of an energy-efficient product, individuals who make up the residential market contribute greatly to public opinion and acceptance of new products. If the residential consumer market is not satisfied with a particular technology, it is unlikely that the intermediate market or manufacturers will adopt it.

Therefore, it is very important for OBCS to understand the residential consumer market to prevent costly marketing and/or research and development errors. First, information about residential market segments can help direct OBCS research toward a specific market. Many products which are conceptualized never make it to the commercialization stage of development. If OBCS can better determine which ideas will produce successful products and which will not, they can concentrate developmental efforts on probable successes and avoid wasting valuable time and resources on probable faitures. Although there is no foolproof way to determine which technologies will fail and which will succeed, a clear understanding of consumers' purchasing behaviors gives valuable insight into their preferences. Secondly, providing consumers with products they need and want will enhance OBCS's credibility as a valuable contributor to the conservation of energy and to society in general. 


\subsection{DIFFUSION OF ENERGY-RELATED TECHNOLOGICAL INNOVATIONS}

In order to understand how new energy technologies such as heat pump furnaces or more efficient insulation are introduced in the marketplace, it is necessary to understand the process through which innovations are introduced and diffused into society. An innovation refers to any product, service, or idea that is perceived as being new or novel by the potential consumer. The product may have been avaitable for a period of time, but it is considered an innovation by the individual who is examining it for the first time (Kotler 1984).

\subsubsection{Characteristics of Consumers}

Individual consumers differ in their willingness to try new products. A person's innovativeness is defined as "the degree to which an individual is relatively earlier in adopting new ideas than the other members of his social system" (Rogers and Shoemaker 1971). Hirshman (1980) distinguishes between three kinds of innovativeness: vicarious, adoptive, and use. "Vicarious" innovativeness is the seeking of information about new products or ideas. Not until the consumer actually buys the product has he participated in "adoptive" innovativeness. "Use" innovativeness involves finding new uses for products which are currently being used by the consumer.

Consumers in the United States can be classified into five adopter categories which include: 1) innovators, 2) early adopters, 3) early majority, 4) late majority and 5) laggards as shown in Figure 2.1. Each of these classes of adopters is believed to have different demographics and value orientations. "Innovators" tend to be younger, highly educated, and more financially able to take a chance on an unproven product. They are confident, venturesome, and enjoy taking risks. The "early adopter" group is a larger group consisting of 13.5\% of eventual adopters. While less adventuresome than the innovators, this group also has sufficient income, education and confidence to adopt a product or idea that has not yet gained wide acceptance. This group tends to be more socially integrated and, thus, members are considered opinion leaders by later adopters. The membership of the "early majority" group usually consists of solid middle-class consumers who are of average socio-economic status. 


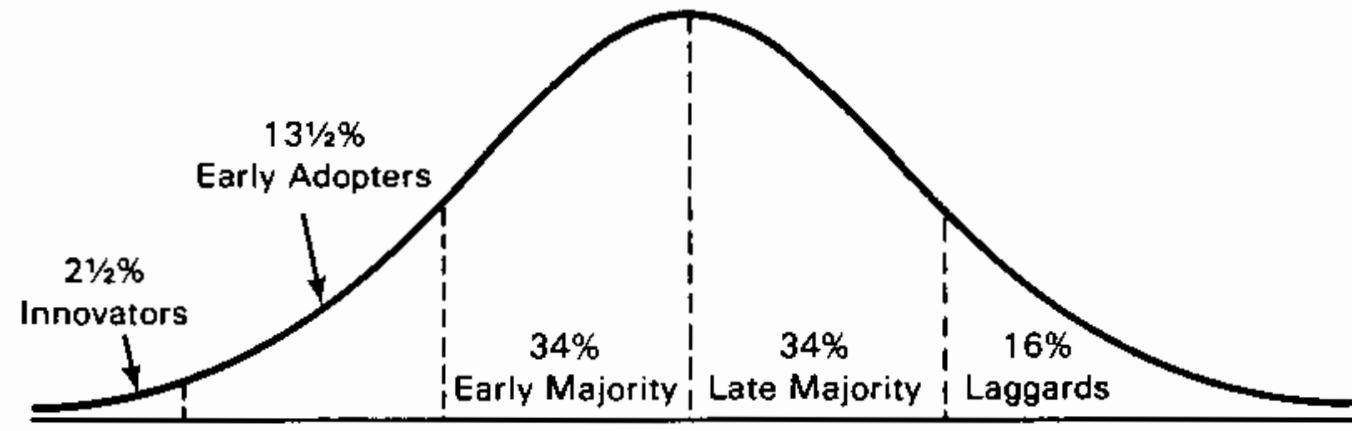

Time of Adoption of Innovations

FIGURE 2.1. Categories of Adopters of Innovative Products Source: Rogers. 1983.

The "late majority" group has similar characteristics but tends to have slightly less education and income than the early majority. "Laggards" or final adopters are the last group to adopt a new product or idea. This latter group of consumers can make use of an innovation but for economic, social, or educational reasons, has been slow to adopt it. Finally, with many products, there may be a group of non-adopters or consumers who will never use the product. This particularly applies to products, such as luxury automobiles, that target a small and distinctive audience (Zikmund and D'Amico 1984).

While dividing individuals into these adopter groups is useful in segmenting consumers into markets that can be targeted at different stages of a product's life cycle, it is not absolute. There have been discrepancies in the profiles generated for the innovative consumer. According to Dickerson and Gentry (1983), descriptions of the innovator range from being socially misfit to being socially integrated and mobile. These discrepancies may occur partially because of differing characteristics of the innovative products. Different groups of consumers may be initially attracted by different types of innovative products. Product differences will be discussed in the next section of this chapter.

One good predictor of the adoption of a set of energy-5aving modifications in the home has been determined to be the presence of an individual who was able to make repairs. Darley and Beniger (1981) explain the relationship as follows: 
"Mechanical ability probably has its impact in three ways. First, those with it are better able to understand energy-conserving innovations and judge which make most sense for their own circumstances. Second, it allows the homeowner to avoid labor costs by doing whatever labor the innovation requires. Third, it increases the certainty that potential savings will be achieved."

Other characteristics of those who invest in conservation measures compared with those who do not invest, include: 1) have higher incomes, 2) are younger, 3) live in older houses, 4) use more energy, and 5) own their homes (Frieden and Baker 1983).

\subsubsection{Characteristics of Innovations}

Not all of the variables in adopting new technology stem from differences in consumer proclivity to adopt a new product. Product characteristics within the innovation itself may also play a major role in determining the success and speed of a product's market penetration.

\section{Degrees of Newness}

One way that new products vary is with respect to their degrees of newness. Three major categories of innovations are 1) continuous, 2) dynamically continuous, and 3 ) discontinuous. Figure 2.2 below shows a continuum of innovations using newness as a scale. The examples shown demonstrate where various energy investments might fit in the continuum.

"Continuous" innovations involve the minor modifications of existing products. Few or no disruptions of the behavioral patterns of consumers occur when using a continuous innovation. A "dynamically continuous" innovation causes some disruption in behavioral patterns, but does not cause substantial alterations. The creation of a new product or the modification of an existing product may be categorized as a dynamically continuous innovation (Dickerson and Gentry 1983). "Discontinuous" innovations are pioneering products so new that no previous product has performed an equivalent function. As a result, new behavioral patterns for consumption and usage must be established (Zikmund and D'Amico 1984). Much of the literature concerning technological innovations deals with the discontinuous variety, although most innovations tend to fall in the other two categories. 


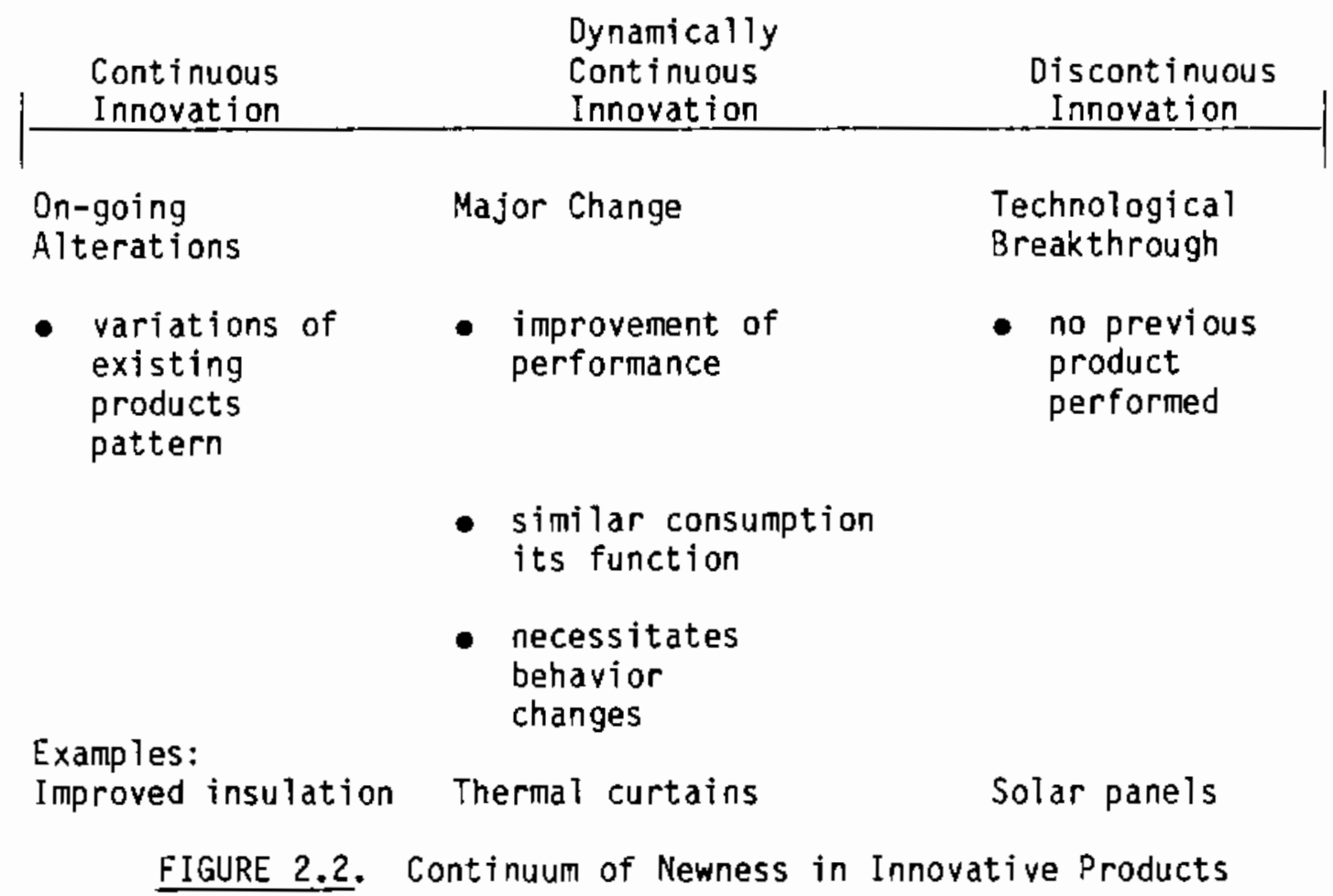

Indications of Innovative Success

Innovative products have several characteristics that make it possible to estimate the commercial success of the product. These include relative advantage, compatibility, complexity, trialability, observability, financial cost, social cost, return on investment, and perceived risk. These are listed in Table 2.1, and the direction of the relationship between each characteristic and chances of commercial success are shown. Relative advantage is determined by how much the new product improves over existing products that provide similar functions. Improvement may be in terms of cost savings or performance. Compatibility refers to how the innovation fits into the potential user's lifestyle and value system. Compatibility may also deal with the fit of new components into an existing system such as a heat pump fitting into an existing HVAC system. An innovation's complexity refers to the level of complication of the product as perceived by the consumer. Often consumers are intimidated by products which they perceive as too complex to understand and/or operate. The trialability characteristic of a product indicates how easy it is to test the product. Testing an innovation often reduces the risk associated with it. 
TABLE 2.1. Product Characteristics of Innovative Success

\section{Characteristic}

Relative advantage

Compatibility with existing lifestyles, behaviors, and values

Perceived complexity

Trialability

Observability

Financial cost

Social cost

Return on investment

Perceived risk
Relationship With Success

$+(a)$

$+$

- (b)

$+$
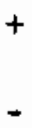

(a) $+=$ positive relationship with comercial success
(b) $-=$ negative relationship with commercial success

Observability is the degree of visibility a product provides to the consumer. The more a consumer can see a product, the more likely he is to consider adoption of the product.

The other characteristics of an innovation are mostly concerned with the costs and risks associated with the product. Costs include the initial (first) cost and the operating cost of the energy technology. Several kinds of risk can be associated with an energy investment and are listed below:

- financial risk - Risk that the outcome will harm the consumer financially. Example: an expensive solar heating system that does not meet payback expectations.

- performance risk - Risk that the product will not perform as expected. Example: A heat pump water heater which does not adequately heat enough water. 
- physical risk - Risk that the product will physically harm the buyer. Example: asbestos insulation.

- psychological risk - Risk that the product will lower the consumer's self-image. Example: Driving a smaller automodile to conserve fuel.

- social risk - Risk that friends or acquaintances will ridicule the consumer for making the purchase. Example: Purchasing an attic fan which detracts from the appearance of the home.

- time risk - Risk that the purchasing decision will cost the consumer too much time. Example: Spending hours deciding upon which heat pump furnace to install.

- opportunity loss - Risk that by taking one action, the consumer will miss out on an activity which he prefers. Example: Purchasing insulation immediately before a more efficient type of insulation is introduced to the market.

The consumer will weigh the costs and risks to determine the feasibility of purchasing the innovation.

To sumarize, research has shown that the speed of adoption is positively related to the product's high relative advantage to alternatives, high degree of compatibility, easy trialability, and communicability, and negatively related to its complexity and its cost (Dickerson and Gentry 1983). It is important to understand that these characteristics are the perceptions of potential purchasers and users of the innovation and are thus not necessarily objective (Darley and Beniger 1981).

Darley and Beniger (1981) studied energy innovations in terms of the above success characteristics. They suggest that since energy innovations are often costly, initial cost and estimated savings are important decision-making factors. An informal payback analysis is often performed by the consumer to determine if the innovation is cost effective. This type of payback analysis will be discussed in Section 2.3 of this chapter. Value compatibility, which was previously discussed, is another characteristic of energy technologies which has had an impact on the adoption. A hypothetical example of this 
concept follows: while most consumers express concern about the energy situation and concur that conservation is necessary. Those consumers with strong opinions and beliefs in favor of conservation will initially adopt energyefficient innovations such as heat pump furnaces and solar panels. Compatibility with lifestyles and action patterns is also a consideration. Some energy innovations such as thermal curtains require specific actions on the part of the consumer in order to effectively conserve energy. If the curtains are not opened in the morning and drawn at night, they are not conserving energy or saving the consumer money. A final characteristic of energy innovations mentioned by Darley and Beniger (1981) is the effort and skill involved required to properly install the innovation. This is very similar to the complexity characteristic of innovative products which was mentioned earlier. The more difficult a product is to install, the more complex it is perceived as being.

\subsubsection{Symbolism and Technology Dimensions}

Another dimension by which innovations can be examined differentiates between symbolic and technological innovations. A symbolic innovation is one which communicates a different social meaning than it previously did. An example may be to use a wood stove to conserve energy and resources rather than merely as a means of heating. On the other hand, a technological innovation has tangible features never before found in the product class. Figure 2.3 demonstrates how products may be classified according to these dimensions. For example, a wood stove is not a new technology, but does have a high degree of symbolic innovation because the reasons for using it have changed. On the other hand, a heat pump furnace does not have any real social meaning (symbolic innovation), but is a technical breakthrough.

Technological innovations are likely to be discontinuous innovations. As such they are less likely than symbolic innovations to be compatible with consumers' backgrounds and experiences. Technological innovations are often complex and more difficult to understand than symbolic innovations. Because technological innovations are often expensive, they are less amenable to trial purchase than symbolic ones. Symbolic innovations tend to be more observable than those of the technological variety. For these reasons, it is assumed that symbolic innovations will be diffused through society at a faster rate than 


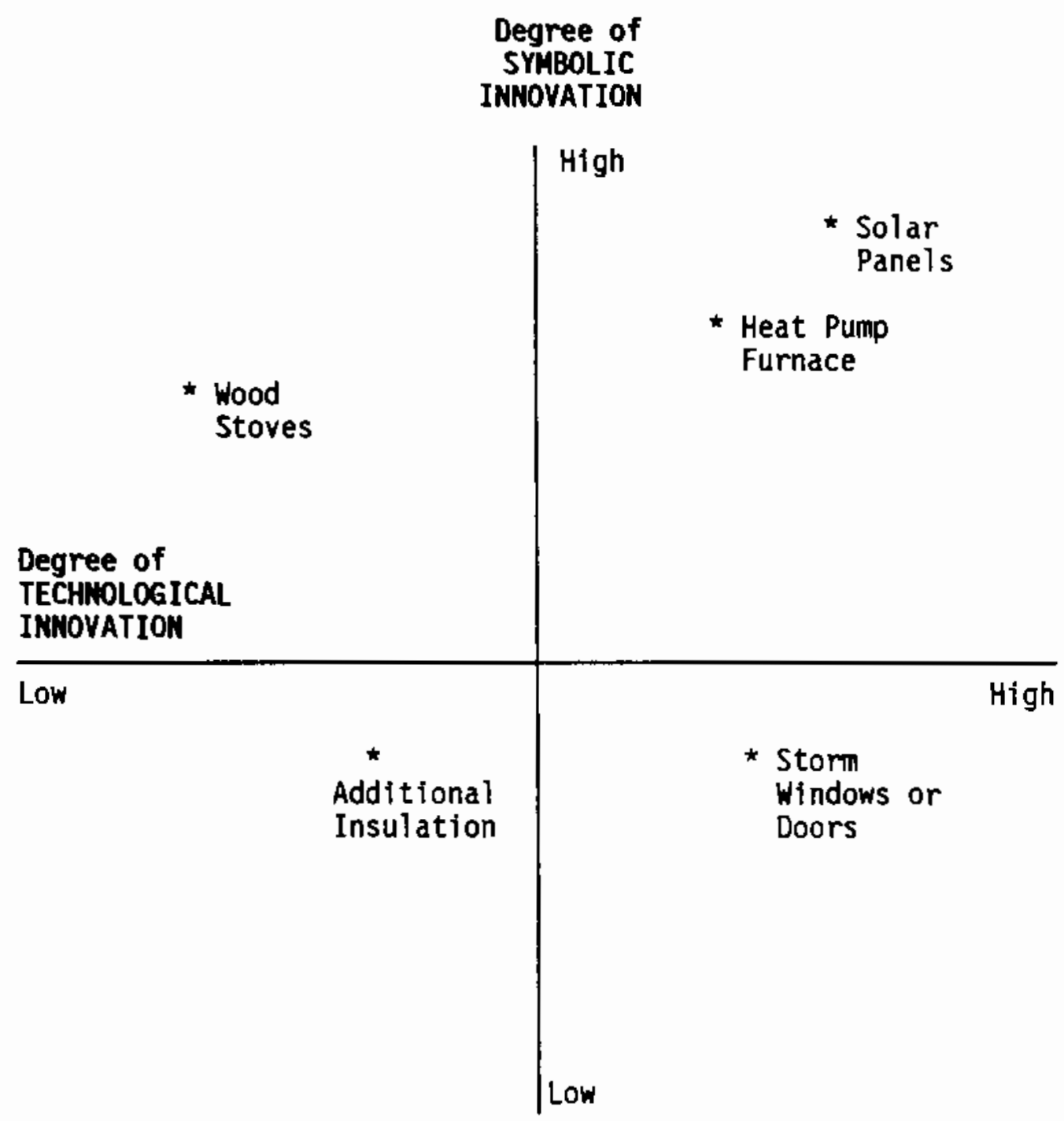

FIGURE 2.3. Energy Investments Categorized by Symbolism/Technology Dimensions

technological innovations (Dickerson and Gentry 1983). This diffusion may also be a function of the consumers' acceptance of the new social meaning associated with the innovation.

It is possible that a perceptual map similar to the one in Figure 2.3 could be developed for energy-conserving products. Some products such as wood stoves are not innovations in the technological dimension. However, the symbolism of using a wood stove to conserve energy and save natural resources is an innovative concept created by the relatively new trends of energy and resource conservation as well as by the rising cost of energy. Thus, the 
purchase of a wood stove has a societal as well as a functional meaning. 0ther energy-conserving innovations such as heat pumps and solar panels are very technological in nature but are also symbolic innovations in that they stress energy conservation and efficiency.

\subsubsection{Effects of Socjal Networks on Diffusion}

There is no one standard method in which innovations diffuse through society. Darley and Beniger (1981) have identified two distinct types of diffusion processes: areal diffusion and network or hierarchial diffusion. Areal diffusion refers to the process of diffusion by means of spatial proximity or contact. In this process, spatially-near potential adopters learn of an innovation before more distant adopters. However, in network diffusion, geographica? distances are not considered. Instead, the innovation is diffused through a network which may reach more distant adopters while skipping closer ones. One such network consists of interpersonal relationships or individuals linked by communication channels.

There is evidence that the spread of energy-conserving household innovations is influenced more by the structure of social networks rather than by areal networks. Second stage innovators or early adopters are often friends, colleagues, and office mates of initial innovators rather than neighbors. The latter is attributed to the fact that neighbors in modern urbanized societies are not necessarily friends or even acquaintances. Thus, it is often difficult to predict the path that an energy innovation will take (Darley and Beniger 1981).

Influential members or opinion leaders in the social networks are largely responsible for the adoption of some innovations and for the rejection of others. Opinion leaders learn of an innovation through mass media sources and then adopt it. Their reaction to the innovation is imitated by later adopters. Darley and Beniger (1981) refer to this phenomenon as "a two-step flow of communication." The nature of the diffusion system depends on the specific innovation being diffused. Some innovations such as heat pump water heaters are more likely to be discussed among males, while others such as thermal curtains are more likely to be discussed among females. More mundane energy investments such as additional insulation may not be discussed much at all among 
acquaintances (Darley and Beniger 1981). Because of the broad range of possible diffusion paths, it is necessary to examine both the social networks of the initial innovators and the specific characteristics of the innovation which may affect its diffusion.

\subsubsection{Summary and Implications}

Many of the technologies and ideas developed by OBCS are innovations to the end consumer of energy. Therefore, understanding the process by which these diffuse through society is important. Many factors which have been discussed above play an important role in new technology diffusion. These include the characteristics of the innovation, the characteristics of the consumer, and the social networks of which the consumer is a member. The relationships of these three major factors should be examined to gain full insight into the best way to present an innovation to consumers.

Examining these factors and their interrelationships is not easy because the number and variability of the factors makes it difficult to do more than make an educated guess concerning the reactions of a specific consumer. When examining an entire group of consumers, this problem is greatly magnified. However, it is possible to predict the general trends which are likely to occur white a specific innovation is being diffused. Understanding these general trends, which may occur as a specific innovation is diffused, is helpful to OBCS in determining an appropriate target audience for its technologies. Once a target audience is chosen, OBCS and/or manufacturers of OBCS technologies can focus their marketing efforts on the most appropriate group of potential consumers. Since only those segments of consumers likely to purchase the innovation will be addressed, costs for advertising are minimized.

\subsection{CONSUMER DECISION-MAKING FOR ENERGY-RELATED INVESTMENTS}

Consumers will vary in the ways they buy a particular product. Some consumers will spend a great deal of time seeking information and maxing comparisons; others will buy a product on impulse without thoroughly examining the alternatives; yet others fall between these two extremes of purchasing behavior. A model of consumer decision-making has been developed which demonstrates the various stages through which a consumer passes when making a purchasing 


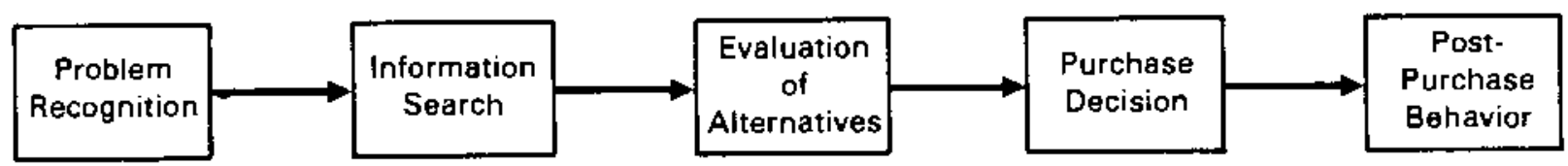

FIGURE 2.4. A Model of Consumer Decision-Making

decision. Not all consumers pass through each of these stages. A buyer making an impulse purchase may omit several stages and proceed directly to the purchase decision stage. The following figure illustrates a commonly used model of the consumer decision process.

\subsubsection{Problem Recognition}

The buying process starts with the consumer recognizing a problem or need. He sees a difference between the state in which he exists and the state in which he wishes to exist. An internal or external stimulus may trigger the need or desire in a consumer. An internal stimulus is an innate feeling such as hunger, thirst, heat, or cold. An external stimulus may be anything external to the consumer, such as an advertisement or a conversation with a friend, for example, a consumer may realize a need for a new form of heating his home if 1) the present system is not heating the house to a comfortable temperature (internal stimulus) or 2) his energy bills are too high (external stimulus). If a marketer can identify the particular need that would trigger a consumer's interest in a product, he could use this to promote the product.

\subsubsection{Information Search}

Once the consumer has recognized a problem or need, he may or may not search for more information. This depends on the price of the object, the prior knowledge the consumer brings to the buying situation, the level of involvement the consumer has with the purchase, and the cost (time) of acquiring additional information. Low involvement purchases tend to be items which are routinely purchased and involve little search activity. A consumer will more likely spend time searching for information in a high involvement purchase situation. Assuming that the consumer does undertake an information search, 
two levels of search behavior are apparent. The first is called heightened attention, and is a state in which the consumer is more attentive to information concerning the product. For example, if an individual is considering purchasing a heat pump furnace for his home he may merely become more attentive to advertisements on television and in newspapers about heat pumps. The second level is an active information search where the consumer looks for reading material and other information concerning the product he is considering purchasing (Kotler 1984). The consumer who considers purchasing a heat pump might read product literature and consumer information guides, talk with neighbors and friends, and visit local distributors.

There are several sources from which the consumer may gather information. These consumer information sources are grouped into four major categories as shown in Table 2.2 .

The relative influence of these information sources varies with the product categories and the buyer's characteristics. Generally, most of the messages a consumer receives about a product are from commercial sources. However, the most effective sources tend to be personal in nature (Kotler 1984).

As a result of gathering information, the consumer becomes acquainted with the alternatives available to him. His choice is successively narrowed down in the manner shown in Table 2.3. This figure uses brands of heat pump furnaces to illustrate the concept of the steps or sets in consumer decision-making.

\subsubsection{Evaluation of Alternatives}

Once a consumer gathers information, he begins to narrow down his alternatives as shown above. However, the question remains, how does the consumer

\section{TABLE 2.2. Consumer Information Sources}

Personal sources

Commercial sources in-store displays

Public sources organizations Experiential sources handling, examining, and using the product family, friends, neighbors, and acquaintances advertising, salespersons, packaging and mass media non-advertising and consumer rating 


\section{TABLE 2.3. Successive Sets in Consumer Decision-Making}

Total Set of Brands

Awareness Set

Consideration Set

Choice Set

Decision
Trane, Coleman, Lennox, Nutone, York, General Electric, Heil, Rheem, Carrier, Intertherm, Janitol, etc.

Brands of which the consumer is aware: Irane, York, Carrier, Coleman, Rheem, Lennox, General Electric.

Brands which the consumer considers purchasing: Trane, Coleman, Lennox, and Rheem.

Brands which have the necessary attributes to be purchased: Trane and Coleman.

Brand the consumer decides to purchase: Coleman.

chouse between brands of a product? There is not one simple evaluation process used by all consumers or even by one consumer in all buying situations. Most current models of consumer evaluation processes are based on cognitive theory. In other words, it is believed that the consumer forms product judgments largely on a conscious and rational basis.

Certain basic concepts help explain the way in which consumers evaluate alternatives. The first of these concepts deals with the specific attributes of the product. For example, a consumer interested in buying a heat pump furnace may be interested in its price, energy-efficiency, effectiveness, and/or convenience. The consumer will pay attention to those attributes which are related to his needs. The market for a product can be segmented according to the different perceived needs or expectations of different groups of consumers.

A consumer is likely to associate different weights of importance to product attributes relevant to him. If the consumer has financial constraints, he may place more importance on the price of a product and less weight on other attributes such as quality, reliability, or convenience.

Next the consumer may develop a set of brand beliefs about each brand and its relevant attributes. The set of beliefs about a particular brand is called the brand image. This image reflects consumers' perceptions of the brand and may not be based on fact. The consumer will then combine all available information concerning the product and form an opinion about the product 
alternatives by using an evaluative process. Many of these processes will be examined in the following sections of this chapter.

\subsubsection{The Purchase Decision}

Once the consumer evaluates the alternatives and forms preferences, he also forms a purchase intention or a plan to buy a particular brand. Two factors are shown in Figure 2.5 may intervene between the purchase intention and the actual purchase decision.

The first of these factors is that of attitudes of others. If a significant other person, such as a spouse or close friend, does not agree with the consumer's choice of a Coleman heat pump, he may be influenced to change his mind and choose another brand. The extent to which another person's attitude will alter a preferred choice depends on two things: 1) the intensity of the other's negative attitude toward the preferred alternative and 2) the consumer's motivation to comply with the other person's wishes. The more intense the others person's negative feelings, and the more important the other person is to the consumer, the more the consumer will conform to the other's negative feelings and revise his purchase intentions.

The second factor which influences purchase intention is that of unanticipated situational variables. The consumer forms a purchase intention on the basis of certain factors such as expected family income, expected price of the brand, and expected benefits from the product. If an unanticipated factor occurs, such as the consumer losing his job or the price of a Coleman heat pump increasing dramatically, the purchase intention may he altered.

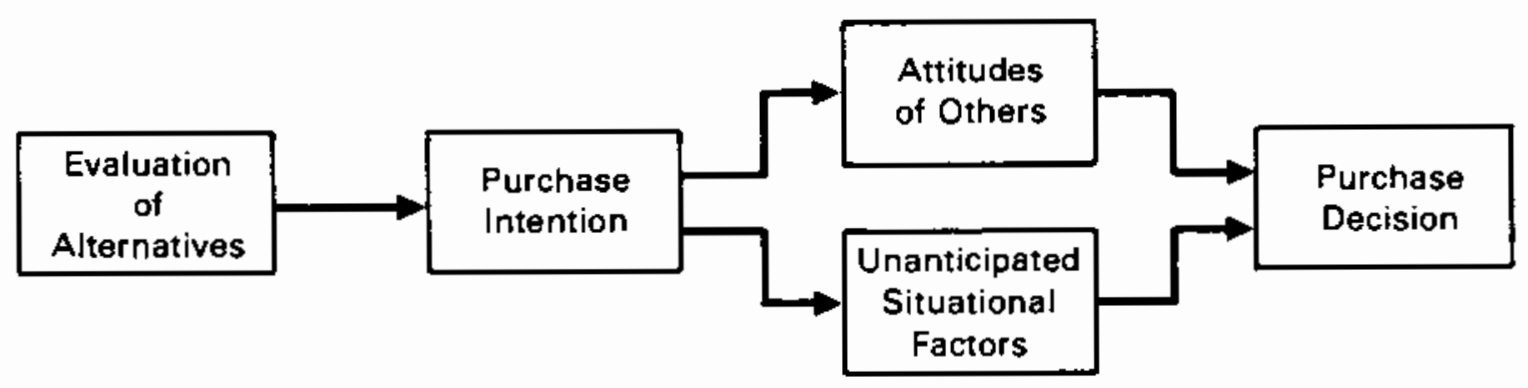

FIGURE 2.5. Steps Between Purchase Intention and Decision 
Once a person has reached a purchase decision, there are actually five subdecisions which must be made concerning the purchase. The five subdecisions are as follows:

- brand decision - which brand to purchase

- vendor decision - which store to patronize

- quantity decision - how many of the product to purchase

- timing decision - when to make the purchase

- payment-method decision - how to pay for the purchase.

These decisions involve the brand, vendor, quantity, and timing of the purchase to be made. Another very important decision is the payment-method decision. The consumer must decide whether to purchase the product by cash or by credit.

\subsubsection{Post-Purchase Behavior}

After purchasing a product, the consumer will experience levels of satisfaction or dissatisfaction. This level is determined by how closely the products performance compares with the consumer's prior expectations. If the product matches or exceeds expectations, the consumer will be satisfied. However, if the product does not meet the expectations, the consumer will experience feelings of dissatisfaction. These feelings may be similar to cognitive dissonance which will be discussed in more detail in Section 2.5.1.

The consumer's satisfaction or dissatisfaction with the product will influence his subsequent behavior. If the consumer is satisfied, there is a high probability that he will purchase the same product again. A satisfied customer will also relay to other consumers the positive qualities of the product. A dissatisfied customer may behave in several different ways depending on the level of dissatisfaction and his individual characteristics. The consumer may take public action such as complaining to the company or filing a lawsuit, a private action such as no longer buying the product, or no action at all. 
Another activity of post-purchase behavior that interests marketers is what the consumer uttimately does with the product. It is possible that a consumer may discover a new use for the product which could then expand its market potential.

\subsubsection{Summary and Implications}

It is important to understand the decision-making processes of the residential consumer of energy. By examining the stage of decision-making at which potential consumers of energy-related products appear to be, it is possible to make informed marketing strategy decisions. For example, if the majority of potential consumers of heat pump furnaces is just beginning to learn that a problem exists because their homes are not heated comfortably or their energy bills are too high, they need to be made aware of the benefits of a heat pump furnace. Once the consumer is aware of the benefits of a product, various methods of persuasion may be employed to induce the consumer to purchase it. However, it is critical to make the consumer aware of the benefits before attempting to persuade him to buy the product. Otherwise, a vital step in the decision-making process will have been neglected. This may result in confused consumers who are unlikely to purchase the advertised product.

One of the aims of OBCS and DOE is to benefit the residential energy user. Therefore, it is important to understand the needs, wants, and prefer-ences of this target market. One way in which to do this is to examine the consumers thought processes while making a purchasing decision. Further studies are warranted in order to more fully understand the specific decisionmaking processes of a consumer of energy-related technologies.

\subsection{ECONOMIC DISCOUNT RATES AND CONSUMER CHOICES}

One of the most widely advocated methods for evaluating energy-related durable good is life-cycle cost analysis. A durable good is defined as any product which is expected to produce a continuation of services or satisfaction (e.g., heat pumps, washing machines, and refrigerators). This analysis calculates the costs and benefits of a durable good over its lifespan and discounts the product at a market rate of interest for the individual. The interest rate 
that the individual places on the investment is often referred to as the discount rate, or the reduction in annual operating cost that is required to induce the consumer to invest one dollar. Therefore, a consumer who demands a high discount rate wants to be reimbursed for his investment faster than one who does not demand as high a rate.

When evaluating new technologies in terms of market acceptance, it is important to understand what sort of payback schedule is expected by consumers. This section will discuss some of the different estimations of consumer discount rates and the diversity of findings from these studies. Reasons for high discount rates and the resulting low-acceptance of many new energyefficient products witl also be discussed.

\subsubsection{Importance of Discount Rates}

The discount rate is the most important component of life-cycie analysis. While some consumers require a $50 \%$ or greater return on investments others will completely reject such a return. Economists have relied on several factors to try and explain the investment decisions of individuals.

\subsubsection{Estimations of Discount Rates}

When estimating consumers' discount rates, many life cycle analysts have based their studies on the individual's interest rate for borrowing or lending (Ruegg 1975; Sedmak and Zampelli 1979; Reid et al. 1977, Lunde 1982), and have failed to consider the imperfections and risks that the consumer faces or perceives when buying an energy related durable. Using the individual's acceptable interest rate assumes that this purchase is as secure and safe as investing in a liquid, controllable and insured bank account (Chernoff 1983). Different studies have concluded a wide range of individual discount rates for energy-related investments. Results of a 1979 study by Hausman found that individuals use a discount rate of about $20 \%$ for purchases of energy-efficient air conditioners. A study conducted by Houston in 1980 found a similar mean disccunt rate of $22.5 \%$ for investments in energy-saving devices. The only real conflict that Houston's study had with Hausman's study was the importance of income to the discount rate. Houston's study concluded that, although income is an important variable in predicting whether an individual would consider the 
investment analysis, it was not statistically significant in explaining the discount rate used by individuats. Hausman's study, on the other hand, found that lower income consumers use very high discount rates.

Other studies show implicit discount rates are much higher than those shown by Houston and Hausman. In a study by Gately (1980) that compared the sales prices of energy-efficient and energy-inefficient refrigerators, estimated discount rates ranged from $45 \%$ to $300 \%$ (Chernoff 1980). 0ak Ridge National Laboratory estimated discount rates that were typically $50 \%$ to $100 \%$ for energy-related durable goods, see Table 2.4. Discount rates far above market rates should be expected for energy-related durables for a number of reasons (Chernoff 1980). These reasons include:

TABLE 2.4. Implicit Discount Rates for 1978 Purchases of Energy-Related Durables by Single-Family Homeowners

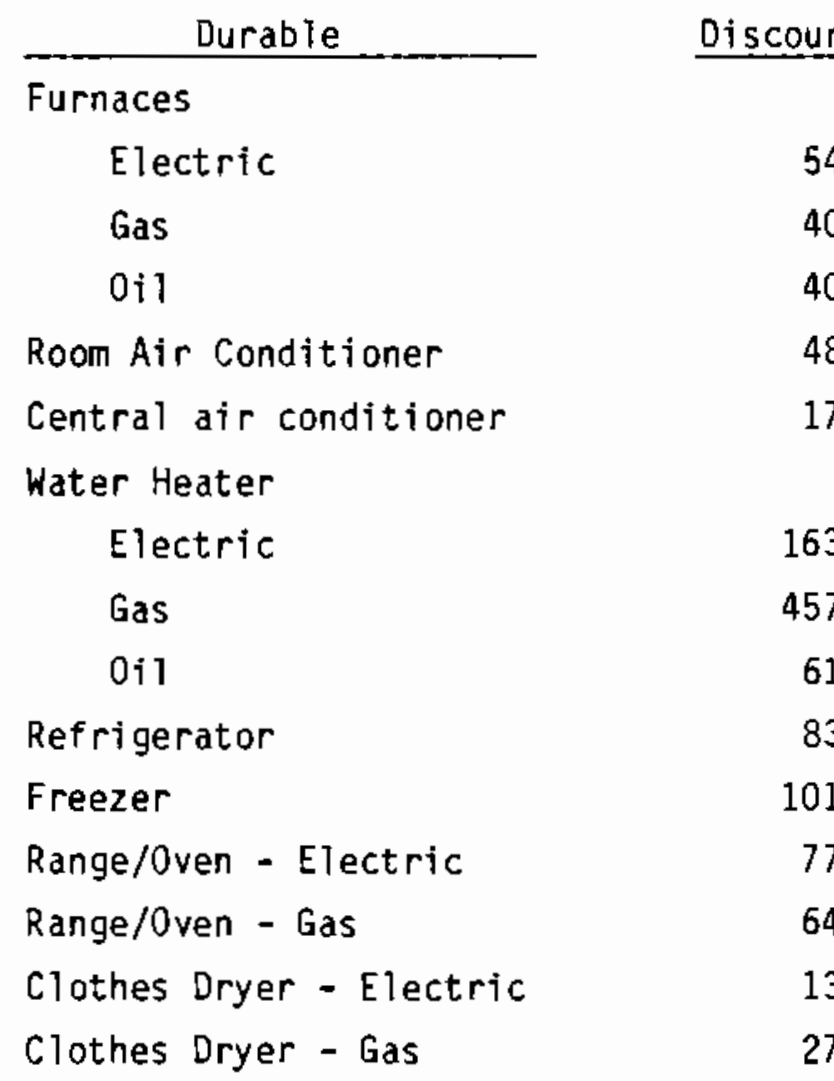

Source: U.S. Department of Energy. 1982. 
- illiquidity of consumer durables - Based on a given interest rate, investments in consumer durables are preferred less by consumers than liquid financial assets. In order to entice an individual to forego liquidity, a liquidity premium must be added to the discount rate.

- risk premium - The market rate of interest assumed for life-cycle analysis is often based on a riskless rate such as the consumer's lending or borrowing rate. However, an investment in a consumer good carries a risk factor. This is especially true in the case of energy energy-saving products where the decision to purchase is based somewhat on the consumer's belief in the manufacturer's savings, comfort and payback claims. These risk premiums should be added to the market rate of interest.

- inefficiencies of capital markets - Capital markets in which individuals function are not as efficient as generally assumed. In an efficient capital market, individuals would borrow to invest in economically attractive measures. When consumers are unwilling to do so , a high discount rate is implied. A 1980 study of the willingness of New Jersey consumers to invest in energy conservation found that the most common reason for not maxing improvements with rapid paybacks was "I don't have the money to invest right now!" ( New Jersey Department of Energy 1981).

- possibility of rapid technological change - If consumers expect the prices of, for example heat pumps, to decline, or the efficiency of air-conditioning systems to increase, they may postpone their purchase rather than incur an economic penalty for not watting for the new model. The possibility of rapid obsolescence or technological change will increase the discount rate.

- energy prices - Energy prices have historically fluctuated widely from year to year, adding an uncertainty premium to the discount rate.

- limited future enjoyment of the durable - While life-cycle analysts evaluate costs and benefits over the physical life of a 
durable, individuals normally evaluate these benefits only for the period of time that they intend to own the durable. Market discount rates are higher for used versus new durables because they of ten have no warranty, unclear seller claims, and unknown repair history. Therefore, energy efficiency will not usually impact the sales price of a used durable such as a heat pump. In fact, for some products, energy efficiency is only the third or fourth most sought after characteristic. For example, with refrigerators, energy efficiency ranks behind initial price, size, and color (Davis and Perry 1982; McNeill and Wilkie 1979). Homeowners, on the average, move every five to seven years, so energy-related benefits 10 to 20 years in the future have little present value to the homeowner.

- evaluation costs - A search cost is imposed on the buyer for the time and effort expended to obtain and evaluate the energy efficiency information that would otherwise be of little value. Also, there may be no economic basis for searching if the individual does not expect the energy savings to be worth the search cost or if the information is too difficult to obtain (Jacoby et a1. 1976).

\subsubsection{The Importance of Short Payback Periods}

Consumers normally demand short payback periods for investments in energyrelated products (Chernoff 1980). Some economists argue that consumers become confused and hesitant when monetary paybacks span many years, and that a longer time span makes it more difficult for them to choose rationaliy among investment decisions (Houston 1983).

In an extensive survey of home improvers questioned about passive home improvements, researchers concluded that "respondents expected passive solar features to pay for themselves in five or less years. Respondents who were more knowledgeable or aware of passive solar were more likely to consider a larger payback period acceptable than those with no knowledge of passive solar. 01 der respondents were less likely to consider even a three-year payback period acceptable (Market Facts Inc. 1981)." It is important to point out that respondents in this survey were not average homeowners, but prime solar buyers. 
They were 30 to 55 years old, college-educated, with annual incomes above $\$ 20,000$. Rapid payback is probably even more important in samples of all homeowners (Chernoff 1980).

The necessity of a five year or less payback period was found in another survey in 1981 by Science Applications, Inc. San Diego homebuilders, lenders, and HVAC distributors were questioned about the buying criteria of upper income homeowners' for photovoltaic systems. Results concluded that a five year payback period would be necessary. There was no interest expressed in life cycle cost of the system by most homeowners.

\subsubsection{Investment Influence Factors}

Dne 1980 study (Houston 1983) examined the factors that influence a homeowner's decision to invest in an untried energy-saving durable. A mail survey was used to ask homeowners what the minimum annual cost reduction on a longlife energy investment would need to be (given an initial purchase and installation price) in order for them to invest.

Homeowners were also able to respond with a "don't know or uncertain" answer. Those who were unable to conceptualize an investment problem normally answered "don"t know or uncertain." Compared to homeowners who did answer the investment question, these respondents were characterized by lower income, larger families, smaller homes, less experience with energy-conserving activities, and fewer intentions to engage in energy conserving-activities.

Consumers who could conceptualize an investment problem (those that gave an answer other than "don't know or uncertain") were influenced by factors related to cost and value of the investment. These consumers generally assumed costs beyond those stated in the survey question and consistentiy integrated these added costs into their investment decisions. In the Houston study this was reflected by lower discount rates for those who expected lower costs or greater value for their investment (Houston 1983).

Internal Factors Affecting the Oiscount Rate

Factors which are both internal and external to the consumer may affect the size of the discount rate which is acceptable. The rate of acceptance of an untried durable good is increased by factors that decrease the discount 
rate. Houston's study states that important variables internal to the consumer and which aid in explaining the discount rate are 1) prior experience with energy-saving activities, 2) intentions to engage in energy-saving activities, 3) number of family members, 4) household square footage, and 5) age of residence.

\section{External Factors Affecting the Discount Rate}

While some studies have outlined the characteristics of consumers most likely to invest in energy-efficient products, other studies have looked to external factors for the residential sector's underinvestment in energy conservation. A 1984 study (Ruderman, Levine, and McMahon) outlined some earlier research that discussed several of these explanations which include: lack of access to capital markets, Tack of information, purchase thresholds, indirect purchase decisions, decisions of manufacturers, and "gold-plating." These explanations deserve further discussion.

First, sufficient capital to acquire funds for energy-efficient products may not be available to purchasers. This problem is most prevalent in the purchase of more efficient furnaces and air-conditioners, where the incremental cost of more energy-efficient devices adds hundreds of dollars to the purchase price. Added to the uncertainty of the benefits of higher efficiency equipment, this extra cost may be seen as too great, resulting in the purchase of lower cost and lower efficiency equipment. Even when the consumer realizes the short payback periods of energy-efficient units, he may not be able to afford the added cost. This is especially true in cases where a purchase needs to be made in the short term, for example if a furnace system fails and the homeowner does not have the time or funds to contemplate purchasing a more energyefficient (and expensive) unit.

Purchasers often lack information about the costs and benefits of purchasing energy-efficient units or they may not understand how to use this if it is available to them. The Federal Trade Commission energy-labeling program of 1980 may change the efficiency choice decisions in the future, although at the time of that study there was no evidence to demonstrate the effects of the 
program. However, if consumers do not understand the information presented to them by the FTC, this information alone will have little impact on the purchase patterns of consumers.

Smal1 differences in price are not often perceived or acted upon by consumers, according to some theories of consumer behavior. Savings below some threshold may not be significant enough to warrant the consumer's additional effort.

"Transaction costs" of obtaining a more efficient appliance relates to the purchaser threshold. The additional time and effort required to locate, purchase, and install the new high-efficiency model may be a barrier to a purchase, especially if the model is not routinely stocked by the dealer. These costs add to the purchase cost of the energy-efficient model. Volume purchasers such as builders would place a different importance on "transaction costs" than would an individual. Efficiency choice data segmented by class of consumer would be useful to determine the effect of purchaser threshold on market behavior.

Indirect or forced purchase decisions, such as the purchase of rental property equipment by landlords, or the need to replace broken-down equipment, may be weakly motivated by energy conservation needs. Ruderman, Levine, and McMahon (1984) estimate that as many as $50 \%$ of purchase decisions are made by consumers who are weakly motivated to invest in energy efficiency, and that approximately $37 \%$ may be insensitive to energy savings. Those who may be responsive to investments in energy-saving equipment make up less than $15 \%$ of the remaining consumers.

In 1982, a more in-depth study of home owner buying patterns for central heating systems, refrigerators, water heaters, and room air conditioners was conducted (Ruderman, Levine, and McMahon 1984). This study concluded that, compared with renters, home owners purchase more energy-efficient products. With the exception of room air conditioners, all products possessed by home owners had between $50 \%$ and $100 \%$ more energy-efficiency features than did those found in rental units. 
According to this study (Ruderman, Levine, and McMahon 1984), manufacturers make decisions to change products primarily based on cost. Although there is competition among manufacturers for existing models, there is little competition to introduce innovative design changes. Design changes normally result from attempts to reduce production costs rather than from attempts to improve product reliability resulting from the demand for more efficient products. In fact, efficiency design changes in the market usually are brought about by an initial design change by one manufacturer that, once successful, results in efficiency changes by other manufacturers if their market share is threatened.

Once decided, manufacturers may take up to two years to implement design changes. Although simple changes such as replacing an existing component with a more efficient one may take as little as six months, these changes may be only a small part of a much larger effort to upgrade an entire product line. Unless the manufacturer can predict changes in energy prices and other market conditions, the design change may not be an optimal one. Therefore, it would be helpful for OBCS to provide manufacturers with information concerning future energy prices and market conditions.

At the time of this report, the most highly efficient models of many products were not manufactured in large volume and energy-efficient models were difficult to obtain without purchasing a unit with numerous extra features. These extra features which may not be desired by the consumer, may add significantly to the purchase price of the "gold plated" unit. The issue of "gold plating" may not be as prevalent now that more energy-efficient products have appeared on the market, however this issue should be studied further to see the types of product options are currently available to consumers.

\subsubsection{Summary and Implications}

Implicit discount rates estimated for individuals are useful in explaining the factors that influence consumers' decisions regarding energy-related investments. As shown in this section, discount rates for energy-related durables have been estimated to be anywhere from the market rate of interest to above $300 \%$. 
It is important to understand that consumers normaliy expect high returns and short payback periods on energy-related investments. Research has found that the amount and timeframe of these returns depend on demographic and psychographic characteristics of consumers and on the external factors discussed in this section.

OBCS technologies must offer these high returns and short payback periods to be successful. Manufacturers will no doubt be interested in consumers' expected payback periods for OBCS technologies and other information from OBCS regarding consumer choices and investment criteria when determining whether or not to manufacture an OBCS technology.

\subsection{CONSUMER ATTITUDES AND ENERGY-RELATEO INYESTMENTS}

Several studies have been conducted which attempt to link consumers' attitudes, knowledge, and beliefs to their energy-related behavior. The majority of these studies have been surveys which have produced little solid knowledge (Black, Stern, and Elworth 1985). However, this may be caused by the broad attitudinal questions asked in the surveys. It is difficult to correlate general attitudes with specific actions and intentions. Instead, specific attitudes concerning the individual's role within the energy situation should be examined (01sen 1981). Attitudes concerning specific energy issues such as comfort, price, and actual adoption have been much better predictors of conservation behavior and energy consumption (Macey and Brown 1983).

\subsubsection{Fishbein's Attitudinal Model}

According to 01sen (1981), general attitudes about energy and conservation are not directly related to energy investments. However, specific attitudes are related. A correlation between energy purchases such as heat pump furnaces and an individual's beliefs concerning the persona? responsibility and personal consequences of an energy shortage has been demonstrated.

0isen uses Fishbein and Ajzen's (1975) attitudinal model to illustrate these relationships. A diagram of this model follows: 


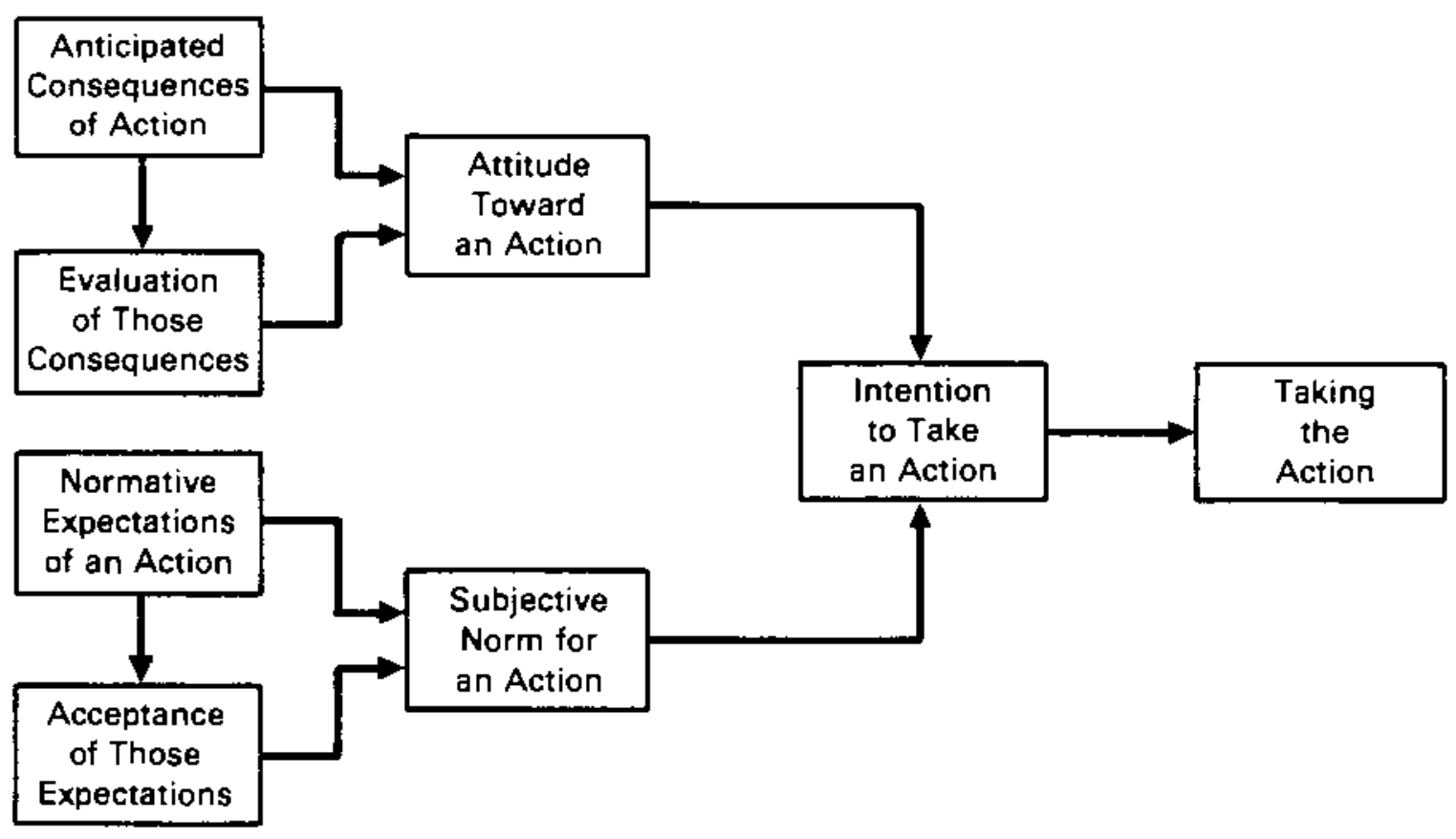

(Olsen, 1981, p. 119)

FIGURE 2.6. Fishbein's Model of Attitude Development

Two variables predict a consumer's behavior. First, the consumer's attitude toward the action is determined by the perceived consequences of the action and the evaluation of those consequences. Second, the consumer's "subjective norm" concerning the action predicts behavior. This subjective norm consists of other's opinions of what the consumer should do in the given situation and the consumer's willingness to accept these opinions. The other individuals must be people who are important to the consumer. Changes in behavior are for the most part triggered by changes in intentions. Intentions are changed by altering attitudes, subjective norms, and their relative importance (Macey and Brown 1983).

\subsubsection{The Role of Past Experience}

At the time of 01sen's article, no studies had been conducted to determine the validity of applying the Fishbein model to energy purchases. However, a recent study by Macey and Brown (1983) attempts to use this model for the study of repetitive household energy conservation behavior. Repetitive conservation measures are those which must be repeated regularly to be effective such as 
setting the thermostat back at night or changing the filter on a furnace. Any purchases necessary are usually inexpensive and are therefore equally available to high and low income households. To predict the success of repetitive measures, Macey and Brown used another predictor of intention/behavior which they have labeled "past experience." They have modified Fishbein's model as follows in Figure 2.7.

Past experience consists of an individual's prior actions and behaviors. Past experience often influences an individual's intentions and subsequent actions. It is also possible for past experience to directly affect behavior without the mediation of intention (Macey and Brown 1983). An example of this is participating in an action which has been frequently performed in the past. Humans often act out of habit without forming concrete intentions every time the action they act. This is especially true with actions that are performed frequently. Macey and Brown found that previous experience was the best predictor of repeated behaviors. The more an individual is familiar with the behavior through direct past experience, the greater the likelihood that he will engage in the behavior again. However, to compensate for the lack of past experience testimonials from credible sources provide consumers with appropriate information. The testimonials could be in the form of local success stories. Also, programs could be established to induce or require the adoption of

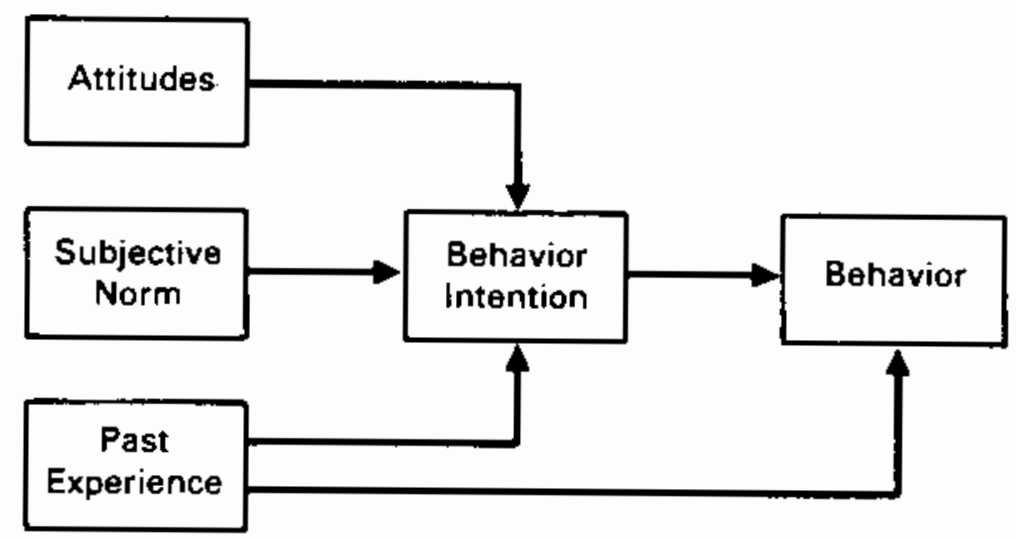

(Macey and Brown, 1983, p. 128)

FIGURE 2.7. Attitude Model which Includes Past Experience 
specific conservation actions (Macey and Brown 1983). An example of this type program is the awarding of tax credits to taxpayers who invest in energyrelated home improvements.

\subsubsection{Other Attitudinal Factors}

Although few studies have dealt specifically with consumer attitudes and purchasing behavior of energy technologies, several studies have dealt with consumer attitudes and behavior towards conservation. According to Shippee (1980), several surveys have shown that a powerful predictor of the behavioral intention to conserve is a set of variables which reflects the respondents ' perception of who is responsible for the energy shortage. If the respondent perceived that his own energy consumption was wasteful and if he accepted responsibility for energy mismanagement, he would be more likely to express an intention to conserve energy in the future.

Beck (1980) describes a survey of households in the Pittsburgh area which indicated four attitudinal variables related to energy conservation behavior. The first variable was termed "energy sophistication" and was defined as the amount of knowledge and understanding an individual has regarding the energy situation. More sophisticated respondents were much more likely to conserve energy. The results of the survey suggest that understanding the energy situation heightens a sense of individual responsibility and thus increases conservation activities. Also more likely to conserve were those respondents who derived satisfaction from energy conservation, those who more concerned about the energy situation, and those who had experienced hardships because of energy shortages. A weak correlation was also demonstrated between an antimaterialism attitude and conservation behavior.

Other studies examined by Shippee looked at predictor variables including the level of the respondents environmental concern, the imrnediate and future perceived effects of an energy shortage on the respondents, and demographic characteristics of those surveyed. However, since the behavioral intention to conserve was a self-reported measure, a question remains as to whether this would reflect actual energy consumption. For example, one study found that political liberalism correlated highly with self-reported levels of 
environmental concern, which in turn related positively to self-reported energy usage (Shippee 1980). However, actual energy consumption levels were not examined.

Two studies which examined actual energy use suggest that specific energyrelated attitudes (such as the comfort, convenience, and health implications of decreasing heating or cooling levels) often mediate between more general energy-related attitudes (for example, belief in the seriousness of the energy crisis) and energy consumption (Black, Stern, and Elworth 1983). Consumers were shown to be more concerned with personal comfort, health and convenience than with the energy shortage as a national crisis.

\subsubsection{Summary and Implications}

Further Study is necessary to determine the effect of attitudes and beliefs on a consumer's energy-related investment decisions. Many of the studies mentioned previously in this section were conducted during the late 1970 s and early 1980 s when the average United States consumer was more concerned about energy shortages and prices than he is today. Therefore, it is possible that a new set of consumer motivating attitudes is now developing. A survey of residential end users would be beneficial to determine specific attitudes which may be related to the use of innovative energy technologies.

One point emphasized in all of the previous studies was that general energy and conservation attitudes do not seem to be related to energy investments. Therefore, specific attitudes that are related to investment must be discovered. It may be possible to get a preliminary idea about these specific attitudes by conducting focus group interviews of residential energy consumers. These focus group discussions would give direction to future research projects concerning consumer attitudes and energy-related purchases.

\subsection{SELF-PERCEPTION THEORIES AND HEURISTICS}

Two fairly new areas in the study of consuner behavior are self-perception and heuristics. Although quite different, both areas deal with factors that can alter a consumer's rational decision-making. 


\subsubsection{Self-Perception Theory}

One way in which a consumer may form attitudes and beliefs is to examine his behavior and determine why he is performing a certain action. For example, if an individual routinely turns the thermostat to $65^{\circ}$ Fahrenheit on winter nights, he may decide that he performs this action because of his concern about the energy situation. This examination of personal behaviors and motives is called self-perception. Self-perception theory states that an individual forms ideas about himself based on his prior actions and behavior. It is possible to use self-perception theory to attempt to persuade consumers to invest in energy-related products. In general, a self-perception-based strategy of persuasion is characterized by cues given to a person to use in forming beliefs about himself (Allen 1982). The following are four examples of self-perception persuasion strategies.

Socially Conscious Consumption

Theories of self-perception may be used to educate consumers as to the causes of their actions and thus encourage them to continue and expand specific actions and behaviors. One such behavior is "socially conscious consumption." The socially conscious consumer can be defined as "a consumer who takes into account the public consequences of his or her private consumption or attempts to use his or her purchasing power to bring about sociat change" (Webster 1975).

One type of socially conscious consumer behavior has been termed "voluntary simplicity." This is defined as "the degree to which an individual selects a lifestyle intended to maximize his direct control over daily activities and to minimize his consumption and dependency" (Leonard-Barton 1981). This selection of a less complicated lifestyle must be voluntary for the behavior to be identified as voluntary simplicity. Therefore, if an individual reduces energy consumption only because of financial necessity, his behavior would not be categorized as voluntary simplicity.

A study by Leonard-Barton examined the relationship between a lifestyle of voluntary simplicity and energy-conserving behaviors and investments. She used a voluntary simplicity index which consists of an 18-item scale. Questions on 
the scale ask about behaviors such as bicycling to work, growing vegetables, and making furniture. Conclusions from a survey of California homeowners show that many voluntary simplicity behaviors are related to reduced energy consumption and an interest in at least one aiternative energy technology (Leonard-Barton 1981).

The concept of the socially conscious consumer is closely linked to that of perceived consumer effectiveness. Perceived consumer effectiveness is the extent to which one believes that his consumption is linked to and affects a societal problem (ATlen 1982). In the case of energy investments, the societal problem is the conservation of energy and natural resources. The consumer's perceptions will vary according to how he feels his actions will influence the energy situation. If he believes that his actions will make little difference, he may not feel the need to invest in energy-efficient products. Thus, one way to encourage energy investments is to use self-perception influencing techniques that promote socially conscious consumption and that give the consumer a sense of contributing to the solution of the energy problem.

Foot-in-the-door Technique

The "foot-in-the-door" technique of influencing consumers another method based on self-perception theory. By persuading the consumer to comply to a small request, this method helps him form an impression that he is the kind of person who performs certain types of actions. He is thus more likely to perform similar actions in order to remain consistent with this self-perception. These new actions may be larger and more involved than the initial action (Mowen 1987). For example, during an energy audit, a consumer may be given or persuaded to purchase an inexpensive device which when attached to a shower nozzle reduces the amount of water used. After using this device for a while, he forms the perception that he is actively interested in conservation. As such, it may be easier to convince him that additional and larger energy investments are necessary for his conservation effort (Allen 1982).

People are more committed to a cause that they have persuaded someone else to adopt. If a consumer talks to his neighbor about the benefits of weatherstripping, he will probably begin to think of himself as someone who is concerned about residential heat loss. People who are concerned about heat loss 
tend to be interested in wall and ceiling insulation, storm windows, drapes, and air leaks (Yates and Aronson 1983). They may also be more interested in energy-efficient purchases, such as heat pump furnaces, which reduce heat loss.

However, the effectiveness of the foot-in-the-door technique appears to be linked to personal contact with the consumer. This limits its practical value when attempting to reach mass markets (Allen 1982).

Attribution/Message Labeling

Another self-perception-based technique which may be more applicable in a commercial-media, impersonal-delivery context is "attribution or message labeling." When using attribution or message labeling, a person is described by a specific trait as a means of affecting his belief formation. The individual's past behavior is labeled and used as a cue for future behavior. For example, a television advertisement may congratulate the American public on their conservation efforts. Viewers of the advertisement may begin to evaluate their past behaviors and may come to the conclusion that indeed they have been energyefficient. As such, they may be more easily persuaded to purchase additional energy-efficient products.

Miller, Brickman, and Bolen (1975) demonstrated the superiority of attribution messages to the traditional persuasive approaches in altering students' littering behavior. In the attribution approach, the desired trait was delivered to the students from the teachers by means of messages such as "our class is clean." Traditional persuasive messages may carry an implicit negative label and this may effect self-perception. If a student is told that he must not litter, it may imply that he has littered in the past. Therefore, he may continue with his perceived prior behavior. However, in the 1975 study, when the student was given a positive label, he tended to expand upon the positive behavior. It is possible that this approach could be used to promote energy conservation and investments. Positive labels such as "you are using our resources wisely" may improve a person's self-perception and persuade him to act according to the label. People tend to behave confirming either positive or negative labels with their post-label behavior (Allen 1982). 
There are two important factors that must be examined when dealing with attribution labels. First, determine if the label is inherentiy desirable or undesirable. An individual is more likely to accept a desirable label than an undesirable label. Second, determine the credibility of the label. Credibility appears to be a function of the label's consistency with an individual's past behavior and self-perception. According to Allen (1982), energy conservation may represent a situation where persons are highly receptive to labeling influence. Prior behaviors, such as turning off lights and setting back thermostats, may be interpreted as conserving actions. It has been suggested that consumers are often unaware of the motives behind their actions until they are interpreted for them. Since energy conservation is a fairly new concept in the United States, this interpretation of actions may lead to self-perception development and more pronounced conservation activity.

Labeling is an effective influencing strategy, but there is some question whether it can be used by the mass media. A study by Allen (1982) demonstrated little support to the concept that individuals were sensitive to positive and negative labels presented in a mass appeal. While the findings were not strong, the pattern of effect was consistent.

\section{Cognitive Dissonance}

The final theory mentioned based on self-perception is Festinger's (1957) theory of "cognitive dissonance." Similar to other self-perception theories this one states that a person's behavior, attitudes, and definitions of himself are influenced by his actions and the situations surrounding him. If an individual simultaneously holds two beliefs that are inconsistent, he will experience discomfort. The individual will then strive to reduce the inconsistency by altering one or both beliefs, or by adding a third belief which may increase consistency of the two original beliefs (Yates and Aronson 1983). In order for dissonance to occur, the person must have strong feelings about his behavior or beliefs and about the resulting consequences. Thus, if a person is not coerced into an activity but is willing to invest time or money in it, he tends to become a believer in the activity. The resulting action must be consistent with this belief in order to reduce the dissonance caused by inconsistent actions or beliefs. 
It is possible to use this theory to promote energy conservation and investment. If an individual willingly joins a group involved in or concerned with the energy situation, he will become actively interested in conservation and will participate in conserving actions. As such, he will make a good target for marketing energy-efficient appliances. Organizations such as the Sierra Club are ideal vehicles for disseminating information concerning energyefficient investments. Members of these organizations will seriously consider the purchase of energy-saving technologies in order to remain consistent with their beliefs in conservation and in order to prevent the occurrence of cognitive dissonance.

Self-perception theories may be useful in encouraging consumers to save energy and invest in new energy-saving technologies. It may be possible to use the three self-perception theories discussed above (socially conscious consumption, foot-in-the-door, attribution labeling, and cognitive dissonance) to influence consumer attitudes and beliefs towards energy awareness and conservation.

\subsubsection{Heuristics}

When a consumer is faced with a complex purchasing decision, such as an energy-related investment, there is a vast amount of information that he must process. Because of the limitations of an individual's processing capacity, the consumer will often take "short cuts" or "heuristics" in making a decision. Rather than seek an optimal solution to his purchasing problems, the consumer will try to reach a decision which he considers satisfactory. This type of behavior is called "satisficing" and often results in the consumer using "choice heuristics" or decision ruTes-of-thumb. This may occur without the consumer being aware that he is making a less-than-perfect decision.

\section{Integrating Complex Information}

A consumer must evaluate a great many factors to determine the cost efficiency of an energy investment. Individuals sften have difficulty integrating complex quantitative information (Kahneman and Tversky 1979). Consumers may attempt to simplify this process by focusing on components of alternatives that are less quantitative in nature. For example, if buying additional insulation 
for the home, a consumer may buy a brand of insulation whose name he associates with quality rather calculate which brand would result in the greatest energy savings.

\section{Vividness and Personal Information}

It has been demonstrated that an individual tends to weigh information in proportion to its "vividness" or personal significance. Because statistica? data summaries and impersonal informational sources are not as vivid as personal communication or actual examples potential consumers do not give them as much attention. Vivid information may be less accurate and less representative than the statistical data, but it will still have more influence with the decision-maker (Yates and Aronson 1983). The following is a hypothetical example of this phenomenon. A consumer wishes to increase the energy efficiency of his home and searches for information on which investments will best accomplish this. After reading several articles on energy investments, he decides to buy additional attic insulation. He mentions this decision to a friend who has recently installed a heat pump furnace. As the friend extols the virtues of his new heat pump, the consumer begins to change his mind about the attic insulation. Despite the fact that all the literature he has read recommends additional insulation as an initial energy investment, he decides to purchase a heat pump. The information from his friend was more vivid and personal and, as such, had greater influence in the purchase decision even though the other informational sources may have been based on quantitative information from a large sample of homes.

Yates and Aronson (1983) cite a study showing that a vivid and personal sales presentation will more likely induce a consumer to buy than will a presentation using statistical data. In order to influence potential consumers of energy-related products, it is important that information concerning energy investments be presented in a vivid and personal manner, as well as completely and accurately. Information can be presented as local success stories and as testimonials concerning energy and money savings. 
The Framing of Information

It has been suggested that consumers react differently to a situation depending on how information about the situation is presented or "framed." For example, an experiment conducted by Kahneman and Tversky (1979) demonstrated that an individual responds more seriously to a loss than to a gain. In other words, the amount of joy felt at winning a sum of money does not equal the consternation caused by losing the same amount. As a result, a consumers is more willing to risk to avoid or minimize a loss than to increase his fortune (Yates and Aronson 1983). Therefore, informational campaigns stressing the amount of money and energy that can be saved by investing in alternative energy sources and conservation devices are interpreted by the consumer as a "gain" or "win" situations. If the same campaign was framed in such a way to emphasize how residents are losing money by not making energy investments, it could be more effective. The consumer may not go out of his way to save money, but he is apparently willing to act to avoid losses. The Canadian government uses this strategy in one of its advertisements stressing adding insulation to residences. In the advertisement a woman states, "After insulating, I saved 178 gailons of oil. Better that the money be in my pocket than in the oil company's" (Stern and Aronson 1984). This advertisement stresses the importance of preventing the loss of personal funds rather than the saving of money.

Trend Extrapolation

A recent study by Mowen and Fabes (1986) defines a consumer heuristic which termed "trend extrapolation." This trend hypothesis states that when forecasting the price of energy, decision makers may use a simplifying heuristic which based on an extrapolation of the trend in the data series occurring after the last turning point in the series. The result is a systematic overweighting of the most recent information received. Since current energy prices have stabilized and in some cases even dropped, consumers base energy investment decisions on that portion of the price trend. The experiment conducted by Mowen and Fabes found that consumers look at the most recent trends in energy price data when determining whether to buy a more efficient or less efficient furnace. Those presented with a recent upward trend in prices were more likely to choose the more efficient and more expensive model of furnace, while those 
presented with a recent downward trend in prices were more likely to choose the less efficient and less expensive model.

\subsubsection{Summary and Implications}

Both self-perception theories and heuristics provide valuable insight into the consumers' decision-making processes. They demonstrate that the consumer is not always a rational thinker who makes optimal purchasing decisions. He often resorts to satisficing behaviors which result in less-than-perfect energy investments. Determining how the consumer makes a satisfactory choice will enable OBCS to better understand the residential energy user, and in turn, be better able to meet his needs. The study of self-perception and heuristics are both relatively new to the field of consumer behavior. Therefore, learning how these processes are involved with the decision to purchase an energy-related innovation is potentially valuable. Only a few of the possible self-perception theories and consumer choice heuristics have been outlined in this section. Other consumer decision-making shortcuts do exist and merely need to be discovered and put into an energy investment context.

\subsection{BARRIERS TO ENERGY EFFICIENCY AND INVESTMENT}

The above models and theories deal with the residential consumer's decision-making processes while investing in energy technologies. However, the individual resident does not always have the freedom to choose energy-efficient

products. Many factors prevent the residential consumer from having total control over energy-related purchases. These factors include the residential intermediate markets, the manufacturers of energy-related products, the financial situation of the potential consumer, and various other factors beyond the consumer's direct control.

\subsubsection{The Role of Intermediaries}

The consumer's choice is limited by various intermediaries. Intermediaries can be defined as "individuals or organizations that effectively make choices for energy users but whose interests may not coincide with those of the 
people or organizations that pay for energy" (Stern and Aronson 1984). Architects, builders, contractors, and building owners are all examples of intermediaries.

Some intermediaries actually make purchases for the residential consumer. Builders and building owners select heating and cooling equipment and built-in appliances for some new homes and rental units. Other intermediaries limit the consumer's choice indirectly. For example, owners of rental buildings make it difficult for occupants who pay for heat to lower their heating bills because those occupants are not likely to make major improvements to property they do not own. (The role of intermediaries will be discussed in greater detail in Chapter 4.)

\subsubsection{Manufacturers of Energy Technologies}

Energy users are also limited by the assortment of energy-related products from which they can choose. Lack of consumer interest can guarantee the failure of a product; but even if interest exists, there is no guarantee that a new product will be manufactured. Manufacturers do not necessarily profit from marketing energy-efficient products. Energy-saving products are usually more costly to produce because of the extra materials needed to provide insulation and to make more efficient motors. Although some consumers would purchase these products despite the higher initial cost, the majority of consumers may prefer a less expensive, less efficient appliance. The manufacturer would have to invest in an expensive advertising campaign in order to educate the public as to the advantages of the more efficient model. Many manufacturers would rather not have to incur this additional expense. (The decision-making processes of manufacturers will be more thoroughly discussed in Chapter 3.)

\subsubsection{Limited Capital of Consumers}

Another barrier of individual consumer's choice of energy-related products is the limited access to capital. Often consumers do not have the necessary capital to purchase an energy-saving product, even though it could save them money in the long run. This is a barrier particularly for low-income households who could most benefit from an investment in energy-efficient products. Because low-income consumers tend to reside in old and energy-inefficient 
housing, the proportion of household income they spend for energy is relatively high. A 1982 study showed that the poorest households spend about 25\% of their income on energy consumption for home use, excluding transportation, while the richest households spend only about $2 \%$ (Stern and Aronson 1984).

The ability to make capital investments, either from saved or borrowed funds, is not only limited by a consumer's income and assets but also by policies of the government and lending institutions. Some utilities sponsor lowinterest or interest-free loan programs for energy-related home improvements such as weatherization. However, these programs have had limited success and have not reached all segments of the population, especially the low-income energy consumer. Even those programs directed at the lower income energy consumer have had less than satisfactory responses. This may happen partially because different groups of energy users respond differently to increasing energy prices. The more affluent energy user will make the needed investments in more efficient products with little sacrifice to comfort. The less affluent are often not able to invest in new technologies and thus of ten respond to raising prices with curtailments. Examples of curtailments include the lowering of the thermostat in winter and the raising of the thermostat in the summer.

\subsubsection{The Invisibility of Energy}

Because of the way energy-using technologies operate, energy users often find it difficult to take effective action when rising prices provide a strong economic motive to save energy. According to Stern and Aronson (1984), progress over the last century has made energy sources less costly and energy flows invisible to energy consumers. When homes were heated primarily by wood stoves, the person who owned the home was usually the one who had to chop, stack, and load the wood. Thus, the consumer of energy was very aware of the amount of fuel necessary. However, in most cases fuel transfer is now effortless and invisible. The individual consumer of energy cannot see the amount of fuel being used. The only visible or tangible measurement of energy use for most households is the utility bill.

However, energy bills are received infrequently and often have other figures beside energy usage included in them. One classic example by Kempton and 
Montgomery (1982) asks people to imagine a parallel situation for grocery bills in "a store without prices on individual items, which presented only one total bill at the register. In such a store, the shopper would have to estimate item price by weight or packaging, or by experimenting with different purchasing patterns." The energy bill combines charges for appliances, lighting, water heating, and temperature control. It is virtually impossible to determine how much of the bill results from each use or how much the bill can be decreased by changing specific consumption practices. It has been demonstrated that many energy users are ill-informed under this billing system. Many people cannot accurately rank the energy consumption of various household appliances (Becker, Seligman and Darley 1979).

Some of the inaccuracies occur because of the high visibility of certain appliances. When energy use is observable, people think that more energy is being used. For example, many people overestimate the energy consumed by household lighting, but underestimate the larger amount of energy used by water heaters. Lights are highly visible and consumer awareness is reinforced when lights are turned on and off. On the other hand, the heavy energy consumption of the water heater takes place out of sight and without human intervention. Therefore, the tendency is to underestimate energy use.

Energy invisibility also makes it difficult for an energy user to conserve energy by trial and error. It is difficult to observe the results and to obtain feedback from attempts to conserve energy. The effects of purchasing an energy-related product to aid conservation will not be immediately apparent. The consumer must wait to receive an energy bill, and even then unforeseen forces, such as changes in weather, may be reflected in the bill rather than the installation of the product. For example, a homeowner may purchase a heat pump furnace just before a severe cold spell. The next energy bill may be higher than the previous bill because of the weather, not the heat pump installation. Even if a homeowner is careful enough to make year-to-year comparisons, chanjes in fuel prices and weather will confuse the issue. Under these circumstances, individuals who make energy investments are disappointed with 
the results of their attempts to save energy. This disappointment frequently leads to discouragement and a feeling of futility that make future actions less likely (Stern and Aronson 1985).

According to Stern and Aronson, this trend in energy invisibility will not be easily reversed. Freedom from concern about energy has produced structural changes in energy-consuming equipment. Central cooling and heating systems allow people to move freely from one room to another without thinking about energy. However, when homeowners wish to conserve energy, they may not have the option to close off unused rooms while retaining comfort in a smaller space. Architects have begun to design apartment buildings with windows that cannot be opened. Thus, residents in these buildings are not able to save energy by using natural ventilation. Because of such changes in the naticnal stock of energy-using equipment, no amount of enerqy awareness can easily reverse the years of energy invisibility.

\subsubsection{Additional Barriers to Energy Efficiency}

Two separate studies by Blumstein et al. (1980) and Crossley (1983) have identified several categories of barriers to energy efficiency and investment. Some of these categories have been mentioned previously. However, several additional barriers were also identified. The categories of barriers include:

- misplaced incentives - The economic benefits of energy conservation do not always accrue to the individual who is trying to conserve. For example, if an apartment tenant pays for the utilities, the owner of the building has little incentive to invest in energy-efficient technologies. And if the landlord pays the bill, the tenant has little incentive to use energy efficiently (Blumstein et al. 1980).

- lack of information or misinformation - If a consumer is unaware of the cost effectiveness of a conservation measure, he is unlikely to adopt it. Also, if the consumer is given misinformation about a product, he might be disillusioned which in turn could prevent future purchases. For example, if a heat pump furnace distributor told a homeowner that a heat pump furnace would effectively heat his home 
and the furnace failed to the job adequately, it is less likely that the homeowner would purchase other technologies designed to save energy and money (Blumstein et al. 1980).

- regulation - If a cost-effective measure conflicts with existing codes or standards, its implementation will be difficult or impossible. Building codes and local regulations may prevent the architect or builder from including all of the desired energy-efficient technologies in a particular building (Blumstein et al. 1980).

- custom - If a cost-effective conservation measure requires an alteration in the habits or behavior of the consumer or seems contrary to accepted values, The adoption of this measure may be difficult. Consumers do not usually like to alter their behavior to accommodate a new product unless there is an obvious advantage to it (Blumstein, et al. 1980).

- barriers arising out of living situations - This category is divided into three distinct areas. The first is the personal living situation of the consumer which includes biological and physiological needs. Elderly consumers may need the temperature setting to be higher than younger consumers. The second area is the social living environment which includes such variables as stage in the family life cycle, the degree of personal control over energy use, and the lifestyles of the consumer and other occupants of the dwelling. The last area deals with the consumer's physical living situation and involves the physical layout, location, age, and condition of the dwelling. Both of these latter categories can affect the use of energy within a residence and create barriers to energy conservation (Crossley 1983).

- barriers arising out of personal predisposition - These are barriers to energy efficiency that arise from the attitudes, beliefs, and past experiences of the consumers. If a consumer is predisposed to act in a way which is not energy efficient, it will be difficult to change his behavior (Crossley 1983). 
- barriers arising out of social costs. Examples of social costs are inconvenience, impracticality, lack of safety, discomfort, and ugliness. An energy technology including any of the above characteristics will be less acceptable to consumers than one without them (Crossley 1983).

\subsubsection{Strategies for Overcoming Barriers}

The study by 8 lumstein et al. (1980) outlines a series of strategies which the government may undertake in order to help remove or lessen the impact of some of the more serious barriers to energy efficiency and investment. These strategies are divided into the following six categories:

- informing - This strategy helps overcome the barrier of inadequate and incorrect information. The government can provide new information by sponsoring research in the area of energy conservation. The government can also facilitate the flow of existing information by supporting libraries and indexing services. Information can be communicated directly to the consumer by providing educational programs and mass media promotional campaigns.

- leading - The government can lead in the attempt to encourage energyconserving behavior by leadership. For example, the President turns down the white House thermostat and begins wearing a sweater. The President is considered an opinion leader by millions of Americans and as such would be widely imitated. In addition, persuasive messages such as the government's "Don't Be Fuelish" advertising campaign may also be effective in reducing energy consumption.

- market-making - Government actions can create markets for energyconserving products or services. One of the most effective ways to accomplish this is through governmental purchasing policies. The government's buying power is so large that merely indicating a desire to purchase a product may create a market. The government can also create markets in the roles of entrepreneur and financier by developing and financing of energy conservation projects. 
- rule-making - The government can make rules and laws that apply to commercial transactions such as what is sold and who is permitted to buy or sell. For example, rules can require that all residential property be insulated before it is rented or soid. Rules can also be used to support other strategies. For example, rules can require that a landlord inform prospective tenants if their apartments are adequately insulated.

- pricing - Government policies can influence the incentive to consume or conserve by changing the net price of energy. This is possible since a significant part of the nation's electricity is marketed by governmental agencies. The government can also regulate prices by taxing energy usage, for example, the gasoline tax.

- rationing - In principle, the government can use rationing to conserve scarce resources by limiting consumption to a predetermined amount. However, rationing is usually established to allocate scarce commodities during difficult times such as wartime. Rationing is usually used as a last resort when other options have fajled to reduce consumption.

\subsubsection{Summary and Implications}

Several barriers to energy efficiency and investment are discussed in Section 2.6. It is critical that OBCS be aware of the potential barriers in the distribution of ideas and new technologies to the residential energy consumer. Better understanding of these barriers will enable OBCS to use the above strategies and other appropriate strategies to overcome or at least minimize the impact of more serious barriers which consumers face when considering investing in an energy-related product.

A national survey of residential energy users is recommended to enable OBCS to determine which barriers are most critical in determining the behaviors of energy consumers. Once these have been identified, it will be easier for OBCS to develop the strategies necessary to combat them. 


\subsection{CONCLUSIONS AND RECOMMENDATIONS}

\subsubsection{A Framework of Consumer Behavior}

The components of consumer behavior examined in this chapter can be combined into a comprehensive framework which will assist OBCS in examining the decision-making processes of potential purchasers of its innovative energyrelated products. Figure 2.8 shows the relationships of many of these components.

Characteristics of the innovations, demographics of consumers and the attitudes of consumers all play an important role in influencing the consumers' decision-making processes. Innovative product characteristics include relative advantage, trialability, complexity, compatibility, observability and various types of risk and costs. These concepts were discussed in more detail in Section 2.1.

Consumer demographics consist of variables such as age, income, education, occupation, life-cycle stage, and geographic location. Another demographic variable closely related to energy investments is home ownership. Tenants who do not own their residences are not likely to invest in an energy-efficient product because the purchase will only improve the landlord's property. If the tenant plans to reside in the rental property for a lengthy period of time, he may decide to make an investment to reduce energy consumption. Other demographic factors and their relationships with the purchase of energy-related products were discussed more fully in Section 2.1 .

Demographics such as age, income, education, and occupation are influential in formatting consumer attitudes concerning energy conservation. The more specific the attitude, the greater the effect the attitude seems to have on the purchasing intentions of the consumer. Attitudes towards a behavior are based on the perceived consequences of the action and the subjective norm concerning the action. These concepts were discussed in more detail in Section 2.4.

Choice heuristics and self-perceptions influence decision-making that is internal to the consumer. A consumer will use a variety of choice heuristics to simplify a complex decision. Heuristics are decision shortcuts which often result in less-than-optimal alternatives for the consumer. The consumer faced 
Characteristics of the Product

- Relative Advantage

- Trialability

- Complexity

- Compatibility

- Observability

- Risk

- Social Cost

- Financial Cost

- Return of Investment

- Product Efficiency

- Symbolism/Technology
Demographics of Consumers

- Age

- Income

- Education

- Life-Cycle Stage

- Home Ownership

- Geographic Location

- Occupation

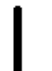

Heuristics and Self-Perceptions

- Degree of Social-Consciousness

- Shortcuts in Decision-Making

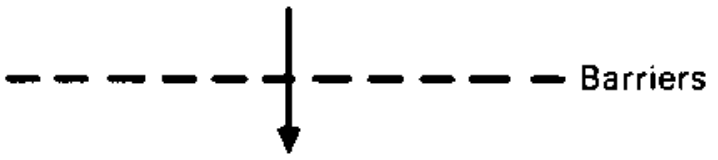

Decision-Making Process

- Problem Recognition

- Information Search

- Evaluation of Alternatives

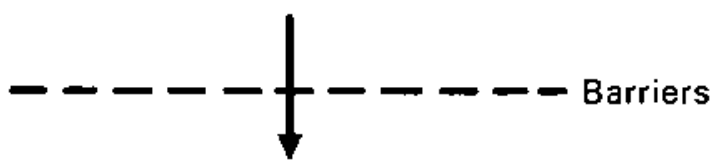

Adoption of Product

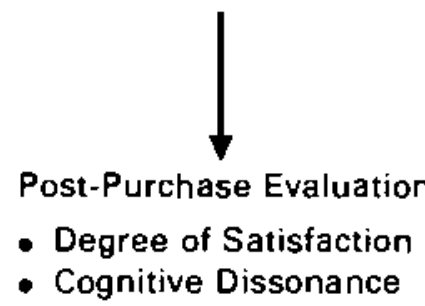

FIGURE 2.8. A Comprehensive Framework of Consumer Behavior 
with a difficult decision, such as the purchase of a heat pump furnace, may settle for a satisfactory solution to his purchasing dilemma rather than spend much time and money carrying out an exhaustive search for the best product. Self-perceptions are the consumer's interpretations of his own actions. Selfperceptions can be used as cues to develop a consumer's attitudes which in turn can influence his purchasing intertions. Studies involving consumer heuristics and self-perceptions are relatively new to consumer research. Therefore, additional research is needed. These topics were more closely examined in Section 2.5 .

The residential energy user may follow a classic decision-making process when choosing an energy-related technology. This process involves the decision-maxing stages of: problem recognition, information search, evaluation of alternatives, adoption of the product, and post-purchase evaluation. A consumer does not necessarily experience all stages of this process. Stages may be omitted in cases such as impulse or habitual purchasing. The decisionmaking process was more fully discussed in Section 2.3.

After a consumer purchases a product, OBCS should also pay attention to his post-purchase behavior. The degree of consumer satisfaction can have a significant impact on subsequent behavior. A dissatisfied consumer may return the product, complain to the manufacturer, or spread negative word-of-mouth information about the product's performance. Thus, it is important to be aware of consumer actions after the sale of a product. Barriers to energy-related investments exist at several stages of the adoption process. The product may have attributes that reduce the possibility of commercial success. For example, a very complex product may overwhelm consumers. The demographics and attitudes of consumers may also present barriers to purchasing. A consumer with little education may not understand the advantages of energy-efficient appliances, or the consumer may have formed the attitude that none of his conservation actions will save energy or money. Barriers may exist in terms of the choice heuristics utilized in making a purchase decision. Some decisionmaking shortcuts result in the consumer making less-than-optimal choices. If OBCS technology is eliminated from the consumers' evoked set, there is little possibility of it being purchased. A consumer's self-perceptions may also 
present a barrier to the adoption of OBCS technologies and ideas. Selfperceptions influence attitudes which in turn influence purchasing intentions. Finally, barriers are present in most stages of the decision-making process. A consumer may not realize that a problem exists or may be unable to find information about OBCS technologies when searching for product information.

It is important that $\mathrm{OBCS}$ take measures to attempt to overcome some of these barriers. They can do this by implementing the strategies suggested in Section 2.6 .

\subsubsection{Gaps in Current Knowledge}

Whereas much research has been done using traditional economic models of consumer decision-making toward energy investments, relatively little attention has been paid to the behavior of consumers of energy-related products. Because of this deficiency in the literature, there are several aspects of consumer behavior research which could be applied to energy-related purchases. One area which needs further investigation is the diffusion of energy-related innovations through society. How is information about new energy technologies disseminated to the end consumer? Understanding how consumers learn about conservation programs and new energy-related technologies and ideas would enable OBCS to use these same channels for providing consumers with information concerning technologies developed by OBCS. If the channels that consumers currently use do not seem to be effective, OBCS can experiment with alternative media. More research is needed in the area of economics of information, or the amount of information necessary for a consumer to make an informed choice without suffering from information overload.

Many studies have been conducted to investigate consumers' decision-making processes. However, more information is needed about specific decision criteria are used by different consumer segments when considering an energyrelated purchase. Before this can be done, it is necessary to discover a means to divide residential energy consumers into distinct segments. This division could be on the basis of demographic or psychographic (or both) characteristics. An example of need for end consumer market segmentation was included in a study by 01sen (1981) which revealed that a "money-saving" approach to energy conservation and investment did not reach all segments of the population. One 
segment particularly ambivalent in regard to this message was the affluent American who led an energy intensive lifestyle, but who did not perceive the economic rewards of an energy investment as substantial enough. Appeals other than economic would have to be directed to this affluent consumer market.

Little is known about the specific attitudes that affect a consumer's buying behavior toward new energy technologies. Because attitudes may be directly related to purchase intention, better understanding of how specific consumer attitudes are necessary to determine influencer of intentions to buy an energyefficient product. It would also be advisable for OBCS to better understand the causes of these attitudes which delve into the area of self-perception and attitude development. These have only been cursorily examined in the energy investment context.

Another area needing further study is consumer choice heuristics when making an energy-related purchase. While several possible varieties of choice heuristics have been suggested in Section 2.5, no concrete empirical evidence supports these theories.

It is true that the behavioral aspects of energy-related consumption are important in understanding the actions of the consumer. However, the economic issues of prices, payback periods, and discount rates must not be ignored. Understanding the economic criteria necessary for a consumer to consider an energy investment would give OBCS insight which could be used for pricing strategies.

It is imperative that OBCS integrate economic and psychological conceptualizations to develop a comprehensive framework of consumer energy-related buying behavior. Specific recommendations for future research that would attempt to fill in some of the current gaps in the literature can be found in Chapter 5 . 


\subsection{MANUFACTURERS}

Before an energy-related technology/process developed by OBCS can be available to residential consumers, it must first be adopted, further developed, and eventually marketed to residential consumers by manufacturers who are familiar with the marketplace. For this reason OBCS needs to attract industry support for new technologies. Industry support may come in some form of joint industry/government venture, or manufacturer(s) may completely take over the research efforts. However, industry support for a new technology does not occur automatically and often does not occur at all. Why do innovative and new technologies that find ardent support in the laboratory not find the same acceptance and enthusiasm when introduced to industry? This question deserves exploration.

A technology's path from laboratory to industry, and later from industry to the end consumer, is a complicated one. There are certain expectations of the technology that must be met at each step to gain acceptance, and these expectations are rarely the same. Successful market acceptance and penetration of new products and processes depends on a manufacturer's clear understanding of consumer needs and desires. This same understanding must also be clear to government organizations attempting to find industry (the government's intermediate consumer) support of new technologies.

Reasons for a company's innovation history and potential for innovation can be considered functions of its internal and external corporate environment. Factors affecting these environments are numerous. The external corporate environment includes social, political, and economic factors as well as the state of technological development. Although the external factors affecting the corporate environment are straightforward, and it is easy to obtain information about them, the internal factors affecting a firm are quite complex. This chapter will focus on internal factors affecting innovation and technology adoption. The following sections will discuss patterns of corporate innovation, technology diffusion, decision-making processes in new product/technology 
adoption and selection criteria, corporate innovation strategies, motivators to the adoption of new technologies, and barriers that may impede technology adoption.

\subsection{CORPORATE INNOVATION PATTERNS}

There is great potential for corporate involvement in government research activities. According to the National Science Foundation, company-funded R\&D expenditures were expected to reach $\$ 58$ billion in 1986 . This is a $9 \%$ increase over 1985 and is based on information obtained from 74 corporate R\&D officials questioned in the spring of 1985 (Research Management 1986). This number compares with a 12\% growth in current dollars in 1985. Between 1974 and 1985, the average (constant) annual percentage increase in R\&D dollars was $5.3 \%$; corporate officials predict a slightly higher increase of $5.9 \%$ for the period 1984 to 1986 (Research Management 1986).

A survey of companies who are members of the Industrial Research Institute revealed that $75 \%$ of the member companies responding to the survey expect to spend the same or slightly more on R\&D in 1986 than in previous years. In 1985, 20\% of the respondents stated that they expected a significant increase in expenditures, while in 1986 only 5\% of the companies expected such an increase. The emphasis on R\&D to produce new business opportunities is expected to continue, despite a stabilization in the areas of basic research and support of existing business. These corporate R\&D programs offer an excellent opportunity for OBCS to develop shared development arrangements for new technologies. Such arrangements will help promote market penetration of OBCS technologies.

R\&O departments funded by a firm have traditionally been considered the primary means for developing new ideas and technologies. Diversification into radically new market areas, however, was normally not the responsibility of the R\&D department (Klavans, Shanley and Evan 1985). This sort of diversification was most often undertaken by a separate new venture unit set up for that specific purpose. One 1985 study found that the number of new ventures was inversely related to $R \& 0$ expenditures, suggesting that R\&D departments are most often devoted to the marginal expansion of existing products versus the 
development of new and innovative products (Klavans, Shanley and Evan 1985). These findings question the use of $R \& D$ expenditures as a measure of corporate innovativeness and are not consistent with Kamien and Schwartz's (1982) contentions that $R \& D$ expenditures are positively related to the invention/innovation process.

Companies sometimes organize for new product development and innovation by establishing joint ventures, mergers, and/or licensing of technology (Mendel\} and Ennis 1985). The U.S. space program in the 1970 s is a prime example of a government/industry collaboration that produced substantial results for both participants. The collaboration succeeded in establishing a U.S. presence in space as well in developing new products and technologies for industry. However, this extensive cooperation between government and industry has not extended to other areas beyond the space program. Understanding the factors that contribute to successful government/industry partnerships, including reasons for innovation by companies, is a start in promoting this type of arrangement.

\section{1 .1 Why Companies Innovate}

Market factors appear to be the primary influences on innovation according to a 1982 study of European companies. This study found that $60 \%$ to $80 \%$ of innovations have occurred in response to market needs or demand. The remainder of these innovations originated in response to new technological developments and opportunities (Research Management 1984). According to Research Management (1984), "there is a striking similarity between the findings of studies in the U.S. and the United Kingdom." In a study conducted by the European Industrial Research Management Association in 1982, the four most important reasons (in descending order) for corporate innovation were to:

- preserve and promote existing business, mainty to stay ahead of competition and increase market share

- diversify into new yet not radically different markets

- respond to government, environmental, and safety pressures, especially in the chemical, pharmaceutical, materials, and energy industries 
- efficient use of diminished resources, especially with regards to increasing energy costs by major users and supptiers

Profit, of course, is usually the underlying goal of most business actions such as the investment in innovation. The stimuli for innovation found in the above study provide important guidance to understanding motivators to innovation by companies. However, these findings were based on a European study and are dated. A new survey of manufacturers could be conducted by OBCS to better understand the motivating factors behind corporate energy-related technology investments and innovation.

Further research conducted by Abernathy and Utterback in 1982 shows that an organization's capacity for and methods of innovation change during the stages of evolution from a small technology-based company to a high-volume producer of goods. Abernathy and Utterback (1982) developed a model that relates patterns of innovation within an organization to the organization's competitive strategy, production capabilities, and organizational capabilities. This study points out the important distinction between product innovation by a smal1, technology based organization and developments of new process equipment developed by a high-volume producer. For large, high-volume producers, cost reductions seem to be the major incentive for innovations. Major innovations in cost reductions are of ten followed by countless minor innovations that typically result in increasingly specialized systems. These systems rely heavily on economies of scale and in production and development of mass markets. The reliance on high volume production to cover fixed costs often results in increasingly specialized processes that can leave the company inflexible and vulnerable to shifts in demand and technological obsolescence.

Many new product innovations do not appear to be consistent with this environment because they would require major alterations in production facilities or reorientation of corporate goals. Thus, these innovations normally do not originate within the company. If those originating outside the business, for example by OBCS, attempt to alter the "specific" production process of the firm, they will often be rejected. "Major product changes are often introduced from outside the firm and are viewed as disruptive; the sources are typically the start-up of a new, small firm, invasion of markets by leading firms in 
other industries, or government sponsorship of change either as an initial purchaser or through direct regulation" (Abernathy and Utterback 1982). The implication is that successful market penetration of new technologies might be initiated by businesses outside the most obvious industry, smalier technologyintensive firms, or by some sort of government regulation.

\section{1 .2 Idea Sources}

Sources of ideas for innovations arise both within and outside the firm. The majority of these ideas originate from within the organization, usually from the R\&D department or from a new venture unit (Research Management 1984). External sources of ideas include the scientific environment, competition, customers and suppliers, and government. A 1982 European study of innovation patterns found that government was a fairly unimportant source of ideas (Research Management 1984). Information concerning industry's perceptions of the government as a source of ideas in the U.S. and, in particular, perceptions of OBCS would be useful. Information sources and media consulted by businesses for new ideas and technology developments would also be useful to OBCS.

\subsubsection{Summary and Implications}

Great potential exists for private sector involvement in government research activities in the U.S. The success of the U.S. space program in the 1970 s proves that this type of arrangement can be extremely successful for both government and industry.

Companies strive to innovate and develop new products for many reasons. The majority of new product innovations occur in response to market needs or demand. Other motivators to innovation include the need for diversification into new business areas, government, environmental and safety factors, scarcity of resources, and concern over the energy situation.

Companies often establish new venture units for identification and development of new and innovative products that may or may not be associated with R\&D departments. However, R\&D departments are often a good place to start when investigating the innovation activities of a company. Ideas for new products usually originate within the firm, mainly from the R\&D department or the new venture unit. External sources of new ideas include the scientific 
environment, competition, customers and suppliers, and government. European studies have found that companies consider government sources as relatively unimportant .

Information that may be useful to OBCS to promote market penetration of new technologies includes:

- Manufacturers perceptions of government as a supplier of new technology and potential partner in research activities

- Manufacturers' perceptions of OBCS as a supplier of new technology and potential partner in research activities

- Manufacturers' idea sources for new technology information

This information could be obtained by a survey of manufacturers of energyrelated technologies and could be used to devise a information transfer plan based on enhancing OBCS' image and credibility as a supplier of new technological information and viability as a potential partner for joint technology development. Information regarding manufacturers' idea sources will provide OBCS with potential "influence channels" that may be vehicles to influence OBCS technology adoption.

\subsection{DIFFUSION OF OBCS TECHNOLOGIES TO MANUFACTURERS}

New products are diffused through the universe of potential adopters in a fairly predictable pattern. Diffusion has been described as beginning slowly with the trial and possible adoption of the product by "innovators" and "early adopters" in society (see Chapter 2.1). The product is then diffused at a faster rate as it is adopted by larger groups of consumers, and finally slows as it moves through the last category of adopters, referred to as laggards.

While the diffusion of consumer products to end residential consumers has been addressed in depth by a number of studies, few have focused on the diffusion of new technology to manufacturers. The diffusion processes are fairly similar. However, different factors are considered when addressing manufacturers versus end consumers. Understanding the process of product diffusion to manufacturers will be beneficial to OBCS in promoting the penetration of new technologies to these manufacturers. This section will discuss factors that 
may promote successful diffusion of new technologies and will focus on the factors that may facilitate the adoption and further development of 0BCS technologies by manufacturer(s).

\subsubsection{Aspects of New Technologies}

Potential adopting organizations are often unfamiliar with new technological innovations that are complex and technical in nature. As a result, potential adopters may lack the knowledge structure needed to make judgments about the product (Robertson and Gatignon 1986). This lack of knowledge is likely more prevalent in regards to a new technology. Uncertainties about the technology itself and the risks associated with the resource allocations required for further technology development all play a major role in the organization's adoption decision process.

Companies unfamiliar with a new technological innovation also require a high level of learning in order to make a decision. For this reason, marketers have difficulty in forecasting diffusion rates of new technologies since potential adopters often lack the knowledge required to make a statement about their purchase or adoption intention. Awareness and knowledge about the technology must be created before potential adopters can provide a statement about purchase intention (Wilton and Pessemier 1981).

\subsubsection{Stage of Research and Development}

As product and process concepts for new technologies studied at 0BCS progress through the various stages of $R 8 D$, they reach a point where industry may view them as viable. This "viability" point usually occurs when the technology has reached the Tater stages of $R \& D$. At the later $R \& D$ stages, there is greater certainty about the resulting end product and the substantial costs of basic research have al ready been incurred by OBCS. For this reason, manufacturers are usually most interested in technologies that have progressed to the engineering development or demonstration stages of research. Companies or industries that rely on new technology are more likely to adopt new technologies in the earlier stages of development (Section 3.3). 


\subsubsection{Industry Factors Affecting Diffusion}

Developers of new technologies such as OBCS and potential adopter organizations such as manufacturers affect the diffusion potential and speed of diffusion of a new technology (Robertson and Gatignon 1986). Developers or suppliers of new technology affect diffusion based on their decisions concerning characteristics of the innovation, pricing, and aliocation of resources to the technology. Adopter organizations, in this case manufacturers of energyrelated products, and the industry in which they operate affect the reception of the innovation. In Figure 3.1, the supply side and the adopter industry competitive environments merge into the diffusion process among manufacturers.

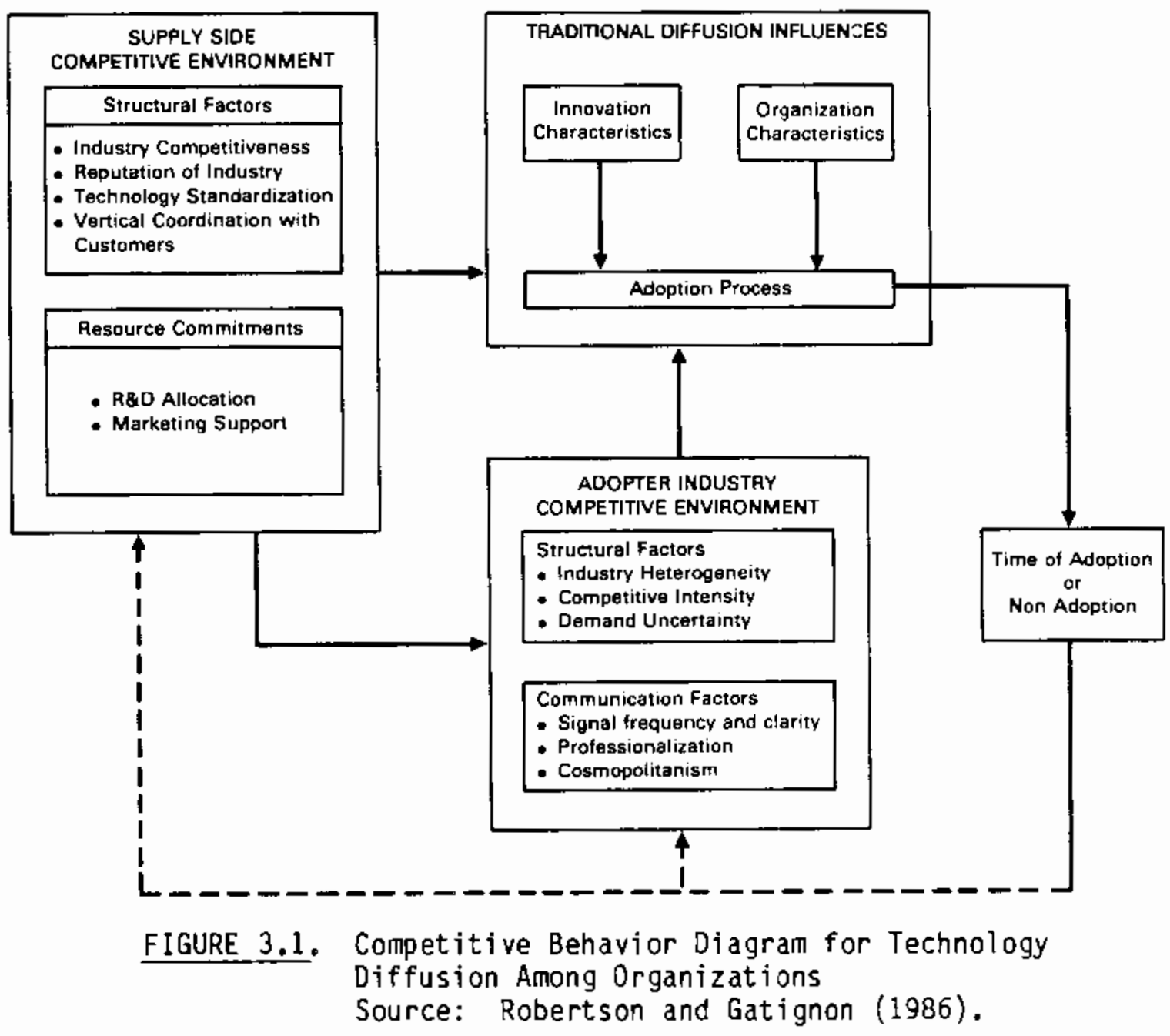


Robertson and Gatignon (1986) studied the diffusion of high technology innovation among business organizations and extended the traditional behavioral studies of innovation diffusion discussed in Section 2.1 by incorporating competitive factors and explanatory variables. Their theory of technology diffusion at the industry level is the basis for the remainder of this section concerning diffusion.

\section{Supply Side Factors Affecting Diffusion}

Structural characteristics and resource commitments of the organization(s) offering the innovation to manufacturers influence the market potential realized and the speed of diffusion. OBCS supported technologies, for example, compete with technologies supported by other government offices, corporate R\&D departments, and private entrepreneurs to gain industry support in the form of funding and/or development agreements for new technologies and ideas. The supplier industry in this section refers to the group of organizations that offer new innovations.

Robertson and Gatignon's (1986) study states that structural characteristics of the supplier industry affect the speed of diffusion and actual market potential realized by the technology. The specific structural characteristics of the supplier group are:

- level of supplier competition

- supplier reputation

- level of vertical coordination

Strong competition among organizations offering new technologies (supplier groups) leads to more rapid diffusion and a higher diffusion level. The competitiveness of the supplier industry for new technology is dependent upon the number of competitors and their concentration in a particular area of business or research (Porter 1980). A number of technology suppliers offering similar new technologies to the same adopter industry "compete" for a limited amount of $R \& D$ resources. The more technology suppliers there are, the more intense this competition becomes. Competition affects the overall resources allocated to technology transfer and other efforts that promote new technologies to manufacturers. Competition also affects the "pricing philosophies" of suppliers. In the case of OBCS, the pricing philosophy may refer to the flexibility in a 
partnership as well as to the amount of ownership or benefits the manufacturer will receive once the technology is introduced. These arrangements are, of course, restrained by certain federal restrictions. Under highly competitive environmental situations where a large number of new technology developers compete vigorousiy to promote the adoption of similar innovations, greater resources and more aggressive pricing strategies are likely to be allocated to the technologies, thus encouraging more rapid diffusion (Robertson and Gatignon 1986).

The more favorable the reputation of the supplier group, the more rapid the initial diffusion. Although it is an illusive concept, the reputation of the supplier group is quite important, especially if the supplier group is in competition with another supplier group. The reputation of the supplier group develops from past relationships and confidence among potential adopters. In instances where there are uncertainties about the viability of the new technology, a supplier with a positive reputation will encounter a better penetration rate. OBCS's reputation among potential adopters (manufacturers) will have an impact on the success of new technology market penetration efforts. Therefore, OBCS may want to determine how it is perceived by manufacturers and, depending on these perceptions, attempt to enhance its image.

Strong vertical coordination between suppliers and customers will increase the diffusion rate. In industries where a large amount of vertical dependence exists, there may be an incentive to coordinate and develop interlocking relationships (PaTmer 1983). Vertical dependence refers to an industry's reliance on or use of external supplier or distribution networks that are vital to success in that industry. If manufacturers relied more heavily on R\&D conducted by government organizations such as OBCS versus their own R\&D departments, the diffusion rate of OBCS technologies would likely increase. Diffusion would increase in cases of strong vertical coordination because of the formation of more fluent information networks. In the medical equipment and pharmaceuticals, for example, the networkirg between suppliers and leading research or teaching hospitals has facilitated the acceptance of medical innovations. OBCS should concentrate on understanding these information networks within 
industries where there is potential for technology adoption. Later, OBCS may be able to become involved in and help further develop the networks.

Robertson and Gatignon's 1986 study also states that resource allocations made by a supplier industry will have a major affect on the speed of diffusion. Ongoing R\&D and marketing programs are believed to speed and increase the diffusion potential of new products/technology (Robertson and Gatignon 1986). Robertson and Gatignon's technology resource commitments are as follows:

- allocation of R\&D resources

- allocation of marketing resources

A greater allocation of R\&D resources within an industry will lead to a more rapid diffusion process and a higher diffusion level. There is evidence of a positive relationship between $R \& D$ resources and the invention/innovation process (Kamien and Schwartz 1982). A greater allocation of R\&D resources to the technology by OBCS may lead to a more rapid diffusion of new technologies. Potential adopting companies are more likely to adopt and further develop a new technology if someone else (OBCS) has already committed substantial resources to its development. These resources lead to success in basic technology development and to reduced risks faced by potential adopters. Manufacturers may a)so be more willing to adopt a technology if they were somehow involved (i.e., consultant or partner) in its development.

A greater allocation of marketing resources will lead to a more rapid diffusion process and to a higher diffusion level. The amount of resources allocated to marketing actions such as advertising, sales promotions, personal selling, and distribution support will have a major impact on the speed of the diffusion process and on the market penetration level. Allocation of funds to marketing research provides a vehicle to introduce market input. This input from manufacturers of energy-related technologies would help guide OBCS R\&D and "position" the product so that it appeals to a particular market segment. OBCS could better steer its own R\&D efforts toward technologies that have greater potential for market acceptance by integrating some of the comments and desires expressed by different consumer groups. The resulting technology could then be positioned to this market according to expressed consumer desires. Increased 
marketing expenditures in communication actions such as technology transfer could enhance the speed and pattern of diffusion of OBCS technologies.

The study of innovators and early adopters (discussed in Section 2.0) is often used as a basis to describe technology diffusion. The acceptance of an energy-related technology by these two groups of manufacturers is believed to be crucial to the successful market penetration and diffusion of new technology, yet no studies have been conducted to determine the characteristics of these "innovative" manufacturers. A survey of all manufacturers of energyrelated products should be conducted to determine the types of firms that have the greatest adoption potential. Limiting the study to only those firms with past adoption history would limit the findings and possibly result in lost opportunities for OBCS. Smaller firms, for example, may never have been approached about funding new technology development but may be receptive to this idea.

\section{Adopter Industry Factors Affecting Diffusion}

A potential adopter's industrial environment will affect the receptivity to a new technology. Competitive pressure often influences a company to consider an innovation, while the lack of this pressure may continue the general apathy toward innovation in the industry. Robertson and Gatignon (1986) propose that the willingness to innovate is a function of two broad sets of variables - structural and communication factors.

The structural factors of the adopter industry believed to be related to the willingness to innovate (Robertson and Gatignon 1986) are as follows:

- level of industry specialization

- level of competitive intensity

- demand uncertainty

An intermediate level of industry specialization will increase the diffusion rate of a new technology. Diffusion is believed to be facilitated by strong communication networks and information sources. If the industry is too specialized in one particular market or product, diffusion of information regarding new technological developments is reduced because there are few 
sources of new information. However, if the industry is highly unspecialized, communication breaks down because of lack of a common focus. Thus, the optimal level is an intermediate one.

An intermediate level of competitive intensity will increase the diffusion rate of a new technology. Competition at a reasonable level will encourage the acceptance of innovation. However, at some point the financial resources of the industry will be depleted and the potential for innovation nearly gone. Monopolistic conditions may also deter innovativeness since there is often little incentive for change. As competition increases, building or maintaining barriers to entry may be a motivating factor to the adoption to innovation, especially of the process type, by many industry participants (Abernathy and Utterback 1978). For example, in a highly competitive industry a manufacturer may have a strong incentive to adopt a process technology to eventually reduce variable costs and to undercut a competitor's prices.

Uncertainty about demand will generally increase the acceptance of innovation. In industries where demand is predictable, companies can estimate with some certainty the level of marketing activity required to discourage new entrants into the market. However, when uncertainty about demand increases, industry participants may uniformly increase marketing activities and, thus, their likelihood for adopting new technologies. Increased marketing activity can discourage new market entrants because of the visibility of competition and dominance in the market. Companies are most receptive to new innovations if their strategy for deterring new entrants requires new means for cost reduction and/or obtaining new market segments (Robertson and Gatignon 1986).

Communication factors offered by Robertson and Gatignon (1986) as determinants of an industry's receptiveness to innovation include the following:

- signaling frequency and clarity

- industry professionalization

- industry cosmopolitanism

Signaling frequency and signal clarity will enhance the speed and level of diffusion. Signaling within an industry refers to statements or explanations by industry members for actions such as new investments, aiterations in production practices, changes in pricing policies, or new product introductions. In this 
case, we are interested in the amount of signaling among competitors and the clarity of these signals regarding the adoption of a new technology. Some industries are generally open in the communication process and unambiguous in signaling while others may be secretive in revealing information - which may even be false. These signals have an impact on the overall industry receptiveness to the technology. Industries that are open in their signaling and information sharing are more likely to disseminate the avaflable information regarding new technology. This increase in available information should facilitate the adoption diffusion process. Signal clarity will normally enhance the value of the information content and announcements will be believed by member companies, also facilitating the diffusion process.

The professionalization of an industry will enhance the diffusion process. The amount of social influence within an industry will have an influence on the amount of information transmitted among industry members and professiona? groups. Examples of professionalized industries include architectural design and medical care organizations. Members of these professionalized industries have the luxury of referring to a professional society as well as to coworkers. This produces a large pool of information sources (Leonard-Barton 1985). Also, organizations are more likely to adopt an innovation if specialized professionals within the firm view it as viable (Moch and Morse 1977). It appears that one target for information regarding new technologies is professional groups since they are an integral part of the information network.

High cosmopolitanism in an industry will speed the diffusion process. Cosmopolitanism, or "external integration", can be assessed according to international sales level, number of target markets, and percentage of personnel who have been involved in other industries. The business consulting industry is an example of a cosmopolitan environment because of the diverse markets served and broad experience of personnel. Some firms are international in scope. These factors extend access to new information sources and thus speeds the difiusion process. Mansfield (1968) found that the most important new sources of innovations were found outside rather than within a mature industry. 
Therefore OBCS may want to target industries that are similar in process, etc. rather than concentrate solely on the most obvious applications of a technology.

\subsubsection{Summary and Implications}

The diffusion process of energy-related technologies from 0BCS to manufacturers is similar to the diffusion process of energy-conserving products to residential end consumers described in Section 2.1. However, some different factors are considered when describing this process in relation to manufacturers. Section 3.2 extended the basic diffusion process model and introduced supplier (such as OBCS) and adopter industry (manufacturers) factors that might speed and enhance the diffusion process.

It is important for OBCS to understand the diffusion process of new technologies and, in particular, how certain factors may affect the potential diffusion level and rate of diffusion of new technologies. In order to increase the potential and speed of diffusion, according to Robertson and Gatignon's 1986 study, OBCS may want to consider the following:

- enhance its reputation in the eyes of potential adopters

- become more involved in potential adopter industry information networks

- place more emphasis on marketing new technologies and potential partnership arrangements to industry

Through examining the existing research, it was found that industries with the following characteristics may be most receptive to the adoption of new technology:

- intermediate level of heterogeneity

- intermediate level of competition

- high level of demand uncertainty

- clear and frequent signaling between industry competitors

- professionalized

- high level of external integration 


\section{3 "DEMAND PULL" VERSUS "TECHNOLOGY PUSH"" INNOVATION STRATEGIES}

A company's business and innovation strategies dictate how new products and technologies are planned for, developed, and introduced to the marketplace. Sometimes products are developed by organizations to meet a strong, we11defined yet unsatisfied market need. In other instances, the invention of a new technology and the awareness of its potential may actually create a need and stimulate demand for products to satisfy that need. These two patterns or philosophies of new product development can be described by many as "demandpul1" and "technology-push" (respectively). A comparison of the two approaches can be seen in Table 3.1 .

It is important that OBCS understand the new product development strategies carried out by firms in a particular industry because it adds insight to their new product opportunity identification and assessment methods.

\subsection{1 "Demand PuTl" Strategy}

Companies that rely on "demand-pul1" strategies of new product development strive to satisfy an existing consumer demand in a familiar market. New product developments typically involve new uses for existing products or efficiency and aesthetic improvements to existing product lines (Petroni 1985). One example of this is the addition of an automatic set-back thermostat to a furnace system based on recognized consumer demand for such a feature. These

TABLE 3.1. Differences in Approach to Planning in a "Technology Push" Versus "Demand Pull" Company

\begin{tabular}{|c|c|c|}
\hline & "Technology Push" & "Demand Pul1" \\
\hline Technology & Emerging or developing & $\begin{array}{l}\text { Mature technologies or } \\
\text { infra-technological } \\
\text { applications }\end{array}$ \\
\hline $\begin{array}{l}\text { Supply } \\
\text { structure }\end{array}$ & 0Tigopoly or monopoly & Vast array of producers \\
\hline Investment & High-risk & Low-risk \\
\hline Profit & $\mathrm{High}$ & Medium-low to low \\
\hline
\end{tabular}


companies usually follow a late-to-market or market-segmentation strategy for new introduction (discussed in Section 3.3.5).

A company's marketing organization plays a major role in the new product planning process when a "demand pull" strategy is utilized since it is consumer needs that stimulate developments in technology (see Figure 3.2). These companies typically operate in "mature" markets where the overall level of technological development is low, there are many sources of supply, and competition between manufacturers is strong.

New product planning in companies that rely on a "demand pull" strategy allow the marketing department to lead the way. As the process progresses, there is substantial interaction between the marketing, engineering, R\&D, and production areas of the firm. In a "demand pull" strategy, technological activities are linked to the company's new product/technology development plan by several methods. These methods are shown by the communication and decisionmaking flows which can be seen in Figure 3.2 (Petroni 1985). In a "demandpul1" strategy, the product portfolio is assessed to identify the conditions that are required for success in a particular market, and to specify those markets that the company wishes to maintain or increase its market share. This analysis may show that new products are needed in particular markets. The company must decide if the required market share might be best obtained by introducing new products, by improving on existing products, or by improving the production process to obtain an advantage in terms of costs. Next, it should be possible to identify those areas of strategic interest that match the company's product needs and specify the role that the marketing department will play.

\subsection{2 "Technology Push" Strategy}

Companies that rely on "technology push" strategies take a different approach to the innovation process and rely mainly on the $R \& D$ rather than on the marketing department. Innovation can sometimes stimulate and develop a strong potential demand. The development of xerography, for example, created an entirely new market as did pocket cameras and instant-print photography. 


\begin{tabular}{|c|c|c|c|c|c|}
\hline $\begin{array}{c}\text { Business } \\
\text { Actions }\end{array}$ & 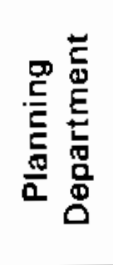 & 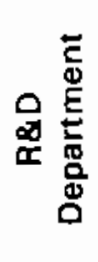 & 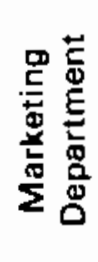 & 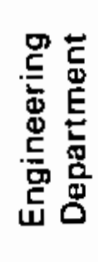 & 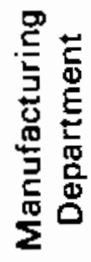 \\
\hline $\begin{array}{l}\text { Start Up Phase: Providing wi } \\
\text { Scenario. Technological Fore } \\
\text { Guidelines, Planning Methoc }\end{array}$ & & & & & \\
\hline $\begin{array}{l}\text { Product Portfolio Analysis (G } \\
\text { Margin, Life-Cycle, Market S }\end{array}$ & & & & & \\
\hline $\begin{array}{l}\text { Proposal of the Pattern or } \mathbf{P} \\
\text { in the Market (in Which Pro } \\
\text { Invest or Disinvest) }\end{array}$ & & & & & \\
\hline $\begin{array}{l}\text { Approval of the Planning De } \\
\text { of the Pattern Proposed by t } \\
\text { Marketing Department }\end{array}$ & & & & & \\
\hline Identification of the Product & & & & & \\
\hline $\begin{array}{l}\text { Identification of "Strategic T } \\
\text { Areas": Assessment of Both } \\
\text { and External Technical Reso }\end{array}$ & & & & & \\
\hline $\begin{array}{l}\text { Definition of Criteria for } \\
\text { Selecting Projects Portfolio }\end{array}$ & & & & & \\
\hline $\begin{array}{l}\text { Approval of Criteria for } \\
\text { Selecting Projects Portfolio }\end{array}$ & & & & & \\
\hline
\end{tabular}

- - - Line of Communication

$\longrightarrow$ Line of Decision-Making and Action

FIGURE 3.2. 'New Product Planning in a "Demand pult" Strategy Source: Petroni 1985. 
Businesses operating under a "technology-push" strategy structure their operations and strategic planning with heavy emphasis on technology. This approach allows technology to be the driving force, cooperating closely with the R\&D department (see Figure 3.3). In fact, some companies that pursue this approach may combine $R \& D$ and strategic planning into one distinct function (Petroni 1985).

The new product planning process in a "technology push" strategy is often steered by the R\&D department. Predicted technological innovations have a substantial influence on the "product concept" that is followed by many of these firms. R\&D heavily influences the long term goals of the company, as well as the directions for change and how that change should be implemented.

\begin{tabular}{|c|c|c|c|c|c|}
\hline $\begin{array}{c}\text { Business } \\
\text { Actions }\end{array}$ & 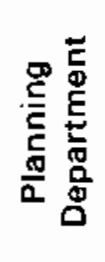 & 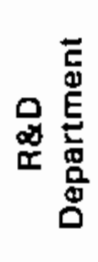 & 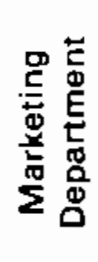 & 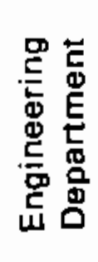 & 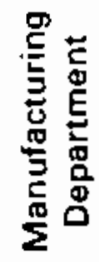 \\
\hline \multicolumn{6}{|c|}{$\begin{array}{l}\text { Providing with Business Scenario, } \\
\text { Guidelines, Method, etc. }\end{array}$} \\
\hline \multicolumn{6}{|l|}{$\begin{array}{l}\text { Providing with Technological } \\
\text { Forecasting, Technology } \\
\text { Applications }\end{array}$} \\
\hline \multicolumn{6}{|l|}{$\begin{array}{l}\text { Analysis of Internal } \\
\text { and External Technical } \\
\text { Resources }\end{array}$} \\
\hline \multicolumn{6}{|l|}{ Product Concept Definition } \\
\hline $\begin{array}{l}\text { Definition of Criteria } \\
\text { for Setting Product } \\
\text { Portfolio }\end{array}$ & & & & & \\
\hline
\end{tabular}

- - Line of Communication

Line of Decision-Making and Action

FIGURE 3.3. New Product Planning Process in a "Technology Push" Strategy Source: Petroni 1985. 
This approach allows for little interaction in the planning process between other departments such as marketing, production, finance, and others. Technology is not used in the planning process to meet the needs for products and processes, but rather to forecast how and in what way the technology will develop.

The marketplace or industrial sector has an influence on a company's new product/innovation strategy. For example, manufacturers operating in the hightech computer industry may rely heavily on "technology push" while the fashion industry will, in general, rely on "demand pull". However, companies within these industries will sway toward one or the other of these approaches. Heating and air-conditioning manufacturers may, in general, be characterized as being "demand pul1". Certain companies within this industry might rely more heavily on their R\&D department for planning strategies. It may be that these companies are the very large, industry leaders who have substantial R\&D budgets; or they may be the smaller, more innovative firms that rely on new technology to gain a niche in the market. This type of information would be valuable to OBCS for planning market penetration strategies for new technologies and could be obtained from a survey of manufacturers.

\subsubsection{New Product Introduction Strategies}

The pattern in which a company introduces new products is related to the company's business and innovation strategy. Some manufacturers, usually "demand pull" companies, rely heavily on market segmentation of established markets and strive to serve these subset markets with slight or superficia? alterations of established technologies. Unless these companies can be shown that substantial demand exists for a new technology, they are the least likely to adopt new technologies. Dther manufacturers, usually those that follow a "technology push" strategy, strive to enter the market first with new products in order to gain a temporary monopoly and enjoy early profits before other companies enter the market. These manufacturers must be committed to basic and applied R\&D to create new products and take advantage of new market opportunities. Because of these R\&D commitments and capabilities, these companies may have great potential for adopting new technologies. 
A manufacturer's innovation strategy can be determined by examining patterns of new product introductions and technology adoption. The nature of the industry has a great deal to do with the overall business strategy of manufacturers. However, when compared to one another, these manufacturers tend to introduce products and adopt new technology at different stages in the product life cycle; some enter early while others wait to see if the new product or process is successful. They then rely on alterations of that product to seize a niche in the market. Maidique and Patch (1978) identified four typical alternative business strategies and related them to innovation in the firm. These strategies, described in Table 3.2, are 1) first-to-market, 2) second-tomarket, 3) late-to-market, and 4) market segmentation strategy. Briefly, these strategies are:

- First-To-Market Strategy. This strategy attempts to introduce the product into the market before the competition in order to experience

TABLE 3.2. Typical Functional Requirements of Alternative Technological Strategies

\begin{tabular}{|c|c|c|c|c|c|c|}
\hline & A\&D & Manufacturing & Marketing & Finance & Organization & Timing \\
\hline First-to-Market & $\begin{array}{l}\text { Requires State of } \\
\text { the Art R8D }\end{array}$ & $\begin{array}{l}\text { Emphasis on } \\
\text { Pilot and } \\
\text { Medium-Scale } \\
\text { Manufacturing }\end{array}$ & $\begin{array}{l}\text { Emphasis on } \\
\text { Stimulating } \\
\text { Primary Demand }\end{array}$ & $\begin{array}{l}\text { Requires Access } \\
\text { to Risk Capital }\end{array}$ & $\begin{array}{l}\text { Emphasis on } \\
\text { Flexibility Over } \\
\text { Efficiency: } \\
\text { Encourage Risk } \\
\text { Taking }\end{array}$ & $\begin{array}{l}\text { Early-Entry } \\
\text { Inaugurates the } \\
\text { Product Life } \\
\text { Cycle }\end{array}$ \\
\hline $\begin{array}{l}\text { Second- } \\
\text { to-Market }\end{array}$ & $\begin{array}{l}\text { Requires } \\
\text { Flexible. } \\
\text { Responsive and } \\
\text { Advanced R\&D } \\
\text { Capability }\end{array}$ & $\begin{array}{l}\text { Requires Agility } \\
\text { in Setting Up } \\
\text { Manufacturing } \\
\text { Medium Scale }\end{array}$ & $\begin{array}{l}\text { Must } \\
\text { Diflerentiate the } \\
\text { Product: } \\
\text { Stimulate } \\
\text { Secondary } \\
\text { Demand }\end{array}$ & $\begin{array}{l}\text { Requires Rapid } \\
\text { Commitment of } \\
\text { Medium to Large } \\
\text { Quantities of } \\
\text { Capital }\end{array}$ & $\begin{array}{l}\text { Combine } \\
\text { Elements of } \\
\text { Flexibility and } \\
\text { EHiciency }\end{array}$ & $\begin{array}{l}\text { Entry Early in } \\
\text { Growth Stage }\end{array}$ \\
\hline $\begin{array}{l}\text { Late-to-Market } \\
\text { or Cost } \\
\text { Minimization }\end{array}$ & $\begin{array}{l}\text { Requires Skill in } \\
\text { Process } \\
\text { Development } \\
\text { and Cost } \\
\text { Effective Product }\end{array}$ & $\begin{array}{l}\text { Requires } \\
\text { Efficiency and } \\
\text { Automation for } \\
\text { Large-Scale } \\
\text { Production }\end{array}$ & $\begin{array}{l}\text { Must Minimize } \\
\text { Selling and } \\
\text { Distribution } \\
\text { Costs }\end{array}$ & $\begin{array}{l}\text { Requires Access } \\
\text { to Capital in } \\
\text { Large Amounts }\end{array}$ & $\begin{array}{l}\text { Emphasis on } \\
\text { EHiciency and } \\
\text { Hierarchical } \\
\text { Control; } \\
\text { Procedures } \\
\text { Higidly Enforced }\end{array}$ & $\begin{array}{l}\text { Entry During } \\
\text { Late Growth or } \\
\text { Early Maturity }\end{array}$ \\
\hline $\begin{array}{l}\text { Market- } \\
\text { Segmentation }\end{array}$ & $\begin{array}{l}\text { Requires Ability } \\
\text { in Applications, } \\
\text { Custom } \\
\text { Engineering, and } \\
\text { Advanced } \\
\text { Product Design }\end{array}$ & $\begin{array}{l}\text { Requires } \\
\text { Flexibility on } \\
\text { Short- to } \\
\text { Medium Runs }\end{array}$ & $\begin{array}{l}\text { Must Identify } \\
\text { and Reach } \\
\text { Favorable } \\
\text { Segments }\end{array}$ & $\begin{array}{l}\text { Requires Access } \\
\text { to Capital in } \\
\text { Medium or Large } \\
\text { Amounts }\end{array}$ & $\begin{array}{l}\text { Flexibility and } \\
\text { Control Required } \\
\text { in Serving } \\
\text { Different } \\
\text { Customers } \\
\text { Requirements }\end{array}$ & $\begin{array}{l}\text { Entry During } \\
\text { Growth Stage }\end{array}$ \\
\hline
\end{tabular}

Source: Maidique and Patch 1978. 
a temporary monopoly in exploiting the new technology. This

"monopolistic" condition enables the company to cover the high costs of $R \& D$ that are required to move a basic technology to a marketable product. This strategy requires a strong commitment to basic and applied R\&D. Companies undertaking a first-to-market business strategy might be the most likely candidates for adoption of new technologies developed by OBCS.

- Second-To-Market Strategy. When compared to the first-to-market strategy, the second-to-market companies would imply commitments to occur later in the R\&D efforts. However, in terms of overall expenditures on R\&D, the second-to-market strategy may spend as much or more as the first-to-market strategy. The first-to-market strategy depends more on internal basic research while the second-to-market may look more toward external sources of technological information. Here again, these companies may be good targets for information regarding technologies developed by OBCS.

- Late-To-Market, or Cost Minimization. Companies following this approach generally are concerned with achieving an advantage in the market through reduced cost. They typically strive for economies of scale in production and distribution through process and product design modifications. Entry into the market usually occurs after a competitor has already become established in the market and sales are growing. The late-to-market company will avoid investments in. capital-intense plants are until products have become fairly standardized by other companies. These organizations spend little or nothing on basic research, especially when compared to the first-and second-to-market firms. OBCS should probably not focus their efforts to gain support from these companies unless the technology would result in some sort of a process innovation.

- Market Segmentation or Specialist. These companies focus their efforts on small units or segments of demand with special applications of the basic technology. Entry into the market usually occurs after competitors have al ready entered the market, sales are 
increasing at a steady rate, and the market can be further segmented by groups of consumers with specific needs. Capabilities surround applied engineering as well as flexibility in the manufacturing area. These strategies require less emphasis on basic and applied research and more on the various areas of marketing and production capacity. These organizations would not provide the most potential in terms of technology adoption of OBCS technologies.

\subsubsection{Summary and Implications}

New product introduction strategies and innovation strategies reflect how a company plans for and develops new technology and products. Identifying past ways that new products are introduced will reveal a company's reliance on first-or second-to-market, late-to-market or market segmentation. This will help determine if a company's innovation strategy is closer to "demand pull" or "technology push". The new product introduction strategy of a company will influence which firms OBCS should approach with information regarding a technology and the approach to be used.

OBCS has traditionally followed a "technology push" strategy for new product development. Planning is typically guided by developments in technology rather than the identification of market demand. Studies have shown that high technology companies that have developed a concerted team effort between $R \& D$ and marketing in their new technology/product development efforts have experienced the greatest success in new product introductions and profitability (Petroni 1985).

Implications of these findings to OBCS include the following:

- OBCS may be able to greatly increase the potential for successful market penetration of new technologies if this sort of $R \& D$ /marketing cooperation is integrated into technology development and commercialization efforts.

- "Demand pull" companies rely heavily on the marketing department and would be best approached by OBCS through this department with information on predicted demand for the new product as well as consumer 
attitudes and needs as they relate to the particular technology or products that the technology might develop.

- "Technology push" companies, because of their strong commitment to R\&D and reliance on new technology, are probably the most likely candidates for many OBCS technologies that are in the early stages of development. These companies would probably be best approached through the R\&D or planning departments with technical information on the new technology.

- By conducting market assessment studies before the technology progresses to later stages of development, alterations to the technology's development path, however slight, may provide a greater potential for commercial success.

- To be successfully commercialized, manufacturers must view these technologies as potentially profitable. This profitability potential is based in part on market predictions and on demand for the resulting product.

\subsection{THE DECISION-MAKING PROCESS OF THE COMPANY}

Organizations, like individuals, go through a decision-making process that varies in complexity depending on the importance of the decision to the decision maker(s). The decision to adopt/not adopt a technology or develop and produce a new product is a very critical one. If the decision results in a successful new product, the company may earn potentially large profits, while failure may result in substantial losses. Companies frequently consult a small number of key individuals within the company to help make the optimal decision. These individuals, or the "decision-making elite", possess specialized skills in areas such as finance, production, manufacturing, marketing, R\&D, and engineering. The chief executive officer (CEO) normaliy has the final say in the decision (Cohn 1980). A number of studies have attempted to explain the decision process and the adoption of innovations for the individual consumer. However, few have focused on the corporate decision and adoption process, especially in a particular industry. This section covers decision-maker attitudes towards risk and change and how they may affect the decision to adopt a new 
technology, selection or evaluation criteria for new technologies and how they differ according to the individual's role or job category within the company, and an example of new product/technology screening methods.

\subsubsection{The Importance of Attitudes}

Studies concerning the adoption of innovations in industry have frequently. concluded that managerial attitudes are a crucial determinant of adoption behavior. These studies have concluded that innovation is extremely disruptive to the internal structure of the firm and that managers who innovate must look favorably on change (Cohn 1980). Because the adoption of technology brings with it the elements of risk and uncertainty, it has been hypothesized that managers who show a greater preference toward risk are more likely to adopt an innovation (Cohn 1980). The studies in this section deal mainly with process versus product innovation that is developed outside the firm.

Hage and Dewar (1973) hypothesized that a firm will be more likely to adopt innovations based on the following:

- the greater the president of the company's preference is for change

- the greater the decision-making elite's preference is for change

- the greater the president of the company's preference is for risk

- the greater the decision-making elite's preference is for risk.

- the less the president of the company's preference is for traditional technologies

- the less the decision-making elite's (usually managers of finance, marketing, and R\&D) preference is for traditional technologies

Hage and Dewar's findings also inferred that the likelihood of a firm's adoption of technology will not be related to the attitudes of the total managerial staff, implying that certain individuals in the decision-making elite may have more authority in the final decision. Cohn (1980) sought to test the hypothesis of Hage and Dewar by conducting a study that included a survey of decision-makers in the footwear industry. Crucial aspects of the footwear industry include the intense competition between manufacturers and the 
machinery suppliers' dominance of the innovation process. Machinery and other process innovations are normally not developed by the footwear firms themselves.

Cohn's study found four variables to be related statistically to actual technology adoption: the change preferences, risk preferences, preferences of the decision-making elite for traditional technologies, and preferences for traditional technologies by the total management staff.

The Cohn study showed that decisions regarding the adoption of new technologies were typically made by the CEO and production managers. The decisionmaking structures were primarily consensual, meaning that there were rarely conflicts over these decisions. Opposition of only a few managers was usually sufficient to block the decision to adopt, making it difficult for one manager to impose his attitudes on the decision-making group. Even though the manager was a member of the decision making group, his attitudes did not necessarily predict the firm's adoption choices. Instead, the attitudes of all managers involved played a rote in the decision process (Cohn 1980).

While it is helpful to understand the role of managerial attitudes in the decision-making process, these attitudes are difficult to obtain and differ from firm to firm. For OBCS, it may be easier to look at the general criteria that decision-makers use depending on their role in the organization. These criteria will be discussed in the next section.

\subsubsection{Issues of Importance to Decision Makers}

Decision makers at potential technology adopting organizations place importance on different criteria depending on their role in the organization. It is important for OBCS to stress different aspects of the new technology to the different decision makers within the firm.

Table 3.3 shows the "importance criteria" and how they differ among decision makers in industrial marketing (Choffray and Lilien 1978). These "importance criteria" will probably be different in assessing new OBCS product technologies since other departments such as marketing and R\&D wouTd probably be involved in the decision. Also, since OBCS technologies have not reached 
TABLE 3.3. Importance Criteria in Industrial Marketing

\begin{tabular}{|c|c|c|}
\hline & Major Importance & Minor Importance \\
\hline Production Engineers & $\begin{array}{l}\text { Operating cost. Energy } \\
\text { savings. Reliability } \\
\text { savings. }\end{array}$ & $\begin{array}{l}\text { First cost } \\
\text { Field proven }\end{array}$ \\
\hline Corporate Engineers & $\begin{array}{l}\text { First cost. Field proven. } \\
\text { Reliability. Complexity. }\end{array}$ & $\begin{array}{l}\text { Energy savings } \\
\text { Up-to-date }\end{array}$ \\
\hline Plant Managers & $\begin{array}{l}\text { Operating cost. Use of } \\
\text { unproductive areas. } \\
\text { Up-to-date. Power failure } \\
\text { protection. }\end{array}$ & $\begin{array}{l}\text { First cost } \\
\text { Complexity }\end{array}$ \\
\hline Top Managers & $\begin{array}{l}\text { Up-to-date. Energy savings. } \\
\text { Operating cost. }\end{array}$ & $\begin{array}{l}\text { Plant noise } \\
\text { Reliability }\end{array}$ \\
\hline
\end{tabular}

the later development stages of R\&D, cost estimates are unclear. However, this table does illustrate how key "importance criteria" differ between different types of decision makers. This may be an area for future research by OBCS.

Top management, for example, is normally most concerned with the technology's affect on the bottom line and is accustomed to reviewing proposals that outline return on investments and paybacks. These managers may also be influenced by strategic considerations such as changing business needs. When largescale automation was introduced to GE's large steam-turbine generator business, management was convinced of the innovation based on changing business needs. These needs surrounded a shift from manufacturing operations of large, one-ofa-kind products to the production of smaller parts. Management's decision to adopt the new technology was also based on the need for continual quality improvements to keep operations competitive.

\subsubsection{New Product/Innovation Screening Methods Potential}

Potential adopters/manufacturers of new technologies developed by OBCS will closely scrutinize the innovation before committing resources to the costly process of transforming the technology into an end product. These organizations will want to assess areas such as market needs, potential demand, production requirements, and other factors. To guard against the high 
potential of failure for new products, many firms have developed elaborate screening processes to evaluate new product ideas based on a number of criteria that take into account the concerns of the various potential decision makers discussed previously. OBCS should be aware of these screening processes in order to conduct an initial evaluation of the new product technology before it is presented to the potential industrial adopter.

\section{New Product Profile Chart}

A new product profile chart, (see Table 3.4) developed by Monsanto Corporation, analyzes the profit, sales, and cash requirements of a new venture, as well as the degree to which the technology converges with the production, R\&D, and marketing capabilities of the firm (Hutt and Speh 1981). This analysis is based on the firm's clear understanding of their market, and, since an innovation may have a potential application in a number of usage groups, the analysis may be examined for a number of market segments.

\section{TABLE 3.4. New Product Profile Chart}

$\begin{array}{ll}\text { Financial Aspects } & \text { Return of investment (before taxes) } \\ \text { Estimated annual sales } & \text { Estimated annual sales } \\ & \text { New fixed capital payout time } \\ & \text { Time to reach estimated sales volume } \\ \text { Marketing and } & \text { Similarity to existing product lines } \\ \text { product aspects } & \text { Effect on present products } \\ & \text { Marketability to present customers } \\ & \text { Number of potential customers } \\ & \text { Suitability of present sales force } \\ & \text { Market stability } \\ & \text { Market trends } \\ & \text { Technical service } \\ \text { Production and } & \text { Required corporate size } \\ \text { engineering aspect } & \text { Raw materials } \\ & \text { Equipment } \\ & \text { Process familiarity } \\ \text { Research and } & \text { Research investment payout time } \\ \text { development aspects } & \text { Development investment payout time } \\ & \text { Research know-how } \\ & \text { Patent status }\end{array}$

Source: Hutt and Speh 1981. 
To implement the new product profile chart, firms often rate the aspects of a technology on a scale. For example, the aspect of "suitability of present sales force" might be rated as:

-2 entirely different sales force

-1 some present sales force

+1 mostly present sales force

+2 all present sales force

Added weights can be assigned to certain factors depending on their importance to a particular firm. OBCS might use these dimensions as evaluation tools for potential market penetration (to manufacturers) of new technologies. However this information provides only a general idea of the criteria a firm might use to evaluate a new product and is not specifjc to any particular OBCS technology's market area. Also, this information deals with a new product idea that is probably later in the development stage than many OBCS technologies. It would be useful for OBCS to obtain information on evaluation criteria regarding technologies in the earlier stages of research since this is when OBCS is probably evaluated by manufacturers. More information about when (at what stage of R\&D) manufacturers usually evaluate OBCS technologies for possible adoption and at what stage of R\&D do technologies have the highest adoption rate would be helpful.

\subsubsection{Summary and Implications}

The decision to adopt and invest in the development of a new technology is risky for an organization because of the time and monetary commitments required. Therefore, the decision to adopt/not adopt is an important one, usually involving the company's "decision-making elite" from specific expertise areas within the company as well as the CEO. Attitudes of the CEO and the decision-making elite toward risk, change, and preferences for traditional process technologies have an influence on adoption, as does the individual decision-maker's role or function in the company. Some companies have developed formal and informal methods for evaluating a new product or technology.

A survey of manufacturers of energy-related technologies could be conducted to determine: 
- overall adoption potential of specific firms and which departments might be most responsive to new technology ideas

- importance criteria for new technologies depending on the person's role or position in the company. This will dictate the type of technology information that shou?d be presented to that person

- which person(s) within an organization normally possess the most decision-making power - characteristics of these persons, such as position within the company, length of time with organization, etc., will be useful to OBCS

- new product/technology screening methods, importance attributes, and attribute weights. These are all used by companies to assess new products and technologies that would be useful to OBCS

- possible means of tracking for changes in "decision-making elite" members

\subsection{BARRIERS TO SUCCESSFUL MARKET PENETRATION}

There are many potential barriers that can impede a company's acceptance and adoption of a new technology. These barriers exist at all stages of market penetration; from the adoption decision process, to the implementation stages of a process technology within a company. Sufficient financial and R\&D resource capabilities are definite barriers to some companies. Other barriers, however, are less obvious and much harder to identify. This section covers barriers encountered in the decision process, barriers to innovation inherent to large firms, and barriers in implementation of process technology. This listing of barriers is not inclusive but provides an initial understanding of potential barriers to successfui market penetration of new technologies and possible solutions to overcome them.

\subsubsection{Barriers in the Adoption Process}

The failure of many new technologically superior products to successfully penetrate the market has often been attributed to problems in managing innovation and the new product development process. In particular, managers have often failed to transform innovative technologies into products with high 
market potential. However, in many cases, problems occur after market entry because of management's misunderstanding of the adoption process (More 1983).

Studies have generally addressed the industrial buying process and purchase behavior in relation to a specific end product. However, many OBCS technologies, especially those in the earlier stages of R\&D, have not yet reached this stage of development and would require adoption or "shared development" by manufacturers. While the adoption process itself, i.e., the stages of awareness, knowledge, information search, and interest, etc. are probably similar, the selection criteria used by a company would be quite different for an immature versus a mature technology. By better understanding this adoption process and anticipating barriers, OBCS can better ensure successful market penetration of new technologies.

As discussed in Section 2.4, diffusion of OBCS technologies to manufacturers, purchasers of industrial products go through a fairly standard buying process. This process is similar to that followed by residential consumers, except there are normally more decision makers involved in the industrial buying or technology adoption decision situation. The group of specialized individuals within a company that normally make purchase decisions is described as the "buying center" by More (1983). More's "buying center" is similar to the group of "decision-making elite" discussed in Section 3.4., so for simplicity the term "decision-making elite" in used in this report. Individual members of the "decision-making elite" often possess different adoption criteria, different uncertainties, different information needs, and different attitudes toward risk.

Potential adopters of OBCS technologies go through a decision process that involves certain steps that must be followed to decide to adopt/reject or purchase/reject. These steps are illustrated in Table 3.5 and involve:

1) unawareness, 2) awareness, 3) interest, 4) evaluation, 5) trial, and 6) purchase/adoption or rejection. These stages are described in more detail in Section 2.2.

There are several barriers that may potentially be encountered which are derived from characteristics of the firms' adoption processes. These potential barriers may impede the adoption process or result in market rejection of the 
TABLE 3.5. The New Product Development Process: The "Decision-Making Elite's" Perspective

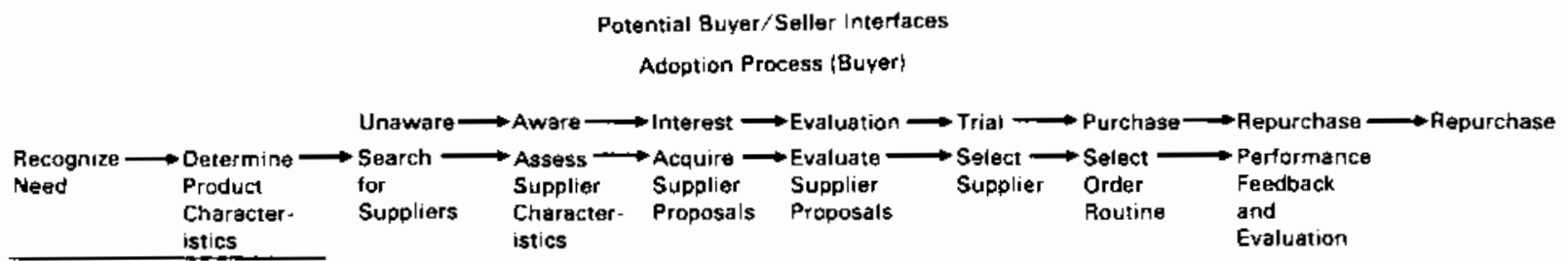

Source: More 1985

technology. Roger A. More described a number of barriers to the adoption of high technology in his 1983 study. These barriers include:

- identification of the "decision-making elite

- identification of the most influential members of the "decisionmaking elite"

- changes in membership of the "decision-making elites"

- identification of individual "decision-making elite" roles

- past experiences of the "decision-making elite"

- trial stage barriers

- adoption criteria barriers

- external negotiation barriers

- time barriers

- persona1 risk barriers

- company resource barriers

- Identification of the "decision-making elite. The rest of the barriers offered are dependent upon overcoming this first barrier. It is important to identify and define the members of the "decisionmaking elite" in order to persuade them to adopt a new technology. The most influential members of the "decision-making elite" should be identified as soon as possible, which will require early interaction with the group. There is no simple method for identifying members of the "decision-making elite". Unless OBCS has some internal contact 
or has dealt with the company before, it will take a lot of effort in terms of reviewing literature to identify potential adopters and later in conducting telephone interviews or mail surveys to determine who within the company make up the "decision-making elite".

- "Decision-making elite" influencers. Different members of the "decision- making elite" possess varying amounts of influence and power over the group as a whole. If these influential members are not accessible or known to OBCS, adoption of the technology will be more difficult. OBCS should make attempts to identify the most influential members of the "decision-making elite". Once these people are convinced of the technology's viability, they may persuade other members that the technology has potential and value to the company. Unfortunately, it is often difficult to identify the "decision-making elite" let alone the most influential member(s).

- "Decision-maxing elite" changes. Members of the "decision-making elite" may change from time to time, causing difficulties in the transfer of information to the correct people. These shifts in the "decision-making elite" may also result in a change in evaluation criteria for new technologies. Some method of tracking these changes over time would be beneficial to OBCS. One tracking method is to keep in close contact with at least one member of the "decisionmaking elite" so that changes in members can be easily recorded.

- "Decision-maxing elite" role barriers. An assumption is often made by the producer of a technology that the person with whom they have the most contact is the primary decision maker. Often this is not the case, and the criteria used by this contact may not be consistent with the criteria used by the "decision-making elite" as a whole. Therefore, the producer may not be stressing the correct information to the overall group. This is a difficult barrier to overcome since this information is not easy to obtain. A survey of manufacturers might be conducted by OBCS to more clearly identify selection criteria of the individual decision-makers and how this criteria differs according to that person's position in the company. 
- Past experiences of the "decision-making elite". Another barrier deals with past experiences of members of the "decision-making elite". If an influential member of the "decision-making elite" has had a negative experience with a similar product or technology, or even in dealing with government offices, he may decide to reject the technology and attempt to persuade other members to do the same. If the OBCS is unaware of these past experience biases, the information required to reduce the decision maker's risk will not be conveyed.

- Irial stage barriers. Technology adoption will be more difficult if potential adopters are unable to try a product. This is a major barrier to OBCS technology adoption since there is no product. There is often no opportunity to try or even see the technology. Therefore, the trial stage of the adoption process is eliminated, increasing the risk for the potential adopter. Earlier interactions with potential adopters during the adoption process can greatly reduce barriers to acceptance. By actively involving potential adopters in the product development process, a relationship can be developed between the two parties and potential adopters can be moved forward in the development process with reduced barriers. The technology is, in effect, being tried! OBCS can facilitate the adoption process by committing resources (time, information, etc.) to help the potential adopter move through the adoption process.

- Adoption criteria barriers. Potential adopters may be unsure of what the evaluation criteria to use regarding a new technology. As a result, the risks and pay-offs of adoption are unclear since the technology is so distinctly different from other options the company might have. Evaluating criteria will require a large amount of information search. Therefore, OBCS should assist potential adopters since it may be difficult for them to assess the risks and payoffs associated with adoption of a complex technology of which they have little understanding. These adopting companies may initially see the risks and problems of adoption rather than attractive payoffs. They may also lack the capabilities or resources to evaluate the technol- 
ogy properly. Therefore, the more information OBCS can provide regarding technical, economic, and marketing aspects of new technologies, the more likely it will be adopted.

- External negotiation Barriers. The "decision-making elite" may reject a technology on the basis of some criteria that may have been negotiable. For example, the "decision-making elite" might reject an $O B C S$ technology because of some misunderstanding regarding the technology that was discussed with one member of the "decision-making elite". Well developed negotiation skills are essential to the adoption process. OBCS must able to negotiate clearly and to be flexible to the unique needs of potential adopters.

- Information and Risk Barriers. At some point in the adoption process an important member of the "decision-making elite" may perceive a major risk in adopting the new technology and may reject it altogether. The decision-maker may not seek information to solve this risk if there is another viable option. OBCS needs to keep in contact with potential adopters. In situations where distributors are closely involved with and may be affected by the adoption of a new technology, they often have a strong influence on potential adopters. Information should be provided to these distributors about the new technology, and an effort should be made to facilitate negotiations between potential adopters and distributors.

- Time barriers. It of ten takes a considerable amount of time to evaluate a new technology. During this period, shifts in priorities for the "decision-making elite's" time may occur and the decision may be put off indefinitely. Because of time constraints, "decisionmaking elite" groups may reject technologies with which they are unfamiliar and about which they take the most time to acquire information. OBCS should be cognizant of these shifts.

- Personal Risk. The adoption of a technology may for some reason pose a personal risk to a particular member of the "decision-making elite". This risk may be due to a change in job scope or personat 
power and influence, so the person may try to deter acceptance of the technology. This would be difficult for OBCS to assess.

- Company resource barriers. Certain potential adopting companies, especially smaller ones, may not have the financial resources to adopt or even to provide for a careful assessment or evaluation of a new technology and, thus, may adopt a simpler technology. Since the adoption of many OBCS technologies would involve substantial commitments of resources by the adopting company, it may be wise to focus on fewer potential adopters so that financial assistance may be available. OBCS may want to focus resources on early adopters. There are certain buyers that have a higher likelihood of adopting a technology. Marketing efforts should be concantrated on these companies to most effectively utilize resources allocated to attract potential adopters. Early interaction with potential buyers should help identify who the earlier adopters might be. Roger A. More listed some characteristics often used to identify early adopters. They are:

- small and stable "decision-making elite"

- effective internal communication

- high expected payoff for adoption

- low risks associated with adoption

- experience with developer

- easy adaption of new technology to present product/process

- past record of technologically innovative actions

- accessible "decision-making elite"

- non-politicized decision process.

This list, while not exhaustive, is a beginning in the identification of the early adopters.

\subsubsection{Barriers to Innovation in Large Companies}

Large firms, because of their access to financial resources and to large R\&D departments, are often the targets for information transfer regarding new technologies. Attempts to gain support for the adoption of technology are usually focused on these larger companies. There are, however, certain 
negative effects and inhibitors to innovation associated with large companies. This section deals mainly with innovation developed within the firm. However, since these barriers inhibit the overall innovativeness of the company, the firm may also be less receptive to new ideas and technologies developed outside the company.

A large firm's access to resources is a benefit to innovation. However, the mere size of these resources may impede management's ability to encourage innovation (Klavans, Shanley and Evan 1985). In large corporations, the structure, controls and reward systems may limit the interests of individuals to narrowly-defined functional activities and short-term outlooks on the future (Klavans, Shanley and Evan 1985). Large firms are generally faced with a dilemma. The need for individual entrepreneurs to bring vitality and new ideas to the firm must be fostered, but formal structures and controls are required to maintain and coordinate ongoing activities (Klavans, Shanley and Evan 1985).

Obstacles to successful corporate innovation relating to bureaucratic and managerial practices of U.S. companies were discussed by McIntyre (1982) and by Mendell and Ennis (1985). Two major criticisms made by these authors are an over-reliance on objective financial measurement tools and a limited outlook on the future by companies. The 11 obstacles mentioned in the studies are as follows:

- large corporations often foster a resistance to change

- innovation may threaten current successes

- the corporate hierarchy produces conservative subordinates

- product/market boundary charters at times preclude innovation

- organizational politics may lead to compromises that make innovation attempts less successful

- the separation of power in a large company may cause a "weakest link" constraint on innovation

- larger firms often emphasize short-run efficiency

- the rotation system often used to train managers may instill a shortrun perspective 
- large organizations sometimes get excited only about "big" opportunities

- marketing departments of large firms often follow rather than lead the market

- large companies often rely on acquisitions for growth

OBCS should be aware of the barriers that deter innovation in large companies. Simply because a company is believed to have the financial resources required to adopt a technology does not mean it will happen. OBCS should keep in mind that intermediate size firms may be likely candidates for technology adoption since they may not be as susceptible to some of these "bureaucratic" barriers to innovation.

\subsubsection{Barriers Encountered in the Implementation of Industrial} Process Technology

Once a technology, usually of the process type, has been adopted by top management and the decision has been made to integrate the technology into the production system, there are often certain markets within the firm that must accept the technology in order for it to be successfully implemented. These internal markets are sometimes not consulted in the adoption decision (i.e., are not part of the "decision-making elite"). The higher on the organizational level that the technology is percejved to have potential, the greater the likelihood of adoption. However, the closer the technological information is to the end users or those that would be involved in continued research or in its use, the greater the probability of implementation.

Successful implementation involves all levels of management and staff support. It is important for OBCS to understand the problems that industrial adopters will have when trying to implement new technologies. This section will discuss some of the challenges that management must overcome if companies are to efficiently implement new technologies. Ideally, OBCS would identify those individuals or groups within the company whose acceptance is most critical to an innovation's success. OBCS would also want to determine when and how to approach these individuals, and with which strategies. Unacceptance of the technology by lower-level management and staff is not uncommon, especially if 
it will change the status quo or skills required by personnel. This opposition may become apparent when staff are initially approached with the idea. However, if these people are not consulted, the opposition may not become apparent until after the decision has already been made by upper management to implement the technology.

It is important for OBCS to recognize these potential problems since they may impede the market penetration of a new technology - even after it has been accepted by upper management. The sort of innovation that causes the greatest disturbance is usually of the process versus product type. The most common reasons for opposition to a new technology are fear of loss of skills or power and the absence of an incentive in terms of personal benefit (Barton and Kraus 1985). These reasons will be discussed below.

- Fear of Loss of Skills. Many new process technologies, especially those involving automation and the reduced need for specialized manual skills, will have strong opposition. Workers with hard-earned manual skills would be displaced by automated systems and would need to be retrained in another skill. These skills are often less attractive to the workers because they involve mundane routine responsibilities such as "button pushing". Unions supporting these workers may introduce opposition to the new technology.

- Fear of Loss of Power. The foremen and supervisors of these new systems have often worked up through the ranks and understand the old system well. They may pose resistance to the new technology if the change challenges their position and authority. If they fee? that they lose control with the introduction of the technology, they will undoubtediy not favor it. A good implementation plan would try to identify these areas of potential loss so that solutions could be found (Barton and Kraus 1985).

- Personal Benefit. New technologies must offer clear advantages over their replacements or there is little incentive for potential users to adopt them. The potential benefits and rewards of the system must be apparent if the costs to the users (financial, convenience, the need to learn new skills) are substantial (Barton and Kraus 19B5). 
These benefits might include expanded influence over work, increased value of work (no in-process inventory), greater recognition (being a part of the implementation team), solution to a problem, and preservation of jobs.

\subsubsection{Summary and Imp 1ications}

Section 3.5 proposed a number of potential barriers to successful market penetration of OBCS technologies. These include barriers in the adoption decision process, barriers to innovation in large companies, and barriers encountered in the implementation of industrial process technology. Individual members of the "decision-making elite" often possess different adoption criteria, different uncertainties, different information needs, and different attitudes toward risk.

This section discussed numerous barriers in the adoption decision process. Barriers to innovation in large firms may be difficult for OBCS to overcome because they are inherent to the essence of many large companies. However, they provide a basis for understanding why large firms with great potential for technology adoption have not done so. OBCS may also be able to identify ways to avoid these barriers. The implementation of process technology is often faced with barriers within the firm, especially if the process will change the status quo of skills required by lower level management and staff. The most common reasons for opposing new technology are fear of loss of skills or job and the absence of an incentive in terms of personal benefit. OBCS should be aware of these potential problems and should assist adopting companies in finding alternatives and solutions to prevent these barriers from impeding adoption.

The above are just a few of the barriers that new technologies face. They provide a basis for understanding why superior new technologies do not gain acceptance by manufacturers who must further develop and market the technology to end consumers, or integrate it into their production process. Potentia? ways to overcome the barriers to adoption of innovations by manufacturers are as follows: 
- become involved in the manufacturer's adoption process

- define and identify the manufacturer's buying/decision-making center

- focus efforts on the most influential member(s) of the "decisionmaking elite"

- develop a method for tracking the "decision-making elite"

- focus resources on early adopters

- identify early cash flow opportunities in the adoption process

- enhance negotiation skills

- assist the potential adopter in assessing technology payoffs and risks

- gain support from certain distribution channels

- understand barriers to innovation in large firms

- focus on all sizes of companies

- help adopters of industrial process technologies overcome potential implementation barriers.

\subsection{SUMMARY AND CONCLUSION}

Numerous factors both internal and external to the firm seem to influence the potential for adoption of technology by manufacturers. This chapter provided a general discussion of corporate innovation methods and concentrated on the internal factors of the company and their jmplications to OBCS. Topics included; patterns of corporate innovation, technology diffusion, decisionmaking processes in new product/technology adoption and selection criteria, corporate innovation strategies, motivators to the adoption of new technologies, and barriers that may impede technology adoption.

The main reason that companies fund the development of new technology is because they believe that the resulting product or service will bring financial prosperity to the company. Most innovations have occurred in response to market needs or demand and have originated within the company, usually by the R\&D department. 
A company's innovation strategy ("technology push" or "demand pu11") will influence its receptivity to innovations at different stages of R\&D. Depending on the company's innovation strategy, different departments possess greater influence in the innovation decision-making process. Therefore, the type of information and information recipients targeted by DBCS will depend on the company's innovation strategy. The overall orientation of the industry towards innovation will also have an influence.

Companies normally consult a number of individuals from different departments of the organization, termed the "decision-making elite," in order to make important corporate decisions. These departments often include finance, R\&D, marketing, production, manufacturing, and engineering. Each department has a different set of importance criteria used to judge a technology. The CEO usually has the final say in the decision, with other members possessing different amounts of influence. The attitudes of these decision makers and the CEO towards risk and change will influence the adoption decision. Some companies have developed elaborate screening methods to evaluate new products. Information regarding methods to screen new technologies for potential adoption by manufacturers would be useful to OBCS.

Barriers that may inhibit successful market penetration of 0BCS technologies exist at all stages of technology diffusion. Barriers in the adoption process, barriers that are present in the large companies, and barriers encountered in the implementation of process technology can all inhibit market penetration. Once potential barriers are identified, strategies can be developed by OBCS to overcome them.

Few studies have been conducted that focus on a company's decision-making process in regards to technology development. Even fewer have focused on technology adoption or joint development of a new technology. Few studies have studied the barriers that may market penetration of OBCS technologies, especia]ly in regards to initial technology adoption by one or a small number of companies. These topics deserve further study by OBCS. The specific questions that might be answered are discussed in more detail in each section. 


\subsection{RESIDENTIAL INTERMEDIATE MARKET OF BUILDERS}

Once an energy-related technology has been accepted by manufacturers and is available in the marketplace, there are two distinct markets for the resulting product. The first is the end consumer (discussed in chapter 2) who will actually use the product in the home. The other market, which we will label the intermediate residential market, is composed of organizations and individwals that make purchasing decisions for many end users. This market inctudes builders, contractors, architectural firms, rental property owners, and other organizations. An interesting feature of the residential intermediate market is that it includes individuals who will probably never ultimately pay for the energy consumed by the products they purchase.

It is important to distinguish between end users and the intermediate residential market because the interests and desires of these two groups can be quite different. While end consumers are often interested in long-term reduction of energy costs, the interests and benefits sought by the residential intermediate market are often more variable and complex.

As with end residential consumers and manufacturers of energy-related products, there is little research available on purchase criteria and other topics related to the residential intermediate market. However, limited information was available regarding bujlders' purchase criteria, decision making process, associated risks, and information sources in North Carolina. This enabled us to gain some insight into the residential intermediate market of bujlders.

Builders must consider installation requirements, design alterations, and building code requirements posed by the new product. They must have some knowledge of residential demand for energy-related products. The adoption of energy related technologies by builders is triggered by some factor either in market demand, competitive position, or awareness of opportunity gained by participation in educational or incentive programs, public interest groups, trade associations, or government (Kaiser, Marsden and Burby 1982). 


\subsection{CURRENT SITUATION}

A large portion of the energy consumed in the U.S. is consumed by equipment and appliances in homes originally purchased residential intermediates such as speculative builders or rental property owners. In fact, $40 \%$ of all major appliance purchases are made by builders. This percentage is probably even higher for furnaces and central air conditioning systems which are nearly always built into the building (Science Applications, Inc. 1982).

The energy crisis of the 1970 s prompted concern and awareness about energy issues and resulted in the demand for more energy-efficient products and features in homes. Recognizing this demand, builders increased construction of energy-efficient homes. A survey conducted by Professional Builder magazine in 1985 found that ninety percent of the builders contacted (out of a total of 426) stated that the current models of homes are more energy-efficient than houses built five years ago. In addition, $70 \%$ said that current homes are more efficient than homes built just three years ago (Professional Builder 1985).

\subsection{TYPICAL ENERGY-EFFICIENT FAILURES ADOPTED BY BUILDERS}

Builders use a variety of methods to increase energy-efficiency in homes. The most popular method is to use ceiling insulation, followed closely by the use of wall insulation (Professional Builder 1985). New technologies for windows have been adopted by many builders, especially double glazing (81\%). Triple glazing was used by $15 \%$ of the builders contacted, and $25 \%$ of the builders have adopted windows that incorporate solar films or contings (Professional Builder 1985).

Builders anticipate that the new breed of super-efficient furnaces will attract potential home buyers' approval and therefore adoption by the building industry. In new homes, $77 \%$ of the builders contacted in the Professional Builder survey currently include furnaces with annual fuel savings of $80 \%$ or higher. Information on builders' perceptions of different types of heating systems and their opinions of new building concepts or technologies would be valuable. 


\subsection{THE ADOPTION OF ENERGY FEATURES BY BUILDERS}

Adoption of energy-efficient technologies is risky for intermediaries. In the construction industry for example, builders introducing solar design features in homes assume large risks because of added costs and demand uncertainties. When adding unfamiliar features to a house, design features must be altered by hiring specialized design professionals and/or new sub-contractors, new building code specifications must be met, and, most importantly, buyers must be willing to pay the added cost of these features.

A change in current practices may also affect the builder's image. Consumers have form perceptions of builders related to the type and quality of homes they expect the builder to construct. By adding energy conservation features such as solar heating to homes, a builder may be perceived as an innovator in the construction industry. However, if these features are not seen as being cost effective or desirable to buyers, then the homes will not sell and the builder's image may suffer. Usually, strong evidence of consumer demand for intermediaries to change familiar and efficient building practices is necessary. This poses a problem since builder perceptions of consumer demand often fail to keep pace with the actual desires of the market (Stern and Arons on 1985).

To intermediaries, energy efficiency becomes important only to the extent that purchasers or renters consider energy conservation in their decisions to purchase or rent. Since energy efficiency is only one factor in this decision, and because it is difficult to determine efficiency levels of products in advance, purchasers or renters may not express concern when making decisions (Stern and Aronson 1985). Therefore, home building firms may spend extra money for brand name kitchen appliances because, to prospective buyers, this indicates the quality of the home (Quelch and Thirkell 1978). The same building firms will be much more concerned with low price and quick delivery when purchasing an item that prospective buyers rarely examine, such as a furnace.

A 1982 study by Kaiser, Marsden, and Burby consulted North Carolina home builders to gain information on past, present, and future construction practices as well as factors influencing the adoption of energy-saving features in homes. The study involved a 60 minute "in-person" interview of 100 randomly 
selected home building companies across the state. The response rate of the survey was $73 \%$. Although this study is dated, it addresses motivational issues affecting a builder's adoption of energy technologies. Even if the outcomes of these decisions vary over time, the motivational factors affecting them probably remain fairly constant. The remainder of this section will outline the research findings of the Kaiser, Marsden, and Burby study (1982).

\subsubsection{Initial Stimuli for Adding Energy-Efficient Features}

Understanding the reasons or stimuli that prompt builders to initially consider adding energy-conservation features to residences is important. This understanding can help identify potential market penetration strategies for new technologies. Marsden, Kaiser, and Burby explored this question in their study (1982). Builders of single family homes were asked, in an open-ended fashion,

what caused them to consider using energy conserving features in their most recently built house and, in general, what factors affect the use of energy conservation features in their market.

Overall, the study showed that builder attitudes and knowledge regarding energy conservation do not seem to influence behavior. Rather, cost and market factors play the main role in stimulating the adoption of energy conservation features. This implies that builders must first recognize a fairly large demand for energy-efficient homes in order to justify the added costs and risks associated with these features. Although this study was limited to North Carolina builders, it provides some insight into the motivational factors affecting the nationwide residential intermediate market.

\section{Marketing and Cost Factors}

Builders (68\%) emphasized that market and cost factors were most important (see Table 4.1) in stimulating them to consider using an energy-saving feature, and were the most important factors affecting the use of features in their building market. Two-thirds of the respondents indicated that either one or both of these factors were the original stimuli in most recent houses. A larger percentage of builders, $84 \%$, stated that either one or both of these factors best explain the overall use of energy-conservation features by builders in their market area. 
TABLE 4.1. Stimuli To Consider Putting Energy Features Into New Houses

\begin{tabular}{|c|c|c|}
\hline Stimulus Category & $\begin{array}{l}\text { Percent of Builders } \\
\text { With respect to } \\
\text { Their Own Most } \\
\text { Recent Specula- } \\
\text { tive House (a) } \\
\quad(n=76) \\
\end{array}$ & $\begin{array}{l}\text { Who Cited Stimuli } \\
\text { with Respect to } \\
\text { Builders in } \\
\text { General in this } \\
\text { Market Area (b) } \\
(n=100) \\
\end{array}$ \\
\hline $\begin{array}{l}\text { Marketing ("Sales," "Customer } \\
\text { Demand," "Consumer Desires") }\end{array}$ & 36 & 41 \\
\hline $\begin{array}{l}\text { Cost Factors (mostly cost } \\
\text { of energy) }\end{array}$ & 32 & 43 \\
\hline $\begin{array}{l}\text { Awareness/Knowledge of energy- } \\
\text { conservation features }\end{array}$ & 21 & 25 \\
\hline Technical efficiency & 17 & NA \\
\hline Government regulations & 5 & 15 \\
\hline Builder ethics, pride & 7 & 6 \\
\hline $\begin{array}{l}\text { Other miscellaneous stimuli } \\
\text { (none greater than } 4 \text { percent) }\end{array}$ & 26 & 16 \\
\hline
\end{tabular}

(a) Question: What was it that caused you originally to consider using (energy feature in most recent house)?

(b) Question: What do you think are the major factors that affect the use of energy-conservation features by builders?

Source: Adopted from Kaiser, Marsden and Burby. 1982.

Builders view the use of energy conservation features as part of their conservative, adaptive, economic behavior rather than an innovation in the sense of creating a new product for expansion into new markets. Their motivation is "to maintain adequate sates and marketability of their (type) houses" (Stern and Aronson 1985).

A close link exists between cost and marketability factors. Cost considerations, both in terms of initial cost and operating costs, are key factors in determining whether the home is marketable and whether or not the energy saving features will be included in the home. 
Since market and cost factors seem to be the most important stimuli for installing energy-efficient features in new homes, information regarding these factors should be provided to builders. Specifically, an estimated initial cost and operating cost of the new feature should be provided since builders may use these costs as the primary determinant of marketability.

\section{Awareness and Knowledge Factors}

The awareness and technical knowledge of energy conservation features ranked third behind cost and marketing factors as stimuli for installing energy conservation features in new homes (see Table 4.1 ). For $21 \%$ of the builders surveyed, these factors were cited as important in their most recently built speculative home, while $25 \%$ cited it as important for builders in general within their market area.

High proportions of builders surveyed stated that they are aware and concerned about the energy situation: $61 \%$ thought that the need to conserve energy is serious and $68 \%$ believed that people do not have the right to consume as much energy as they can pay for.

Builders in the study seemed to have mixed knowledge about causes of heat Toss. These opinions include:

- Eleven percent of the builders answered incorrectly that, in a home, windows are a larger source of heat loss than are floors and walls.

- Forty-seven percent of the builders answered incorrectly that adding ceiling insulation is usually more effective than improving infiltration around windows and doors.

- Sixty percent of the builders were unaware that the addition of a conventional fireplace will not reduce the heating requirements in a typical North Carolina home. In reality, it is a source of heat loss if operated in conjunction with the normal heating system.

These findings indicate that builders may need to be educated in the causes of heat loss. A larger study of builders conducted by OBCS may provide a better indication of builders' knowledge about energy conservation. 
Interestingly enough, Kaiser, Marsden and Burby (1982) found that greater knowledge of the causes of heat loss and gain did not lead to an increase in the use of energy conservation features in new homes. Also, there is no evidence that builders with strong positive attitudes toward energy conservation are more likely to use energy-saving features based on past behavior.

Size and Price of the Home

Kaiser, Marsden and Burby's study (1982) found that size and sale price of speculative homes are important factors in the decision to use energy-saving features. Although only half of the builders identified price as an important factor, it was clear from the analysis of comparisons between the number of conservation features and house prices that price does make a difference. Over twice as many energy-saving features had been added to the over $\$ 55,000$ houses than to the under $\$ 55,0000$ houses. This probably occurred because the cost of adding energy-saving features to a lower priced house is proportionately more than adding those same features to a higher priced house.

For technology transfer purposes, OBCS may want to segment builders by average size and price of homes constructed. Since builders of larger, more expensive homes currently incorporate more energy-efficient features, they may be more aware and receptive to information regarding new energy-efficient features. Builders of smaller, less expensive homes may be less aware of new energy-efficient features and also less receptive to new technology information, even though their homes may pose the greatest potential for energy conservation savings.

\subsection{DECISION CRITERIA FOR SPECIFIC ENERGY-EFFICIENT FEATURES}

Besides asking builders about the initial stimulus that prompted them to consider installing an energy-efficient feature, Kaiser, Marsden, and Burby (1982) also asked about the decision criteria used in deciding to incorporate a specific energy feature. As in the "initial stimulus" question, market demand was the main factor. In fact, it was mentioned by nearly $90 \%$ of the builders, and over half felt it was the single most important factor in their final decision, see Table 4.2. 
TABLE 4.2. Decision Criteria Used in Making Final Decision About Use of an Energy Conservation Feature

\begin{tabular}{|c|c|c|}
\hline \multirow[b]{2}{*}{ Decision Criteria } & \multicolumn{2}{|c|}{ Percent of Builders $(n=75)$} \\
\hline & $\begin{array}{c}\text { Used as a } \\
\text { Criterion (Perhaps } \\
\text { Among Others (a) }\end{array}$ & $\begin{array}{c}\begin{array}{c}\text { Most } \\
\text { Important } \\
\text { Criterion (b) }\end{array} \\
\end{array}$ \\
\hline $\begin{array}{l}\text { Consumer demand, interest, } \\
\text { acceptance }\end{array}$ & 89 & 47 \\
\hline Performance reliability & 69 & 28 \\
\hline Availability & 40 & 1 \\
\hline Ease of installation & 40 & 0 \\
\hline $\begin{array}{l}\text { Cost in comparison with } \\
\text { alternatives }\end{array}$ & 36 & 4 \\
\hline $\begin{array}{l}\text { Degree of change from other houses } \\
\text { company was building }\end{array}$ & $\begin{array}{l}28 \\
27\end{array}$ & $\begin{array}{l}1 \\
0\end{array}$ \\
\hline Use by competition & & \\
\hline $\begin{array}{l}\text { Willingness/unwillingness of } \\
\text { subcontractors to participate }\end{array}$ & 24 & 0 \\
\hline Building regulations & 20 & 8 \\
\hline Profit margins & 19 & 1 \\
\hline Others & 23 & 9 \\
\hline
\end{tabular}

(a) Question: Thinking back when you were deciding whether to use (NAME OF FEATURE), which of the following factors did you consider in making up your mind about it ?

(b) Question: Again, thinking about the factors you considered in deciding to adopt (NAME OF FEATURE), which factor was the most important in your decision?

Source: Adopted from Kaiser, Marsden, Burby. 1982.

The second most important criterion was performance reliability. It is interesting that builders are concerned with the performance reliability of the feature even though they will probably never use it themselves. Performance reliability was ranked even higher than availability and ease of installation, both of which are much more specific to the builder. The builders may possibly feel more comfortable doing business with a manufacturer they know and trust. 
A1so, the implication is that the builders surveyed may be quite concerned with their reputations or images as discussed earlier and possibly about potential after-construction maintenance.

\subsection{INFORMATION SOURCES FOR ENERGY-EFFICIENT FEATURES}

Sources used to create awareness of energy conservation products in the residential building industry and sources of information used by builders to make final decisions regarding energy-saving features are the focus of this section. Potential sources include written material as well as personal contacts. Examples include trade journals, magazines, trade associations, certain companies, and individuals.

These sources of information are important because they influence the adoption of energy-related technologies in several ways. First, by creating awareness on the part of the builder, the message may induce the builder to consider including the particular energy-saving feature in a house. Once the builder is aware of the feature and its benefits, he/she may evaluate the information according to some decision criteria in order to decide whether or not to include the feature. If the energy feature is still in the initial stages of development by OBCS and is not yet available in the marketpTace, OBCS should provide the preliminary information to builders as well as manufacturers. If the technology looks viable to builders, they may express an interest to manufacturers and thus provide manufacturers with some demand for development of the technology.

Builders perceive that the credibility of certain information sources is greater than that of other sources. Builders refer to these credible sources and to those believed to contain the most usefut information. These sources may themselves induce builders to incorporate certain energy conserving features in homes. If these sources can be identified, OBCS may be able to influence the adoption of energy technologies in this market. Kaiser, Marsden, and Burby (1982) attempted to determine which of the information sources listed by manufacturers was statistically related to the use of energy-efficient features actually included in houses (see Table 4.3). 
TABLE 4.3. Builders' Use of Sources of Information About Energy Conservation Features and Their Influence on Adoption

\begin{tabular}{|c|c|c|c|c|}
\hline \multirow{2}{*}{$\begin{array}{l}\text { Independent Varlable: } \\
\text { Source of Information } \\
\text { About Energy Conser- } \\
\text { vation Features } \\
\end{array}$} & \multirow{2}{*}{$\begin{array}{l}\text { Parcent } \\
\text { of Sample } \\
\text { Using the } \\
\text { Source } \\
(n=100) \\
\end{array}$} & \multicolumn{3}{|c|}{$\begin{array}{c}\text { Dependent Vorlable: } \\
\text { Number of Features Used }\end{array}$} \\
\hline & & $\begin{array}{l}\text { Energy } \\
\text { Effictent } \\
\text { Equlpment }\end{array}$ & $\begin{array}{l}\text { Thermat } \\
\text { Ef ficlency } \\
\text { Features }\end{array}$ & $\begin{array}{c}\text { Total } \\
\text { Number of } \\
\text { Features }\end{array}$ \\
\hline $\begin{array}{l}\text { Electric } \\
\text { Company }\end{array}$ & 79 & $N S^{(d)}$ & NS & NS \\
\hline Suppl lers & 67 & NS & .23 & .24 \\
\hline $\begin{array}{l}\text { Popular magazine, TV, } \\
\text { Newspaper }\end{array}$ & 67 & NS & NS & NS \\
\hline Consumers ${ }^{(c)}$ & 61 & NS & NS & NS \\
\hline Trade publicetIons & 60 & NS & NS & NS \\
\hline $\begin{array}{l}\text { Semfnars and neetings } \\
\text { on energy }\end{array}$ & 59 & NS & .24 & NS \\
\hline Subcontractors & 59 & NS & NS & NS \\
\hline $\begin{array}{l}\text { Federal government } \\
\text { publ ications }\end{array}$ & 53 & NS & NS & NS \\
\hline $\begin{array}{l}\text { Natlonal Assoclation }(c) \\
\text { of Home Bullders' } \\
\text { Handbook on Energy }\end{array}$ & 51 & .29 & .27 & .34 \\
\hline $\begin{array}{l}\text { State governmental } \\
\text { officials }\end{array}$ & 50 & .28 & NS & NS \\
\hline $\begin{array}{l}\text { Local governmental } \\
\text { of ticlals }\end{array}$ & 46 & NS & NS & NS \\
\hline Other butlders & 45 & NS & NS & NS \\
\hline Consultant engineers & 45 & .27 & NS & NS \\
\hline Books & 43 & .23 & .34 & .36 \\
\hline Architects & 41 & .37 & .22 & .36 \\
\hline Gas utility company & 40 & NS & .21 & .22 \\
\hline
\end{tabular}

\footnotetext{
(a) The flgures In the table are Kendall's Tau.

(b) Question: Here Is a list of posslble sources of information about energyconservation features. For each, I want you to tell me whether or not you used It durlng the past year In finding out about energy conservation features you would Include in the houses you have bullt.

(c) Sources bullders relled on most in making their final decisions about the use of energy-conservation features.

(d) $\mathrm{NS}=$ Not statistlcally signifl cant at the .05 level.

Source: Adapted from Kaiser, Marsden and Burby, 1982.
}

As shown in Table 4.3 , builders relied on a variety of sources to obtain information on home energy-conservation features. These sources include electric utility company, suppliers, other builders, seminars and meetings on 
energy, and certain government officials. The sources relied upon most in making the final decision were the electric utility companies, consumers, and the National Association of Home Builders' (NAHB) Handbook on Energy.

Forty percent of the builders surveyed stated that they used all of the information sources offered, and 10 of the 16 sources were used by over half of the responding builders. Although the electric company, TV, popular magazines, newspaper, consumers, and trade associations were sources used by at least $60 \%$ of the builders, their use was not found to be statistically related to the use of energy-efficient features in new houses. In fact, suppliers were the only commonly-used source showing any statistical significance.

The information sources that appear to be most related to whether or not energy-efficient features are included in new homes are used by only a minority of builders when compared to other sources. Books, architects, gas utility companies, and the National Association of Home Builders' Handbook on Energy were all used less often than a number of other sources, yet were found to be more strongly related to actual use of energy-saving features. The credibility associated with these sources may be the reason for this correlation.

Information obtained from state governmental officials (type not mentioned) was used by $50 \%$ of the builders and was found to be statistically related to the number of energy efficient features used by builders. Federal government officials were used as a source by a larger percentage (51\%) of builders, but this was not found to be statistically related to actual adoption. Local government officials were used less often than either federal or state officials.

\subsubsection{Information Desired by Builders}

Kaiser, Marsden and Burby (1982) also asked builders what kinds of information they needed to make decisions about the use of energy-efficient features in new houses. Ten percent of the builders stated that they already had all the information they needed about energy efficiency in housing. The information most frequently mentioned was:

- information about the cost implications of energy-conservation features, including the cost added by using a feature (added cost 
over using other features), and the operating cost savings expected to result from the feature (to be experienced by the homeowner) (34\%)

- information about building product characteristics including their reliability and effectiveness (34\%)

- information on consumer demand for energy conservation features (9\%)

- information about solar energy (9\%)

- availability of one reliable source of information about energy in housing $(4 \%)$.

It is interesting that only $9 \%$ of the builders stated that information on consumer demand for energy conservation features was needed to help make decisions regarding the use of energy-efficient features in new homes; yet this factor was a major motivator to adoption by these same builders. This may occur because builders predict no difficulty in acquiring this information through their own personal information networks, and they may not view certain other consumer demand information sources as credible.

The use of such a wide range of information sources by builders regarding the use of energy-conserving features in new houses makes it difficult to develop an efficient, overall strategy for influencing the adoption of energyefficient technologies by builders. This is especially true since the information sources used by the majority of builders do not seem to be the ones most related to actual adoption of energy-efficient features in new homes. However, it is possible that information could be provided differently from these sources to better affect actual adoption rates.

Based on this information, OBCS may want to target the most effective sources of information, such as the NAHB handbook, and supplement the approach with a general widespread effort using other sources in order to reach the rest of the builders. Also, a different type of approach or message delivery mechanism might be explored to better influence the less effective media sources. The information contained in the widespread approach may refer the builders to a more credible (or successful) source such as the NAHB handbook. 
Since builders refer to governmental officials for information regarding energy-conservation features, OBCS may want to promote some sort of program to disseminate information from these sources. State governmental representatives in particular, because of the significant correlation between builders' use of these sources and actual adoption of energy-efficient features installed in houses, may be important vehicles for promoting the adoption of energy technologies. OBCS may want to make information on specific energy-efficient residential products available to builders through State Energy Offices.

Once an energy technology is offered to builders by a manufacturer, the manufacturer must be confident that there is adequate demand in the residential housing market for the product (or the product would not be marketed). Therefore, the manufacturer will also provide builders with information regarding consumer demand for the technology.

\subsection{SUMMARY AND IMPLICATIONS}

The adoption of energy conservation, features by builders is an important step in the market penetration process of certain new OBCS technologies. The adoption of a new feature is not easy for builders, the consumer must be willing to pay the extra costs (this is an added risk for builders), current and familiar construction practices may be altered, new material suppliers and subcontractors may need to be consulted, and information regarding the feature may require consultation by the builder. Most importantly, builders must recognize a fairly strong residential consumer demand for these features in order to install them in new homes, especially speculative homes. Builders rely on a number of sources to obtain information about energy-efficient features for new homes. However, builders' motivation for seeking this information depends on the importance they believe consumers place on these features. Figure 4.1 illustrates the adoption process of energy conservation features by builders. 
Initial Influences on the Decision to adopt an Energy-Efficient Feature:

- Perceptions of consumer demand for energy-efficient housing

- Cost of energy

- Awareness/knowledge of Energy-conservation features

- Technical efficiency

- Government regulations

- Builder ethics/pride
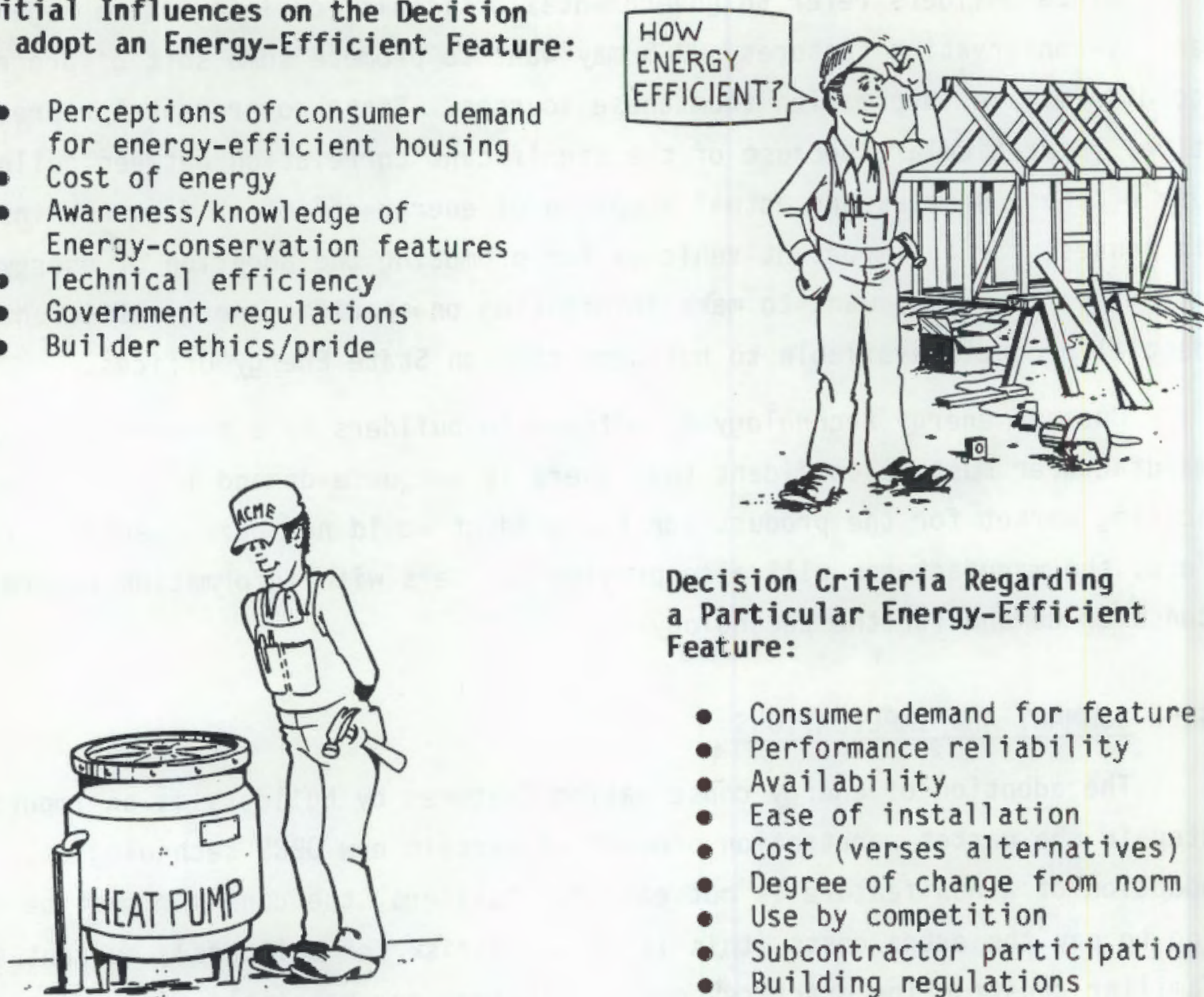

Decision Criteria Regarding a Particular Energy-Efficient Feature:

- Consumer demand for feature

- Performance reliability

- Availability

- Ease of installation

- Cost (verses alternatives)

- Degree of change from norm

- Use by competition

- Subcontractor participation

- Building regulations

- Profit margin

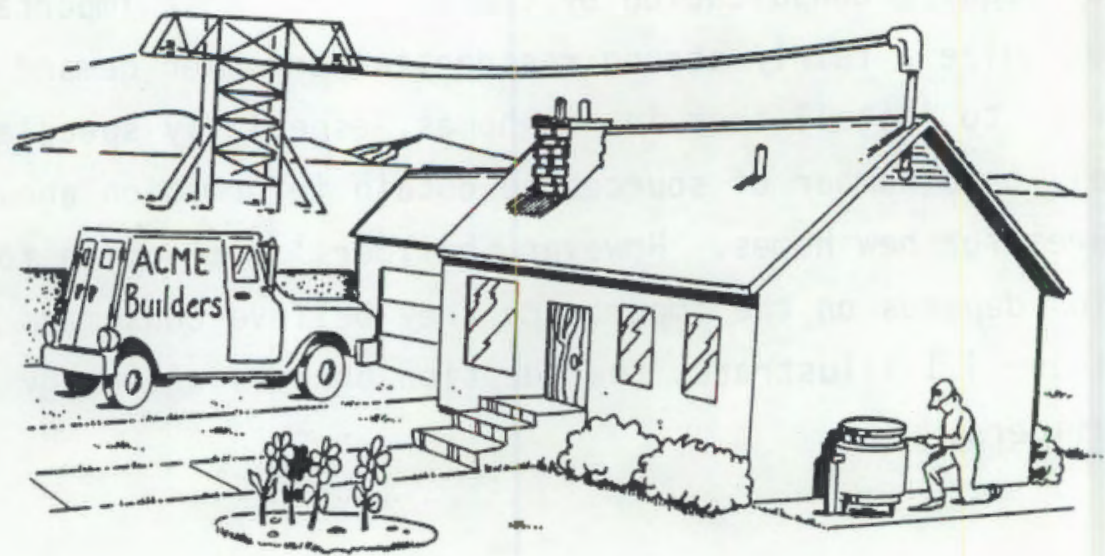

FIGURE 4.1. The Adoption Process of Energy-Conservation Features by Builders 


\subsection{RECOMMENDATIONS FOR FUTURE STUDY}

This study provides a basis for understanding the adoption and diffusion process of energy-related technologies in three residential oriented markets; end consumers, manufacturers, and intermediate markets such as builders. However, important information is currently lacking on all three markets in a number of areas important to OBCS. These areas center around: 1) the adoption decision-making participants, criteria, and processes, 2) barriers to adoption, and 3 ) influence channels. Based on the finding of this study, it is recommended that OBCS:

- conduct a geographically stratified survey of each of the three OBCS market areas of end residential consumers, manufacturers of energy-related technologies, and intermediate residential markets such as builders, architects, and engineers. Focus group sessions could be held to gain insight into the types of questions that should be asked in the survey.

Information obtained from this survey could be used to help promote successful market penetration of OBCS technologies. Specifically, this information could be used to:

- develop a technology transfer/commercialization plan to promote market penetration of new OBCS technologies based on the results of the survey

- better determine each market segment's role in the diffusion process of new energy-related technologies

- segment markets by participants' potential to be innovators and focus on those segments which appear most likely to adopt new energy technologies

- concentrate resources on those technologies which seem most likely to be commercially successful

- develop information strategies that will effectively appeal to the consumers' level of decision-making and focus on those attributes that consumers perceive as most important 
- cultivate those attitudes which would encourage investment in energyrelated technologies. One way in which to develop desirable attitudes is by using self-perception based persuasion techniques

- develop strategies to overcome or lessen the impact of the barriers encountered in the adoption and diffusion process

\subsection{DETAILED INFORMATION NEEDED IN THESE THREE OBCS MARKET AREAS}

Additional information needed in each of the three major market areas was enumerated in previous chapters and is consolidated below. Most of this information could be obtained from the survey recommended in Section 5.0 (above).

\section{Residential End Consumers:}

- determine characteristics of each OBCS technology being considered for commercialization to ascertain its potential for successful market penetration

- determine which attributes of an energy-related product the consumer is attaching more importance to when evaluating product alternatives

- evaluate consumers' post-purchase behavior to determine their degree of satisfaction with an energy-related product

- determine consumers' optimal discount rates and payback periods for energy-related technologies and compare this rate to the expected payback period of OBCS technologies. The payback period may vary depending on different energy technologies and different consumer segments

- understand the specific consumer attitudes related to their purchasing intentions towards energy investments

- identify consumer choice heuristics utilized during an energy-related purchase decision 
- determine consumer influence channels and information sources

- define barriers which consumers face when making energy-related investments

\section{Manufacturers:}

- identify characteristics of firms that are most related to adoption potential. These characteristics may include; size, financial position, apparent corporate business and innovation strategies, past adoption behavior, size and scope of R\&D department, etc.

- identify selection criteria for technology adoption used by manufacturers. If these selection criteria vary widely among manufacturers, segment the manufacturers according to similar characteristics of firms

- categorize DBCS technologies according to their stage in the R\&D process in order to target technology transfer or commercialization partnership information to the companies that are potential adopters/ partners for technologies in that stage of R\&D

- determine potential barriers encountered by manufacturers that might deter technology adoption

- identify new product/innovation idea sources both within and outside companies

- obtain information about manufacturers perceptions of government (DOE) sources of new product/technology ideas

- determine the type of partnerships or arrangements most preferred by industry for technology development or adoption

- determine the department(s) within an organization that are likely to have an influence in the decision to adopt/not adopt a new technology

- determine differences in new technolojy selection criteria depending on the decision-makers' role in the company 
- identify formal or informal methods used by organizations to screen new technologies and ideas

- identify manufacturers' influence channels and information sources.

Intermediate Market of Builders:

- determine estimated initial and annual operating cost of OBCS technologies that are likely to be accepted by builders

- determine the amount of residential demand for an energy related product that is required before builders will install such a feature in a speculative home

- identify builders' influence channels and information sources

- segment builders by average size and price of homes constructed to deliver appropriate messages regarding new technologies

- identify the specific builder attitudes that are most related to energy-related purchase intentions

- define barriers that may deter builders from adopting an energyefficient feature so that strategies to overcome these barriers can be developed 


\section{REFERENCES}

Abernathy, W. J. and Utterback, J. M. 1978. "Patterns of Industrial Innovations." Technology Review. 80(June/Juiy):41-47.

Abernathy, W. J. and Utterback, J. M. 1982. "Innovation Over Time." in Readings in the Management of Innovation, Pp. 97-108. Pitman Publishing Inc., Boston, Massachusetts.

Allen, C. T. 1982. "Self-Perception Based Strategies for Stimulating Energy Conservation." Journal of Consumer Research. 8:381-390.

Anderson, C. D. and J. D. Claxton. 1982. "Barriers to Consumer Choice of Energy Efficient Products." Journal of Consumer Research. 9:163-170.

Andrews, E. L. 1985. "Gift Wrapping Sells R\&D Partnerships." Venture. 7 (September): 92 .

Baker, N. R., S. G. Green, and A. S. Bean. 1985. "How Management Can Influence The Generation of Ideas." Research Management. 28(6):35-40.

Baran, S., P. Zandan, and J. Vanston. 1986. "How Effectively Are We Managing Innovation?" Research Management. 29(6):23-25.

Beck, P. A. 1980. "Correlates of Energy Conservation." Public Poljcy. $28(4): 451-471$.

Becker, L. J., C. Seligman, and J. M. Darley. 1979. Psychological Strategies to Reduce Energy Consumption: Project Summary Report. Center for Environmental Studies, Princeton University, Princeton, New Jersey.

Becker, L. J., C. Seligman, R. H. Fazio, and J. M. Daily. 1981. "Relating Attitudes to Residential Energy Use." Environment and Behavior. $19(5): 90-98$.

Berkowitz, M. K. and G. H. Haines, Jr. 1984. "The Relationship Between Attitudes, Relative Preferences, and Market Shares: The Case of Solar Energy in Canada." Journal of Consumer Research. 11:754-762.

Black, J. S., P. C. Stern, and J. T. Elsworth. 1985. "Personal and Contextual Influences on Household Energy Adoption." Journal of Applied Psychology. $70(1): 3-21$.

Blumstein, C., B. Krieg, L. Schipper, and C. York. 1980. "Dvercoming Social and Institutional Barriers to Energy Conservation." Energy. 5:3j5-371.

Chernoff, H. 1983. "Individual Purchase Criteria for Energy-Related Durables: The Misuse of Life Cycle Cost." The Energy Journal. 4(4):81-86. 
Choffray, J. and G. L. Lilien. 1978. "Assessing Response to Industrial Marketing Strategy." Journal of Marketing. 42(April):30.

Cohn, S. F. 1980. "Industrial Product Adoption in a Technology Push Industry." Industrial Marketing Management. 9:89-95.

Cook, J. 1985. "It's Just Too Powerful a Force." Forbes. December 16:118-120.

Craig, C. S. and J. M. McCann. 1978. "Assessing Communication Effects on Energy Conservation." Journal of Consumer Research. 5:82-89.

Crossley, D. J. 1983. "Identifying Barriers to the Success of Consumer Energy Conservation Policies." Energy. 8(7):533-546.

Cunningham, W. H. and B. Joseph. 1978. "Energy Conservation, Price Increases, and Payback Periods." Advances in Consumer Research. 5:201-205.

Czepie1, 3. A. 1974. "Word-of-Mouth Processes in the Diffusion of a Major Technological Innovation." Journal of Marketing Research. 11:172-180.

Darley, J. M. and J.R. Beniger. 1981. "Diffusion of Energy Conserving Innovations." Journal of Social Issues. 37(2):150-171.

Davis, W. L. Jr. and S. L. Perry. 1982. "Retail Appliance Dealer Survey." Florida Power and Light Company.

Dickerson, M. D. and J. W. Gentry. 1983. "Characteristics of Adopters and Non-Adopters of Home Computers." Journal of Consumer Research. $10(2): 225-235$.

Dinan, T. M. 1985. A Review of Literature Examining the Consumer Decision Process with Regards to Energy Use and Conservation Investment. 0ak Ridge National Laboratory, Oak Ridge, Tennessee.

Dinan, T. M. 1986. Understanding the Market for Conservation Technologies in the Commercial Sector." Oak Ridge National Laboratory, Oak Ridge, Tennessee. DOE/CE/27460/T14.

Edwards, M. September 1984. "Government/Industry Cooperation - Lessons from Europe and Japan." Office Administration and Automation.

Fang, J. M. 1985. Household Attitudes Toward Energy Conservation in the Pacific Northwest: Overview and Comparisons. Pacific Northwest Laboratory, Richiand, Washington. PNL-5405.

Festinger, L. 1957. A Theory of Cognitive Dissonance. Stanford University Press, Palo Alto, California.

Fishbein, M. and I. Ajzen. 1975. Beliefs, Attitudes, Intention and Behavior. Addison-Wesley, Reading, Massachusetts. 
Freeman, C. June 1979. "The Determinants Of Innovation." Futures.

Frieden, B. J. and X. Baker. 1983. "The Record of Home Energy Conservation: Saving Bucks, Not BTU's." Technology Review. 86:22-31.

Frieden, B. J. and K. Baxer. 1983. "The Market Needs Help: The Disappointing Record of Home Energy Conservation." Journal of Policy Analys is and Management. 2(3):432-448.

Gately, D. 1980. "Individual Discount Rates and the Purchase and Utilization of Energy-using Durables: Comment." The Bell Journal of Economics. 11 (Spring):373-374 .

Gates, R. W. 1983. "Investing in Energy Conservation." Energy Policy. March:63-71.

George, S. S., J. da Silva, and M. R. McRae. 1986. Impact of Short-Term Leases on Conservation Investments of Commercial Landlord and Tenants. XEnergy. Inc. for Bonneville Power Administration.

Gilly, M. C. and V. A. Zeithaml. 1985. "The Elderly Consumer and Adoption of Technologies." Journal of Consumer Research. 12(December):353-357.

Gomory, R. E. 1985. "Aspects of Research and Development." Research Management. 28(November-December) :32-33.

Guagnano, G., G. R. Hawkes, C. Acredolo, and N. White. 1986. "Innovation Perception and Adoption of Solar Heating Technology." Journal of Consumer Affairs. 20(1):48-64.

Hage, J. and R. Dewar. 1973. "The Prediction of Organizational Performance: The Case of Program Innovation." Administration Science Quarterly. 18:279290.

Hausman, J. A. 1979. "Individual Discount Rates and the Purchase and Utilization of Energy-Using Durables." Bell Journal of Economics. $10(1): 33-54$.

Hendrickson, P. L., B. L. Mohler, Z. T. Taylor, A. O. Lee, and S. A. Onisko. 1985. Marketing Energy Conservation Options to Northwest Manufactured Home Buyers. Pacific Northwest Laboratory, Richland, Washington. PNL-5496.

Heslop, L. A., L. Moran, and A. Cousineau. 1981. "'Consciousness' in Energy Conservation Behavior: An Exploratory Study." Journal of Consumer Research. $8(3): 299-305$.

Hirshman, E. C. 1980. "Innovativeness, Novelty Seeking, and Consumer Creativity." Journal of Consumer Research. 7(0ecember):283-295.

Hirst, E., R. Goeltz, and H. Manning. 1983. "Analysis of Household Retrofit Expenditures." Energy Systems and Policy. 7(4):303-321. 
Houston, D. A. 1983. "Implicit Discount Rates and the Purchase of Untried Energy-Saving Durable Goods." Journal of Consumer Research. 10(2):236-246.

Huebner, R. H. 1986. "Lessons From A Decade Of Energy R\&D." Research Management, $29(3): 30-34$.

Hutt, M. D. and T. W. Speh. 1981. Industrial Marketing Management. The Dryden Press, San Francisco, California.

Jacoby, J. et al. 1976. "Time and Consumer Behavior: An Interdiscipiinary Overview." Journal of Consumer Research. 2 (March):320-339.

Kahneman, D., and A. Tversky. 1979. "Prospect Theory: An Analysis of Decision Under Risk." Econometrica. 47(2):268-291.

Kaiser, E. J., M. E. Marsden, and R. J. Burby. 1982. "The Adoption of Energy Conservation Features in New Homes: Current Practices and Proposed Policies." North Carolina Homebullders Association, Raleigh, North Carolina.

Kamien, M. I. and N. L. Schwarty. 1982. Marketing Structure and Innovation. Cambridge University Press, Cambridge, England.

Kasulis, J. J., R. F. Lusch, and E. F. Stafford, Jr. 1979. "Consumer Acquisition Patterns for Durable Goods." Journal of Consumer Research. 6:47-57.

Kempton, W. and L. Montgomery. 1982. "Folx Quantification of Energy." Energy. 7:817-827.

Klavans, R., M. Shanley and W. W. Evan. 1985. "The Management of Internal Corporate Ventures: Entrepreneurship and Innovation." Columbia Journal of World Business. 20:21-27.

Kotler, P. 1984. Marketing Management: Analysis, Planning and Control. 5th Edition. Prentice-Hall, Inc., Englewood Cliffs, New Jersey.

Labay, D. G. and T. C. Kinnear. 1981. "Exploring the Consumer Decision Process in the Adoption of Solar Energy Systems." Journal of Consumer Research. 8(3):271-278.

Leonard-Barton, D. 1981. "Voluntary Simplicity Lifestyles and Energy Conservation." Journal of Consumer Research. 8:(3)243-252.

Leonard-Barton, D. and W. A. Kraus, 1985. "Implementing New Technology" Harvard Business Review. $63(6): 102-110$.

Lunde, P. J. 1982. "A Simplified Approach to Economic Analysis of Solar Heating and Hot Water Systems and Conservation Measures." Solar Energy. 28(3): 197-203. 
Longstreth, M., A. R. Coveney, and J. S. Bowers. 1984. "Conservation Characteristics Among Determinants of Residential Property Value." Journal of Consumer Research. 11(1):564-571.

Macey, S. M. and M. A. Brown. 1983. "Residential Energy Conservation: The Role of Past Experience in Repetitive Household Behavior." Environment and Behavior. 15(2):123-141.

Maidique, M. A. and P. Patch. 1982. "Corporate Stracegy and Technological Policy." in Readings in the Management of Innovation, pp. 273-285. Pitman Publishing Inc., Boston, Massachusetts.

Mansfield, I. 1968. Industrial Research and Technological Innovation. Norton Publishing, New York City, New York.

Market Facts Inc. 1981. "Final Report on Latent Home Buyer Study for National Passive Solar Program." Solar Energy Research Institute, Golden, Colorado.

McIntyre, S. H. 1982. "Obstacles to Corporate Innovation." Business Horizons. January $\rightarrow$ February:23-28.

MCNeill, D. L. and W. L. Wilkie. 1979. "Public Policy and Consumer Information: Impact of the New Energy Labels." Journal of Consumer Research. 6(June): 1-11.

Mendell, S. and D. M. Ennis. 1985. "Looking at Innovation Strategies." Research Management. 28(6):33-40.

Midgley, D. F. and G. R. Dowling. 1978. "Innovativeness: The Concept and Its Measurement." Journal of Consumer Research. 4:229-242.

Miller, R. L., P. Brickman, and D. Bolen. 1975. "Attribution Versus Persuasion as a Means of Modifying Behavior." Journal of Personality and Social Psychology. 31:430-441.

Milstein, J. S. 1977. "Attitudes, Knowledge and Behavior of American Consumers Concerning Energy Conservation." Advances in Consumer Research. $4: 315-321$.

Moch, M. K. and E. V. Morse. 1977. "Size, Centralization, and Organizational Adoption of Innovations." American Sociological Review.

42 (October): $716-725$.

Mohler, B. L., R. M. Scheer, and V. Barnes. 1985. Consumer Decision and Behavior Research Agenda for the Office of Building and Community Systems. Pacific Northwest Laboratory, Richland, Washington. PNL-5702.

More, R. A. 1983. "Overcoming Barriers to the Adoption of High Technology in Industrial Markets." Business Quarterly. 48:110-116. 
Mowen, 3. C. 1987. An Introduction to Consumer Behavior. McMillan Publishing Company, New York City, New York.

Mowen, J. C. and K. J. Fabes. 1986. "Implications of the Trend Bias for the Purchases of Energy Efficient Products." American Marketing Association Educators Conference Proceedings. 99-103.

Mowery, D. and N. Rosenberg. 1979. "The Influence of Market Demand Upon Innovation: A Critical Review of Some Recent Empirical Studies." Research Policy. 8:102-153.

Neels, K. 1982. "Reducing Energy Consumption in Housing: An Assessment of ATternatives." International Regional Science Review. 7(1):69-81.

New Jersey Department of Energy. 1981. "Revisions to the New Jersey Energy Master Plan." Newark, New Jersey.

Nieves, L. A. and J. M. Fang. 1985. Literature Review on Energy Conservation Investment in Non-Residential Buildings. PNL-5459, Pacific Northwest Laboratory, Richland, washington.

0lken, H. 1986. "Cooperation Between Private Industry and the National Laboratories." Research Management. 28(March-Apri1):6.

01sen, M. E. 1981. "Consumers' Attitudes Toward Energy Conservation." Journal of Social Issues. $37(2): 108-131$.

01sen, M. E. and C. Cluett. 1984. "Public Willingness to Invest in Household Weatherization." The Energy Journal. 5(1):165-168.

Palmer, D. 1983. "Broken Ties: Interlocking Directorates and Intercorporate Cooperation." Administrative Science Quarterly. 28(March):40-55.

Petroni, G. 1985. "Who Should Plan Technological Innovation?" Long Range Planning. 18:108-115.

Porter, M. E. 1980. Competitive Strategy. The Free Press, New York City, New York.

Professional Builder. 1985. "Buyers, Lenders, Products Spur Energy-Efficient Housing." October: 109.

Quelch, J.A., and P. Thirkel. 1978. "'Imposed Choice' Purchase of EnergyUsing Equipment In The Residential Sector: A Review." School of Business Administration. The University of Western Ontario.

Reid, R. L. et al. 1977. "Economics of Solar Heating with Homeowner-Type Financing." Solar Energy. 19(5):513-517. 
Reizenstein, R. C. and D. J. Barnaby. 1977. "The Consumer and the Energy Shortage: A Post-Embargo Assessment." Advances in Consumer Research. $4: 308-314$.

Research Management. 1984. "Stimulating Industrial Innovation." $28: 30-33$.

Research Management. 1986. "Perspectives." March-April.

Ritchie, J. R., G. H. G. McDougall, and J. D. Claxton. 1981. "Complexities of Household Energy Consumption and Conservation." Journal of Consumer Research. 8:233-242.

Robertson, T. S. and H. Gatignon. 1986. "Competitive Effects on Technology Diffusion." Journal of Marketing. 50(July):1-12.

Rogers, E. M. 1962. Diffusions of Innovations. The Free Press, New York City, New York.

Rogers, E. M. 1976. "New Product Adoption and Diffusion." Journal of Consumer Research. 2:290-301.

Rogers, E. M. and F. F. Shoemaker. 1971. Communications of Innovations. The Free Press, New York City, New York.

Ruderman, H., M. D. Levine, and J. E. McMahon. 1984. The Behavior of the Market for Energy Efficiency in Residential Appliances Including Heating and Cooling Equipment. Lawrence Berkeley Laboratory, Berkeley, California.

Ruegg, R. T. 1975. "Solar Heating and Cooling of Buildings: Methods of Economic Evaluation." U.S. Department of Commerce, National Bureau of Standards, Washington, D.C.

Ryans, J. K. and W. L. Shanklin. 1984. "Positioning and Selecting Target Markets." Research Management. September-Dctober:28-32.

Science Applications, Inc. 1982. Consumer Products Efficiency Standard Economic Analysis Document. U.S. Department of Energy, Washington, D.C.

Sedmak, M. R. and E. M. Zampelli. 1979. "The Determination of the 0ptima] Solar Investment Decision Criteria." PRC Energy Analysis Company.

Sethi, N. K., and K. D. Hickey. 1985. "Can Technology be Managed Strategically?" Long Range Planning. 18(4):89-99.

Shippee, G. 1980. "Energy Consuinption and Conservation Psychology: A Review and Conceptual Analysis." Environmental Management. 4(4):297-314.

Soderstom, E. J. and B. M. Winchel1. 1986. "Patent Policy Changes Stimulating Commercial Application of Federal R \& $D . "$ Research Management. $29(3): 35-38$. 
Starr, C. 1985. "Industrial Cooperation In R \& D." Research Management. $28(5): 13-15$.

Stern, P. C. 1984. "Saving Energy: The Human Dimension." Technology Review. 87:16-25.

Stern, P. C. 1985. Energy Efficiency in Buildings: Behaviora1 Issues. Committee on Behavioral and Social Aspect of Energy Consumption and Production. National Academy Press, Washington, D.C.

Stern, P. C. and E. Aronson. 1985. Energy Use: The Human Dimension. Committee on Behavioral and Social Aspects of Energy Consumption and Production. National Research Council. W. H. Freeman And Company, New York City, New York.

Stern, P. C., L. G. Berry, and E. Hirst. 1985. "Residential Conservation Incentives." Energy Policy. Apri1:133-142.

Stern, P. C. and G. T. Gardner. 1981. "Habits, Hardware, and Energy Conservation." American Psychologist. 36:426-428.

Stern, P. C. and G. T. Gardner. 1981. "Psychological Research and Energy Policy." American Psychologist. 36(4):329-342.

Tripple, P. A. and C. J. Makela. 1985. "Energy Conservation Actions: Analysis of Predictors." Advances in Consumer Research. 473-475.

Utterback, J. M. and W. J. Abernathy. 1975. "A Dynamic Model of Process and Product Innovation." OMEGA, The International Journal of Management Science. $3(6): 639-656$.

Van Raaij, W. F. and M. M. T. Verhallen. 1985. "Determinants of Home Insulation Intention." Advances in Consumer Research. 476-480.

Verhallen, T. M. M. and W. F. van Raaij. 1981. "Household Behavior and the Use of Natural Gas for Home Heating," Journal of Consumer Research. $8: 253-257$.

Watts, R. L., D. R. Johnson, S. A. Smith, and E. J. Westergard. 1985. Research Utilization in the Building Industry: Decision Model and Preliminary Assessment. PNL-5607, Pacific Northwest Laboratory, Richland, Washington.

Webster, F. E., Jr. 1975. "Determining the Characteristics of the Socially Conscious Consumer." Journal of Consumer Research. 2:188-196.

Weeks, R. G. 1977. "Limits of Conservation: implications for Energy Policy." Advances in Consumer Research. 322-323. 
Wilton, P. C. and E. A. Pessimier. 1981. "Forecasting the Ultimate Acceptance of an Innovation: The Effects of Information." Journal of Consumer

Research. 8(September): 162-171.

Winett, R. A. and M. S. Neale. 1979. "Psychological Framework for Energy Conservation in Buildings: Strategies, Outcomes, Directions," Energy and Buj\}dings. 2:101-116.

Winkler, R. C. and R. A. Winett. 1982. "Behavioral Interventions in Resource Consumption: A Systems Approach Based on Behavioral Economics." American Psychologist. 37:421-435.

Wolff, M. F. 1986. "Companies To Spend 9\% More On R \& D in 1986...." Research Management. 29(2):2.

Wolff, M. F. 1984. "Government Urged to Rethink Role in Diffusing Know-How." Research Management. July-August:2.

Yates, S. M. and E. Aronson. 1983. "A Social Psychological Perspective on Energy Conservation in Residential Buildings." American Psychologist. $38(4): 435-443$

Zikmund, W. and M. D'Amico. 1984. Marketing. John Wiley and Sons, New York City, New York. 


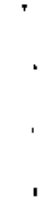




\section{DISTRIBUTION}

No. of

Copies

OFFSITE

30 DOE Technical Operations Office

$50 \quad \mathrm{~F}$. Abel

Senior Economist

Office of Building \&

Community Systems

U.S. Department of Energy

Forrestal Building, CE-11

1000 Independence Ave., S.W. Washington, DC 20585

L. J. Davis

14602 West Beach

White Rock, BC V4B 2T8

J. Ryan

Office of Building \&

Community Systems

U.S. Department of Energy

Forrestal Building, CE-11

1000 Independence Ave., S.W.

Washington, DC 20585

T. Kapus

Office of Building \&

Community Systems

U.S. Department of Energy

Forrestal Building, CE-11

1000 Independence Ave., S.W. Washington, DC 20585

J. Mithone

Director, Building \&

Community Systems

U.S. Department of Energy

Forrestal Building, CE-11

1000 Independence Ave., S.W.

Washington, DC 20585
No. of

Copies

B. J. Klosterman

Customer Interface

1623 5th Street

Suite C

Davis, CA 95616

J. Holmes

Office of Building \&

Community Systems

U.S. Department of Energy

Forrestal Building, CE-11

1000 Independence Ave., S.W.

Washington, DC 20585

$T$. Dinan

Oak Ridge National Laboratory

P.0. Box $X$

Oak Ridge, Tennessee 37831

T. Anyos

Manager, Commercial Development

Electric Power Research

Institute

3412 Hillview Avenue

P.0. Box 10412

Palo Alto, CA 94303

K. Kazmer

Manager, Building Systems Research

Gas Research Institute

8600 West Bryn Mawr Avenue

Chicago, IL 60631

J. Lamontagne

Building 120

Brookhaven National Laboratory Upton, NY 11973 
No. of

Copies

ONSITE

DOE Richland Operations Office

J. J. Sutey

17 Pacific Northwest Laboratory

C. L. Bruneau (5)

B. A. Garrett

S. A. Harkreader

D. L. Ivey

B. L. Mohler

R. 0 . Weijo

Publishing Coordination $\mathrm{MH}$ (2)

Technical Report Files (5) 